\title{
Interrupting the Artefact: \\ The Reorientation of the Royal Canadian Yacht Club
}

\author{
Trevor Wallace, B.A.S. \\ 二 \\ A thesis submitted to the faculty of Graduate Studies and \\ Research in partial fulfilment of the requirements for the degree of \\ Master of Architecture (M. ARCH) Professional.
}

Carleton University, Ottawa, Ontario, Canada

Trevor Wallace (C) 2006 


\section{Abstract}

Architecture is the physical manifestation of a culture; like a palimpsest, it has the capacity to record cultural transformations and make visible shifting social dynamics. A contemporary intervention into a historical architectural framework produces an architectural layering that reveals a dialogue between the diverse moments of culture and creates a temporal narrative of time which allows the architecture to actively participate in contemporary society. This thesis will propose an intervention, guided by the deterioration of formality in society, that will reorient the century-old Georgian architecture and programming of the Royal Canadian Yacht Club on the Toronto Island. The method of interruption will be used to de-form the rigid, formal tectonics of the monolith by introducing a new architecture that will explore the contemporary relationships between the realms of service and served. By dissolving traditional boundaries and redrawing thresholds, both formally and programmatically, the spaces are transformed such that they may reengage the needs of contemporary inhabitants.

Denoting this transformation, the thesis will furthermore reveal how the juxtaposition and layering of architectural syntaxes will manifest an invaluable discourse between Toronto's past and present era such that it reveals its place in contemporary culture while embracing the identity and memory embedded within the character of the architecture and the identity of the Royal Canadian Yacht Club. This thesis poses the question of the role of architectural intervention, in its capacity to use the cultural shifts that have antiquated the architecture, to generate a new way of inhabiting traditional space such that the architecture is profoundly revitalized reflecting contemporary culture. 


\section{Acknowledgments}

I would like to thank my parents for supporting and encouraging me throughout this year, and for their unconditional love and guidance through my day-to-day life.

Also, I would like to thank the rest of my family, the strongest link to my past that I am so fond of; and my friends, for helping me through these six years, by reminding me that life is to be enjoyed.

Finally, I would like to express my gratitude to my thesis advisor, Sheryl Boyle; for her patience and well-anchored guidance throughout this thesis. 
$\underline{\text { Table of Contents }}$

$\begin{array}{ll}\text { Abstract } & 2\end{array}$

$\begin{array}{ll}\text { Acknowledgements } & 3\end{array}$

$\begin{array}{lr}\text { Introduction } & 6\end{array}$

Architecture In Place

1.1 Tablau raza and the Modernist Response to Place 9

$\begin{array}{ll}1.2 & \text { Architecture Engaging Contextual Place } \\ \end{array}$

1.3 Defining Cultural Moments and Social Transformation $\quad 14$

\begin{tabular}{ll}
1.4 & Nostalgia - Place Framing Experience \\
\hline
\end{tabular}

$\begin{array}{ll}1.5 & \text { Summary } \\ \end{array}$

Memory Framing the Contemporary Event

2.1 Antiquated Monuments Generating New Events 20

2.2 Contemporary Functions and Architectural Vitality 23

$\begin{array}{lll}2.3 & \text { Summary } & 24\end{array}$

A Site Under Transformation

3.1 The Evolution of the Royal Canadian Yacht Club and Toronto 27

3.2 Between Architecture, Program, and the New Inhabitant 37

3.3 Summary

Between the Architecture and the City

4.1 Understanding Transition 45

4.2 Crafting the Passage 48

4.3 The Compression of the Metropolis 49

4.4 Summary 51

Liberating Traditional Spaces

5.1 Away from Le Mathematique raisonable 53

5.2 Dissolving the Boundary 57

5.3 Interrupting the Syntax - Reorienting Traditional Order 58

5.4 Inhabiting the Void 61

5.5 Summary $\quad 66$ 


\section{Reorienting the Edwardian}

$\begin{array}{lll}6.1 & \text { Two Systems of Transformations } & 68\end{array}$

$\begin{array}{lll}6.2 & \text { Three Perspectives } & 69\end{array}$

6.3 Designing for the New Inhabitant 78

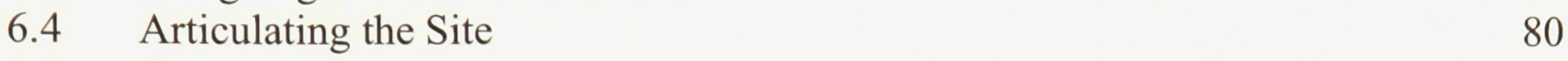

$\begin{array}{lll}6.5 & \text { Summary } & 82\end{array}$

$\begin{array}{lr}\text { Conclusion } & 83\end{array}$

$\begin{array}{lr}\text { Design Plates } & 85\end{array}$

Appendix 1: List of Images 104

$\begin{array}{lr}\text { Appendix 2: Bibliography } & 108\end{array}$

Appendix 3: Meetings and Interviews 111 


\section{Introduction}

As our character is defined by the sum of the events that have transpired in our past, architecture with the capacity to record the events our culture will reveal an invaluable narrative of social transformation. It becomes evident that character, and identity, is bereft without history; and in our constant state of transformation it is only through an understanding of this narrative that we can truly begin to appreciate who we are.

The first chapter of this thesis establishes the necessity for architecture to respond to place; both in its immediate site and in the greater context of cultural evolution. Thereby, making it a response to a moment amidst an ever transforming culture; a marker denoting the conditions in society that sculpted the architecture. It suggests that an architectural discourse, through the juxtaposition of contemporary and historical syntaxes, would enhance the notion of place revealing a narrative of cultural transformation. The second chapter reinforces this idea by suggesting that transformed architectural monuments, embedded with the memories of past eras, can offer contemporary programs and remarkable spaces that would allow antiquated architecture to once again participate in the generation of events within a contemporary cultural context. 
By suggesting that the Royal Canadian Yacht Club is a monument of the Edwardian era, the third chapter reveals the rapid and storied transformations of Toronto's relatively immature existence, as it pertains to the architectural and cultural shifts within the clubhouse. While still being a place of escape from the growing metropolis, this chapter reveals how the incapacity of the current architecture to transform over the past century, has manifested a growing schism between the Edwardian architecture and the inhabitants of contemporary culture it is meant to serve.

Before investigating a method by which to liberate the antiquated architecture of the monument, the next chapter discusses the relationship between the metropolis and island oasis through their juxtaposition, suggesting that the experiences of each is enhanced by its relative presence to the other and the space between them. The penultimate chapter looks at the work of Gordon Matta-Clarke in its capacity to interrupt and reorient the traditional spaces that make visible a century of transforming social dynamics. By dissolving the boundaries of traditional architectural space, and the programmatic realms that their forms imply, the architectural intervention opens a discourse between spatial and programmatic thresholds, allowing traditionally isolated realms to transform and be re-read through a contemporary perspective.

The final chapter uses the decline of formality, innately occurring through the flattening of social hierarchy, to manifest an intervention that opens a dialogue between the realms of service and served through the catharsis of three characters forever deeply imbedded in functioning of the club. It introduces a syntax that disrupts the rigid architecture allowing 
it to be reengaged by a contemporary inhabitant, while further revealing an architectural layering that denotes unique moments among culture's infinite transformations; and like a palimpsest, the architecture reveals a narrative of culture. 


\section{$\underline{\text { Architecture In Place }}$}

\subsection{Tablau raza and the Modernist Response to Place}

"All the material and intellectual forces of society converge towards the same point; architecture... [is] humanity's grand writing and principle form of expression in its diverse states of development."

- Victor Hugo

Architecture is fundamentally charged with the responsibility of engaging the culture that it intends to serve. As a result, architecture is the physical manifestation of a culture's needs amidst its constant transformation. It becomes apparent that 'place', both in how it relates to its physical, contextual fabric, and its more metaphysical, cultural fabric; is an essential aspect of the architecture. If the architecture is successfully embedded into its context, and its respective culture, it continues to participate in the greater evolution. However, if the culture that necessitated the architecture transforms beyond the capacity of the program-defined spaces, then they become antiquated and the essential link between architecture and culture will be severed, stripping the architecture of vitality. Thus, in its failure to participate in contemporary culture, architecture will be reduced to a mere artefact embedded only with static notions of memory and place, echoing from the era in which the architecture was conceived.

Buried in the industrial revolution, Europe's urban condition had deteriorated to a point of crisis challenging architects to create a new architecture; the modernist style was their solution. It was an architecture for the masses, "one (architectural) idea for a single

\footnotetext{
${ }^{1}$ Dendy, William. Toronto Observed (Toronto: Oxford University Press, 1986) viii.
} 
man." Autonomous to any existing traditional architectural syntax, it was the antithesis of the dim, dense, urban fabric Europe, and was generally founded on a tabula rasa approach. Formally, it completely ignored the existing fabric of the city to which it was innately trying to respond to, and was criticised for being an empty architecture, devoid of human presence. Its intention was to be a blank canvas on which to paint a contemporary character; however, it became evident that character itself is bereft without history. As a result "in its late, post war phase, modern architecture had become meaningless, whether in the sense of sterile schematism or as arbitrary invention. It did not speak anymore, and the built environment often lost its traditional identity."3

At the height of modernism in 1925, architect, and a founder of CIAM ${ }^{4}$, Le Corbusier had created an urban design known as the 'Plan Voisin'; a proposal to erase Paris' entire right bank replacing it with sixteen cruciform towers protruding from an void fabric. Because of the style's autonomous, antithetical nature; the architecture, was conceived without a connection to its respective 'place'. Le Coubusier believed that architecture could not lose the fundamental connection to the city or to history. However, this approach to creating architecture fatally severs the fundamental connection between a culture defined by its history and the space it is to inhabit. In Aldo Rossi's book 'The

${ }^{2}$ Sorkin, Michael. Lecture. National Gallery of Canada (02/13/06)

${ }^{3}$ Norberg-Schulz, Christian. "Order and Change in Architecture" Constancy and Change in Architecture (Huston: Texas A\&M University Press, College Station, 1991) 43.

${ }^{4}$ CIAM (Congress International D'Architecture Modern) was an organization of architects (including Le Corbussier and Sigfried Giedion), and a set of meetings, founding the Modern Movement or International Style (1928-1959) 


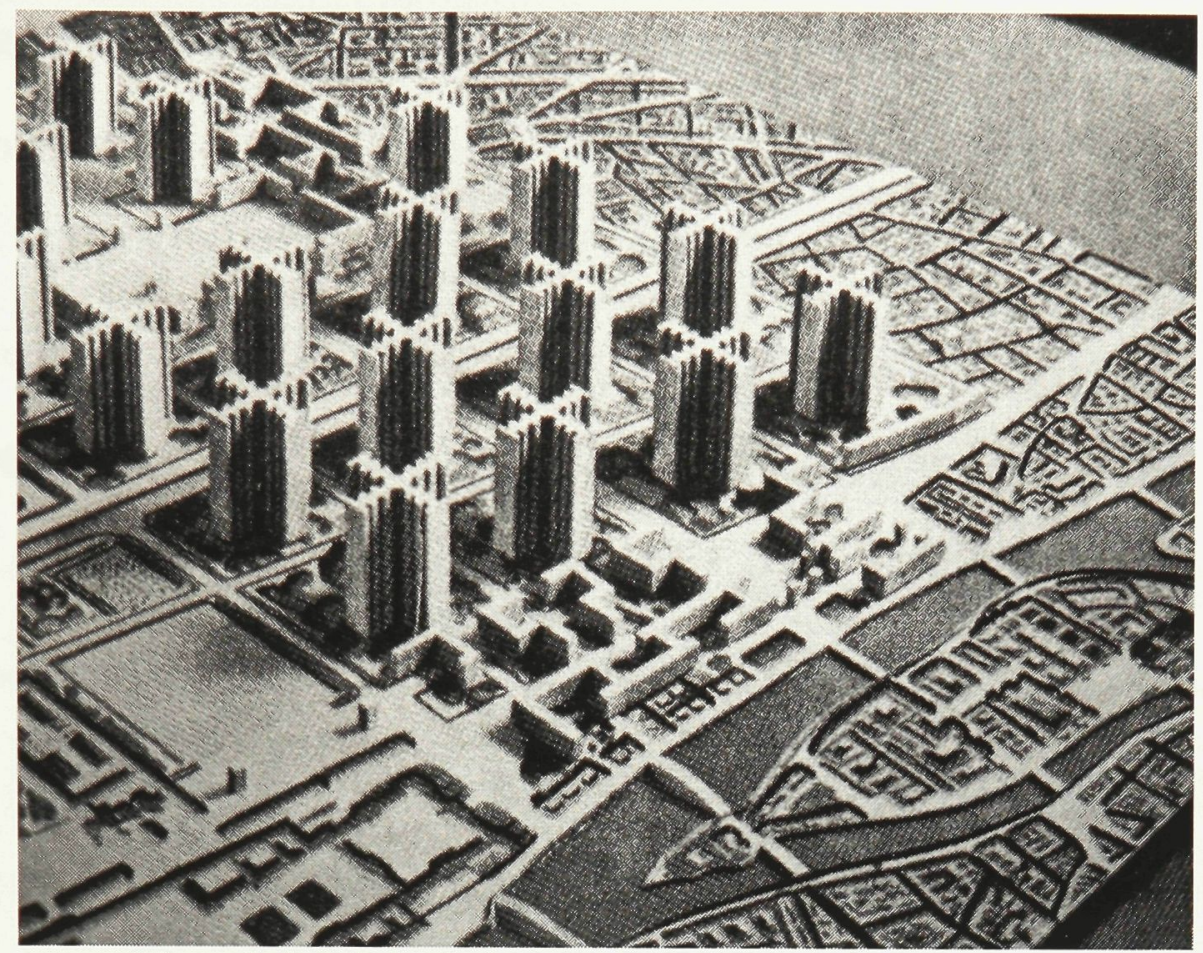

Figure 1: Le Corbusier's master plan for Paris: Le Plan Voisin

Architecture of the City' he emphasises this connection between history and the contemporary culture, suggesting that this lineage, when translated into architecture, generates profound, vital architectural. It could then be argued that modernism was a style born without vitality. Fundamentally, the ideas behind modernism were a response to a condition in culture, but failed to engage the naturally evolved fabric innate to the architectures place. Detached from the fabric of the city there was little discourse with the culture that the architecture intended to serve. "When modernism abolished styles a vacuum was created which the modernists hoped, rather optimistically, to fill, with the aid of the idea that form follows function. The history of modern architecture shows that this hope has not been fulfilled." It became apparent that architecture had an inexorable connection to history and place; and architecture must respond to an ever-changing

\footnotetext{
${ }^{5}$ Norberg-Schlutz 52.
} 
society. The failure of architecture to engage history and culture would produce something outside of society and fundamentally without place.

\subsection{Architecture Engaging Contextual Place}

Each architectural endeavour has the responsibility to engage its site and the culture in which it is embedded. For example, 'place' defined by the forms, and the well evolved culture of Barcelona's Gothic Quarter, would embody a set of conditions that are completely antithetical to the 'place' that would be defined by the orthogonal forms, and relatively immature culture, of Manhattan. In the case of Manhattan, the formal conditions of the island challenge the architects to respond to the conditions of its unique place.

It forces Manhattan's builders to develop a new system of formal values, to invent strategies for the distinction of one block to another... Since there is no hope that larger parts of the island can ever be dominated by a single client or architect, each intention- each architectural ideology- has to be realized fully within the limitations of the block. ${ }^{6}$

It demanded a response to its unique place envisioning

architecture's relationship to the city through the notion of type and context, or the analogous gestalt model of the figure-ground relation, acknowledging the "place making" capacity of architecture and its embeddedness at a given site. In contrast to what was regarded as "placelessness" of much of the modernist architecture and the universalizing imperatives of the avant-guard, contextualism recognized the mutually constitutive relationship between building and context and was deeply sceptical of the totalizing solutions to urbanism. ${ }^{7}$

\footnotetext{
${ }^{6}$ Koolhaas, Rem. Delirious New York (New York: Monacelli Press, Inc., 1994) 20-21.

${ }^{7}$ Lee, Pamela M.. Object to be Distroyed: The Work of Gordon Matta-Clark (Cambridge: MIT Press, 2000) 35-36. 
Frank Gehry's Guggenheim Museum is sited aside a small river in the once industrial town of Bilbao, Spain. It's twisted titanium forms are claimed to be a response to the ships that once navigated the industrial canal, however it bears shocking similarity to his proposal for a new Guggenheim at the edge of Manhattan's lower west side. The architectural similarities question the architecture's fundamental connection to its contextual place. The issue emphasises the importance of understanding the vernacular condition of place, suggesting that each architectural site has an inherent set of

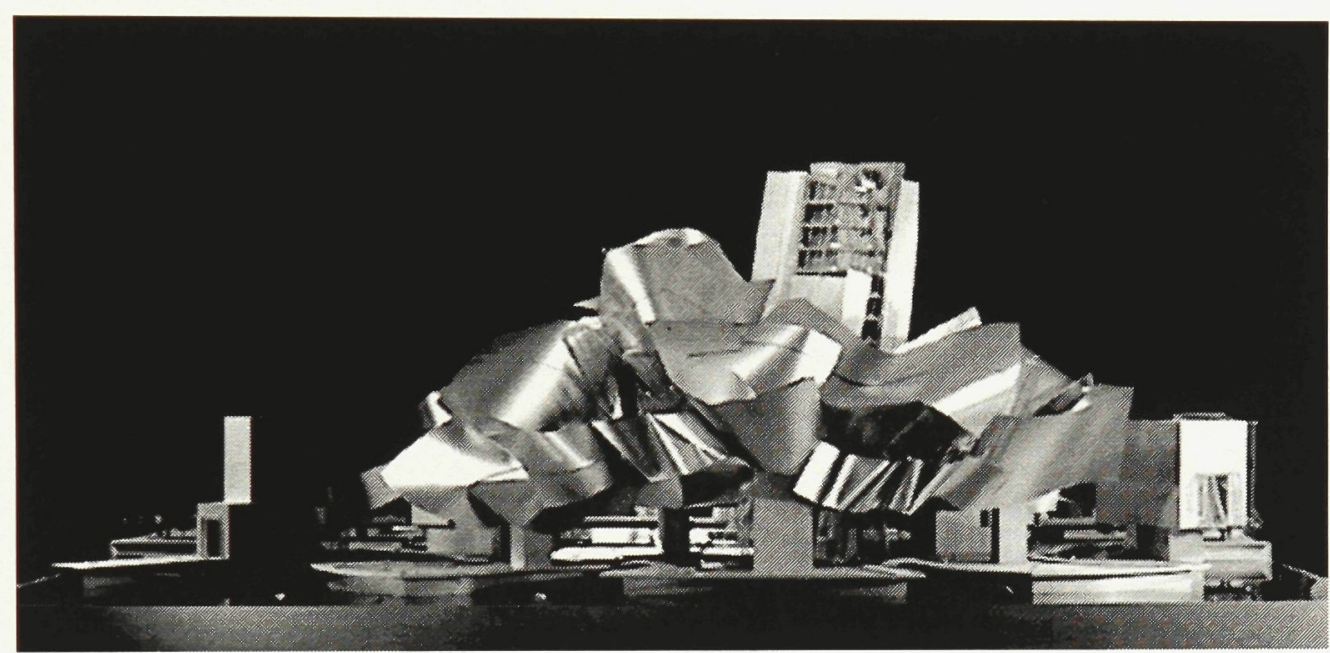

Figure 2: Frank Gehry's Guggenheim proposal, NY.
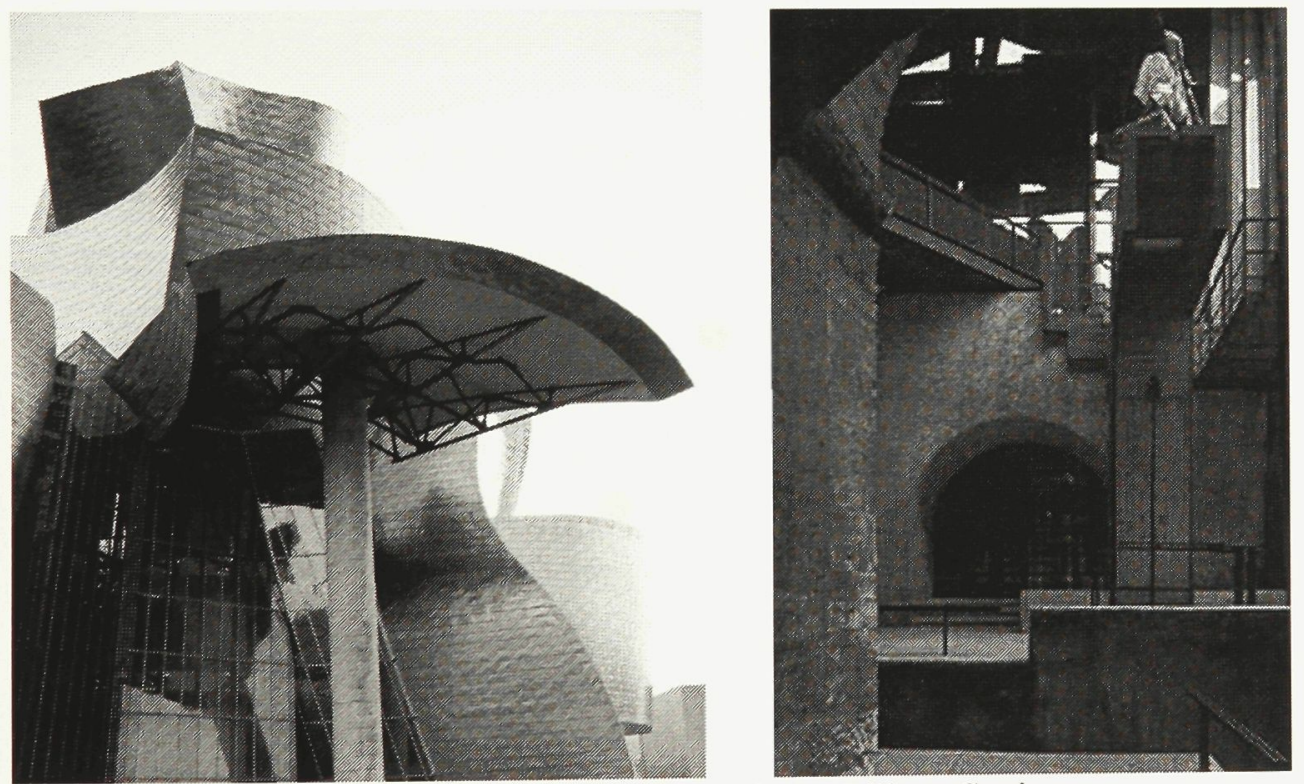

Figure 3: Frank Gehry's Guggenheim Bilbao, Spain.

Figure 4: Carlo Scarpa's Castelvecchio Museum, Verona, Italy. 
properties that should influence how architecture is made. Carlos Scarpa is noted for his ability to make architecture that is a product of a deep understanding of a local vernacular. The "Castelvecchio Museum, with his linked sequence of precise, almost surgical operations affecting the great walled enclosure... was an urban design achievement of a remarkable scope." ${ }^{8}$ In this case, 'urban design' does not refer to any specific, physical element of the city, but rather to a fundamental knowledge of a culture that Scarpa possessed, giving him the capacity to create contemporary architecture that is profoundly embedded the site's well developed identity and sense of place.

\subsection{Defining Cultural Moments and Social Transformation}

The notion of 'place' in architecture can furthermore be the foundation upon which we can layer contemporary architectural endeavours such that a single building can speak of different moments in culture - a new syntax in discourse with an architecture sculpted by a time past. "Architecture is human history made manifest; in architecture the past lives on into the future." ${ }^{\prime 9}$ Furthermore, as the physical manifestation of a moment in culture, architecture can tell a narrative of transformation by revealing social changes through juxtaposition of syntaxes from different eras. This thesis proposes that the most powerful definition of this narrative comes from the juxtaposition of entities that speak of many different moments in time. It allows a single architectural entity to define its era through contrast and dissimilarity to other entities to which it is juxtaposed. Situated in contrast at the end of a series of row houses, the Reitfield house denotes a new

\footnotetext{
${ }^{8} \mathrm{Dal}$ Co, Francesco and Gluseppe Mazzariol. Carlo Scarpa: The Complete Works. (Milano: Editrice Electa,1984) 159.

${ }^{9}$ Greenhill, Ralph. The Face of Toronto (Toronto: Oxford University Press. 1960) 10.
} 
understanding of architecture, manifested by a new era. An icon of the DeStijl movement, the house's juxtaposition to the older architecture in its context denotes a cultural shift time defined by contrast and dissimilarity.

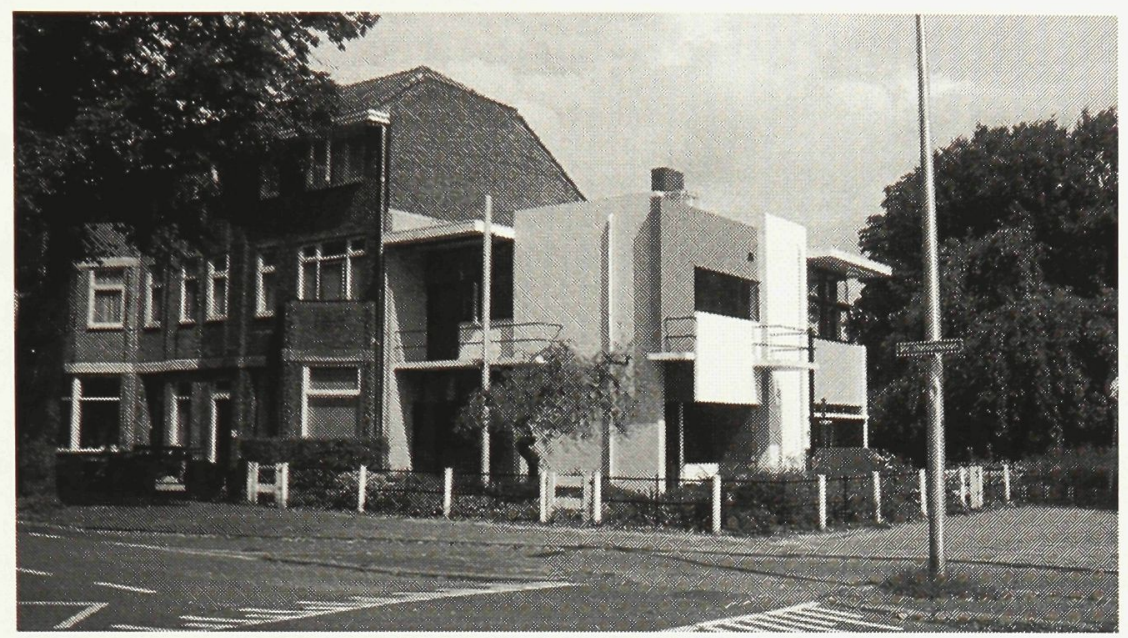

Figure 5: Rietfield house

Conceived in the Romanesque Revival style, the first Toronto City Hall was constructed in 1891. It was replaced in 1964 by the new city hall designed by Finnish architect Viljo Revell, and was considered to be one of the city's first piece of truly public architecture; its square said to be the great living room of Toronto. ${ }^{10}$ As the first piece of architecture for the public, it was a major step in physically manifesting Toronto's contemporary identity. "At the opening ceremonies, Prime Minister Lester B. Pearson said of the New City Hall: "It is an edifice as modern as tomorrow - as modern as the day after tomorrow." Set in close proximity to the old city hall, the two pieces of architecture open a dialogue of time that reveal key architectural components each denoting moments in the city's transformation. The new architecture speaks of contemporary conditions of the city, denoting Toronto's intention to create public spaces

${ }^{10}$ Fulford, Robert. Accidental City (Toronto: MacFarlane Walter \& Ross, 1995) 7. 
and a new urban architectural identity; ${ }^{11}$ a transformation inharent to its shift from Canadian town to world metropolis. The dichotomy between two moments in Toronto's history heightens ones understanding of the city's transformation; each clearly denoting their respective moments in Toronto's evolution, and together denoting its change.

Suggesting that two different architectural entities, each representatives of their place and time in their respective eras, can open a dichotomy that will reveal cultural transformation, alludes to the existence of a similar dichotomy potentially existing within a single piece of architecture. Aldo Rossi discusses his experiences of walking through a city after it was bombed as experiencing architectural fragments that revealed opportunities in which new architecture could engage the memory embedded historical framework. These voids in the architecture allowed the traditionally formed architecture to bleed out into the public spaces of the street, evoking a new understanding of the building, its spaces, and fundamentally its traditional identity. The bombing was essentially the cutting open of the architecture of the city, the revealing of its most private identity. Engaging this architectural framework with a contemporary intervention would create a new architecture, profoundly conceived through a response to the built character of nations, cultures, and epochs. ${ }^{12}$

Norman Foster's design for the Reichstag in Berlin is loaded with political and cultural evolution. The once paradoxical icon of German

\footnotetext{
${ }^{11}$ Fulford 7.

${ }^{12}$ Rossi, Aldo. The Architecture of the City (Cambridge: MIT Press, 1984) 131.
} 


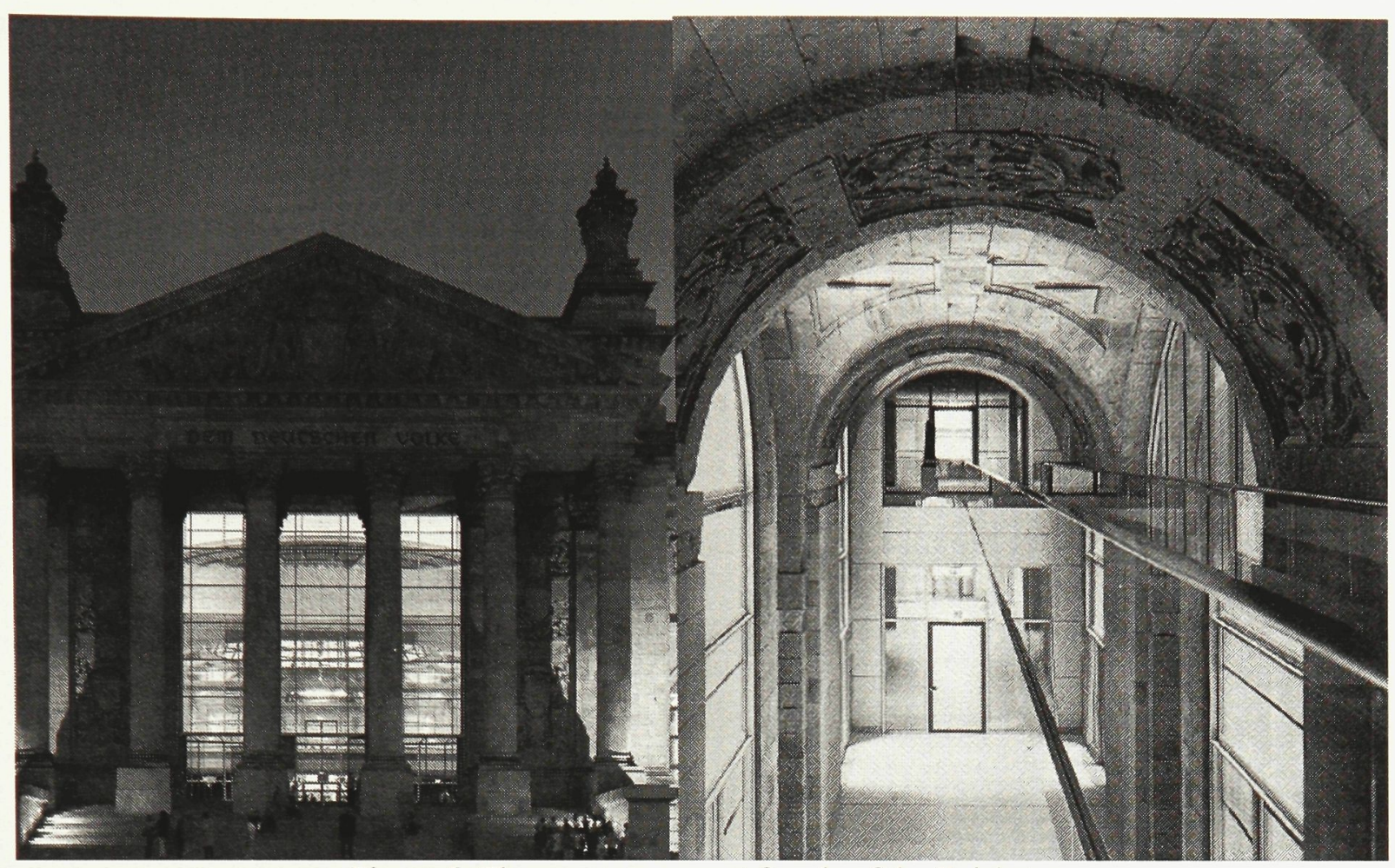

Figure 6: The new transparent façade of the Reichstag

Figure 7: Interior shot of new elevated walkways

aggression in Europe ${ }^{13}$, worn by 120 years of dramatic cultural evolution, was

transformed by Foster's powerful intervention such that the architecture is again the center for German Politics. After World War 2 it sat for decades as a derelict relic in which political torment, power struggles, war, hatred, and tremendous loss, were buried. The German Government decided to keep, the building as a framework, "bearing the imprint of time and events" ${ }^{\prime 14}$, on which to build a new architecture to embody a new Germany. This thesis proposes that it is in the dichotomy between the syntax of old and new architecture where the strength of the architecture lies. In the case of the Reichstag

${ }^{13}$ Paradoxical in that, when the Nazis came into power the building was not used as a political office, but rather a site for anti-Semitic rallies. The sole reason the Reichstag was not initially destroyed was because Hitler and his architect Albrecht Speer liked the architecture. However, when Berlin came under attack from the Soviets, the Nazis fell back to the Reichstag, using it as their fortified headquarters. Thus, it was perceived as the last object to capture to signal victory over the Germans.

${ }^{14}$ Foster, Norman. Rebuilding the Reichstag (Woodstock: Overlook Press, 1999) 76. 
the building becomes "a living museum of German history to future generations"15, as the new architecture produces a dialogue that embraces the buildings storied character and tells the story of Germany.

\section{$1.4 \quad$ Nostalgia - Place Framing Experience}

While our more scientific and practical disposition tends to obscure the more psychological and spiritual sense of places in deference to a more rigorous analytical understanding, we continue to recognize, if only on a personnal and unspoken level, those special responses that certain places evoke deep within us. ${ }^{16}$

This facet of place alludes to the relationship that humans have with physical space; the idea of 'place' embodied by material space yet transcending the physical geometry of the space. Furthermore, the evolved patinas of the materials that create the physical space allow for the materials themselves to speak to the metaphysical understanding of place. This sense of place has to do with a certain level of recognition in the physical space, both conscious and subconscious. ${ }^{17}$ It speaks of nostalgia, the euphoric feeling related to a memory, which is rooted in the Greek word nostos meaning to return home. ${ }^{18}$ Home, often the place of our most primal memories and the most personal aspect of our life, is clearly not solely defined by the walls that enclose us, but more importantly by the events that transpired within those spaces. The tangibility of an event becomes more real in the

\footnotetext{
${ }^{15}$ Foster 60.

${ }^{16}$ Crowe, Norman. Nature and the Idea of a Man-Made World (Cambridge: MIT Press, 1997) 76.

${ }^{17}$ Crowe 70 .

${ }^{18}$ Crowe 71.
} 
physical context that the event was generated. "We use place to make events concrete, and events to make place meaningful." $" 19$

\subsection{Summary}

In the 1920 s search for universality, modern architecture failed to respond to the human need to be a part of something. Now, in an era where differences between people and cultures are dissolving, "a sense of place concerns that need to find a familiar landscape as a refuge from the unknown, perhaps from the terrifying prospect of being set adrift in what would otherwise be a dimensionless, timeless, and chaotic world.,20 Architecture exists as a stage on which the events of human life are played out. It engages its culture, site, and inhabitants with its capacity to affect the events that transpire within its space such that it is constantly recording our evolution. As spaces generate a history they become attached to, making visible where we have been, where we are, and perhaps they can indicate where we are going. It gives a place to events, and substance to memories that define our characters.

\footnotetext{
${ }^{19}$ Crowe 78 .

${ }^{20}$ Crowe 71 .
} 


\section{Memory Framing the Contemporary Event}

\subsection{Antiquated Monuments Generating New Events}

"By traveling in our minds between the present, and other times and places, we seem to make connections, to build bridges of knowledge and cultural continuity."21 Persistent urban artifacts ${ }^{22}$ become monuments by existing symbolically and physically as a testament to the culture that demanded them, and the moment in which they were conceived. We can look to these monumental artifacts, to challenge our perception and understanding of the past, while using them to inform how we engage new programs and architecture inherent to contemporary culture.

Drawing on Alois Riegl from his text 'The modern Cult of Monuments: Its Character and its Origin', Pamela M. Lee discusses the idea that "the monument was conceived through a range of methodological categories, among which the intentional monument - the object specifically erected to commemorate and event or moment or person - was its "oldest and most original" form. Riegl further notes that any historical monument innately has what he referred to as 'age value', and any object that shows signs of history guarantees its function as a valued thing. Therefore, no matter how mundane, any object can attain the status of monument by these terms ${ }^{23}$ Aldo Rossi, on the other hand, suggests that the artefacts existance as a 'monument' is based on its

\footnotetext{
${ }^{21}$ Malcolm and Webb x.

${ }^{22}$ Rossi 61.

${ }^{23}$ Lee 54.
} 
capacity to constitute the city, its history and art, its being and memory within its context. $^{24}$

A valuable example of the 'transformed monument' can be seen in the Tate Modern Gallery towering over the left bank of the Thames river in London, England. The building was designed as an enormous coal burning power plant and constructed in the middle of the $20^{\text {th }}$ century. Shut down not half a century later, it sat idly as a frozen, monumental testament to the great city's industrial past, before it was transformed into one of the worlds leading contemporary art venues. The new intervention by architects

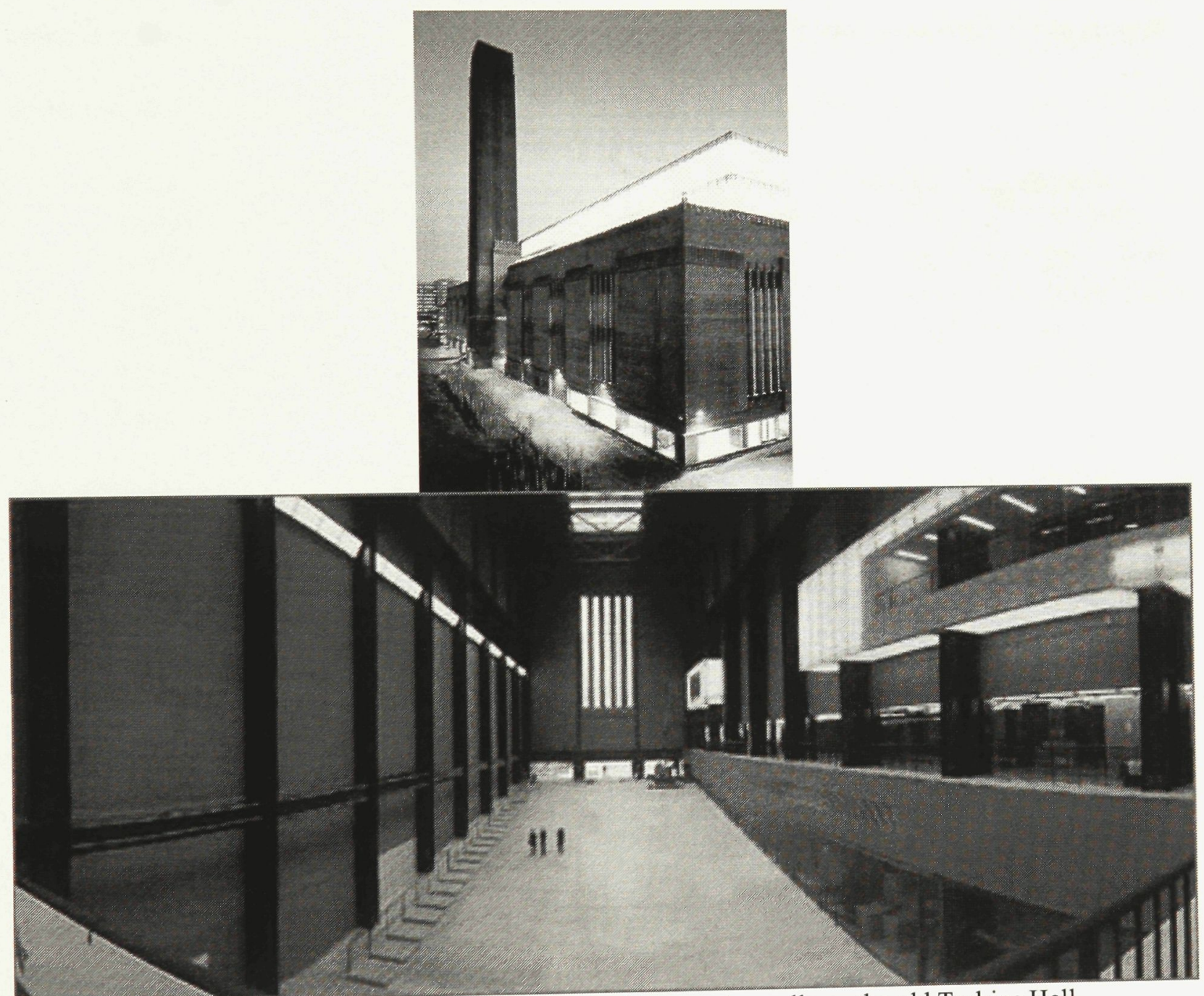

Figure 8-9: The Tate Modern, London. And its massive gallery- the old Turbine Hall

${ }^{24}$ Rossi 60. 
Jacques Herzog and Pierre de Meuron celebrate the original space of the power plant by transforming the spaces from their industrial roots, such that they may participate in the culture of contemporary London. Embedded in its massive walls and steel beams, the memory of the power plant is left to prevail while subtle interventions allow for the building's completely new program to operate within. The power of the architecture is in the intervention's capacity to reshape the production and perception of contemporary art by revealing new opportunities for reading and experiencing the power plant's old monumental spaces. The main space of the Tate is the old Turbine Hall now internationally known as an artistic venue that challenges the art community, begging it to respond to its unique architecture.

As a place for the display of art this was almost unprecedented. The nearest analogy in sheer volume would be a religious structure such as St Peter's, into which Gianlorenzo Bernini inserted some vast sculptural objects. But the Turbine Hall is barer, and still less related to the human scale. It represented a challenge to which five artists - Louise Bourgeois, Juan Muñoz, Anish Kapoor, Olafur Eliasson and Bruce Nauman - have responded in very different ways and with varying levels of success. ${ }^{25}$

The Tate Modern offers contemporary culture a space, foreign in scale and materiality, to the way architecture is made today, while still resonating with the era of its creation. The architecture of the new program embraces the monument in such a way that the memory of making and production, originally associated with the power plant, directly translates to the idea of generating of new art, and fundamentally the production of new events and culture within a contemporary context.

${ }^{25}$ Gayford, Martin. "A New Space for a New Art" Tate Modern: The First Five Years (London: Tate, 2005) 7. 


\subsection{Contemporary Functions and Architectural Vitality}

Architectural "function must always be defined in time and in society: that which closely depends on it is always bound up in its development." ${ }^{26}$ If culture evolves such that a building is no longer capable of the fundamental task of engaging culture by framing and encouraging new events, then architecture has lost what Aldo Rossi refers to as vitality. ${ }^{27}$ "History exists so long as an object is in use; that is, so long as a form relates to its original function. However, when form and function ${ }^{28}$ are severed, and form remains vital, history shifts into the realm of memory. When history ends memory begins. ${ }^{, 29}$ An architecture solely existing in the realm of memory has no vitality. It fails to engage its contemporary context, thus becoming an artifact that is void in its capacity to generate new events. Where the Reichstag continues to contribute to contemporary governmental activities while further speaking the its inhabitants as a 'living museum, ${ }^{30}$, a 'dead museum' would conversely be a building like the Alhambra ${ }^{31}$ in Granada, Spain. In this case, the Moorish Place of Nasrid has been turned into an artifact existing outside the contemporary events of a city by being preserved in its origional, $14^{\text {th }}$ century condition. This idea is summed up in Rossi's theory of permanencies being either propelling elements or pathological elements. Permanencies, are objects that have lost

\footnotetext{
${ }^{26}$ Rossi, 60.

${ }^{27}$ Rossi, 57.

${ }^{28}$ Function being the nature by which architecture responds to a societies contemporary needs

${ }^{29}$ Rossi 7.

${ }^{30}$ Foster 60 .

${ }^{31}$ Alhambra is an Arab palace in Granada, Spain dating from the $13^{\text {th }}$ and $14^{\text {th }}$ century. It is currently a tourist site with no function other than as an artifact to be viewed from a time long lost. Other than through tourism, there is no manner by which the architecture engages its surrounding contemporary culture and fabric.
} 
their original function, but their form persists within the fabric of the city. Propelling elements are those where the physical form still exists denoting and era lost, but the function has been transformed and it continues to be used, thus, "conditioning the urban area in which it stands and continuing to constitute an important urban focus... This proves vitality." 32 On the contrary are pathological elements. Like the Alhambra, these permanencies stand virtually isolated from the city, and reject any potential shift of the program. ${ }^{33}$

Regardless, I [Aldo Rossi] believe that persistence in an urban artifact often causes it to become identified as a monument, and that a monument persists in a city both symbolically and physically. A monument's persistence or permanence is a result of its capacity to constitute the city, its history and art, its being and memory $^{34}$

\subsection{Summary}

Towards the end of the $20^{\text {th }}$ century, well before North America, Europe's history laden culture had acknowledged the power of using antiquated monumental architecture as an invaluable framework on which to begin contemporary architectural endeavors.

Obsessed with technology and 'the new', Toronto's far younger culture had developed an unfortunate disregard for history. In his book 'Toronto Observed' William Dendy, discusses this idea in context to Toronto staying: "time and again a lust for the grandest, the latest, or the most fashionable has lead to casual neglect or cavalier destruction of our urban heritage. $" 35$

\footnotetext{
32 Rossi 59.

33 Rossi 59.

${ }^{34}$ Rossi 60.

${ }^{35}$ Dendy Toronto Observed viii.
} 
The contemporary engagement of antiquated monuments, laden with memories of time past, offers contemporary culture an opportunity to engage the history and events that define us today. It embraces our past, good or bad, such that we may continue to evolve with a profound understanding of our place, embodying the memories that define our character. It celebrates the multitude of stages that have hosted and sculpted the events of the culture that defines us, while providing a sound foundation for the architectural endeavors of tomorrow's culture. "The character of whole nations, cultures, and epochs speaks through the totality of architecture, which is the outward shell of their being." $" 36$

"When the pace of daily life and innovations in the world around us seem to be accelerating beyond our control, we yearn for some reminder of continuity with our past. ${ }^{, 37}$ An architectural dialogue between past, present, and the future reveals through difference and likeness, our identity that is all too often forgotten. "We should not live in a bright shinning future, anymore then we should hide in the comfortable pastiche of the past. We must inhabit an ever evolving present, motivated by the possibilities of change, restricted by the baggage or memory and experience. ${ }^{, 38}$ It becomes the challenge of the architect to craft interventions that respectively engage these memory-laden artifacts such

\footnotetext{
${ }^{36}$ Rossi 131.

${ }^{37}$ Mostaedi, Arian. Building Conversion \& Renovation (Barcelona: Filabo, S.A., 2003) 8.

${ }^{38}$ Chipperfield, David. Recent Work (New York: Watson-Guptill Pubns, 1997) 131. 
that they can reveal places and moments that evoke a response from its inhabitants while engaging contemporary culture.

Today it has become increasingly difficult for us to see that sometimes the cradles of lesser events may provide us with the places that are important to the memory of who we are and remind of the important truth that our society at any given moment is still a product of what has gone before. Past and place are inextricable. A place that is important to our past must rise above nostalgia in our consciousness lest it become merely quaint. ${ }^{39}$ 


\section{$\underline{\text { A Site Under Transformation }}$}

\subsection{The Evolution of the Royal Canadian Yacht Club and Toronto}

The1993 commemoration of Toronto's $200^{\text {th }}$ birthday was a moment amidst infinite shifts that have sculpted Toronto's transformation from a British settlement into a major western metropolis. These constant social shifts, and subsequent architectural evolution, have fuelled Toronto's transformation through the Georgian era of the late $18^{\text {th }}$ and early $19^{\text {th }}$ century, through the century long Victorian era, Edwardian era, and into its present era where it is poised among the great metropolitan cities of North America.

In the mid $19^{\text {th }}$ century, Toronto's population reached 35000 , and the city's water supply was confidently pumped directly from the harbor. The city's waterfront, still 60

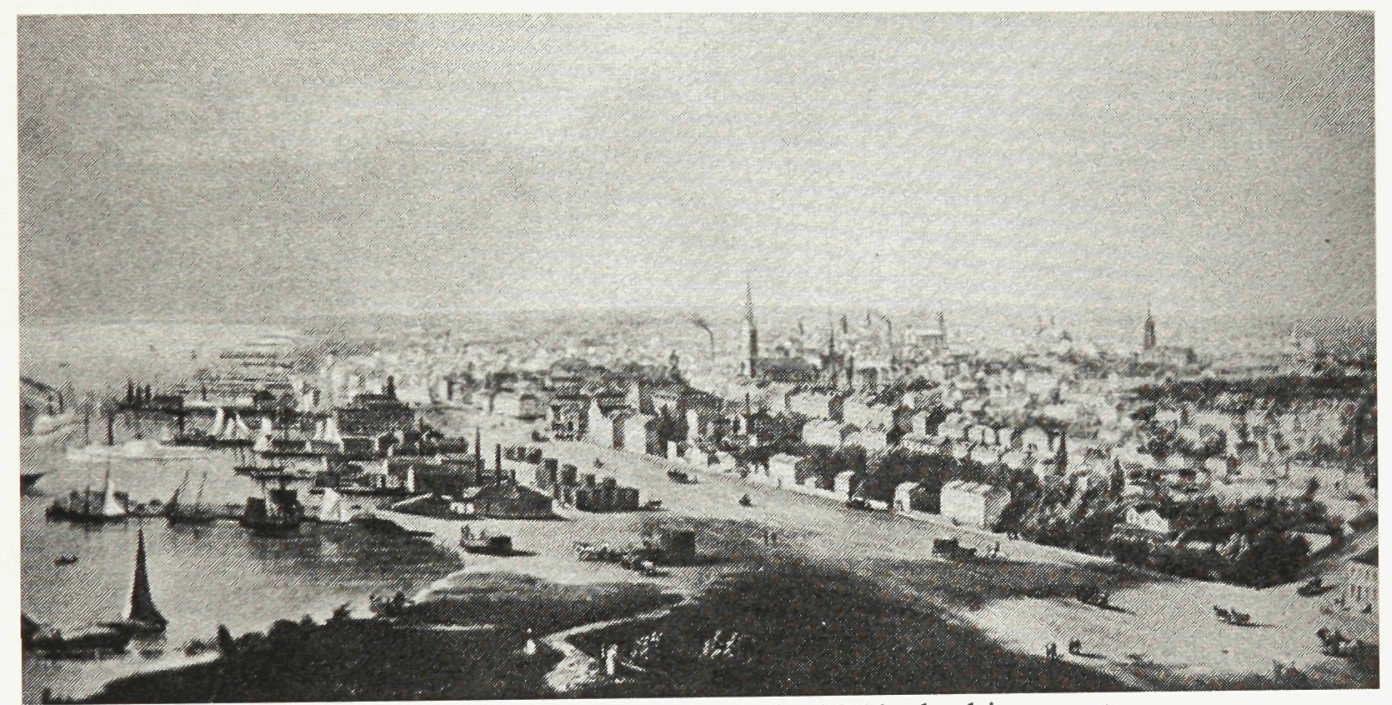

Figure 10: Toronto waterfront in 1854 - looking west

years from the inescapable momentum of the industrial revolution, was a relatively placid esplanade.

The harbor attracted all types of "messing-about in boats" - sailing, rowing, sculling, and canoeing- by all classes and ages of Torontonians. The Craze for boating was summed up by C. S. Clark in his book, Of Toronto the Good (1898): In spite of all of its drawbacks... Toronto is a delightful place to live. Its boating is unsurpassed. The bay on a summer night is one mass of skiffs and sail boats, 
there is not a youth in the city who has not experienced the delights of rowing, and a large number are owners or part owners of boats...All the waterfront comprises interminable lengths of boat houses both public and private and the houses owned by organizations such as the Royal Canadian Yacht Club are perfect places in their way. Aquatic sports comprise very largely the principle division of Toronto's men and boys, and there is scarcely a boy in the city whose sympathies are not enlisted in some of the great summer events. ${ }^{40}$

Until the mid $19^{\text {th }}$ century, yachting was considered either a franchise of commerce, or a domain of the Queen's Royal Navy; yachting for pleasure at that point was unheard of. The notion of pleasure sailing was conceived out of the military belief that sailors, not under service conditions, had time to experiment with new naval techniques and technologies that could be valuable to the Royal Navy; while their boats and crews, could also be quickly adapted for use in war if necessary. In fact, the racing yacht America, whose victory named the famous America's Cup, served as a military vessel for both sides during the American Civil War. The program of the mid $19^{\text {th }}$ century 'Yacht Club' was place for Messrs ${ }^{41}$ to assemble, in the name of the Queen, over their common interest in development of yachting. The program of the clubhouse's architecture was still years away from resembling any form of the multifaceted facilities of the contemporary yacht club or 'country club' that is today.

The Royal Canadian Yacht Club (henceforth RCYC), then Canadian Yacht Club, was established in 1852 by a few gentlemen sitting on barrels in the office of Captain Fellows before the meetings were moved to a room over the John Steel's Saloon, now the present site of Toronto's Academy of Music. All eight members congregated there once a

${ }^{40}$ Dendy, William. Lost Toronto (Toronto: McClelland \& Stewart Inc., 1978) 41.

${ }^{41}$ Messrs - referring formally to one or more men 
week to discuss sailing related issues, until the club moved to its own space owned by Gzowski and Macpherson; soon to be the present site of Union Station. Toronto's growing and densifying city core, increasing property value, and consequent infilling of the harbor, drove the club to move once more to the city's southern edge on the waterfront, also a more logical site for a sailing club. During its early years on this site, the harbor sailing regattas could be viewed from the balconies of the Canadian Yacht Club's clubhouse erected on a scow ${ }^{42}$ moored just west of what was known as Rees'

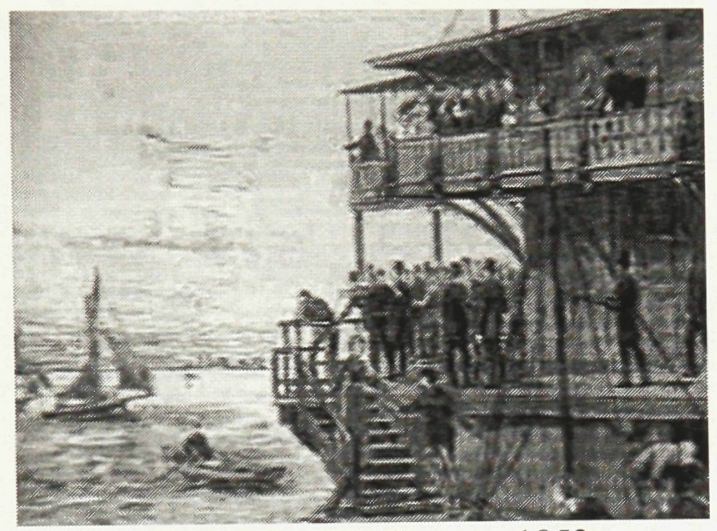

Figure 11: RCYC scow- 1852

Warf. In 1854, the club petitioned to England for the right to use a Royal designation. To more surprise than anyone is willing to admit, the designation was granted, and the Canadian Yacht Club became RCYC.

The steady deterioration of the clubhouse around 1858 lead the club to purchase the wreaking steamer Provincial. The Provincial was used as a clubhouse with increasing frustration until 1869 when the club hired James Smith to construct a new clubhouse on the end of a pier just off the foot of Simcoe Street. The waterfront, now punctured by

${ }^{42}$ scow - a flat bottomed boat with slanted ends otherwise known as a barge 

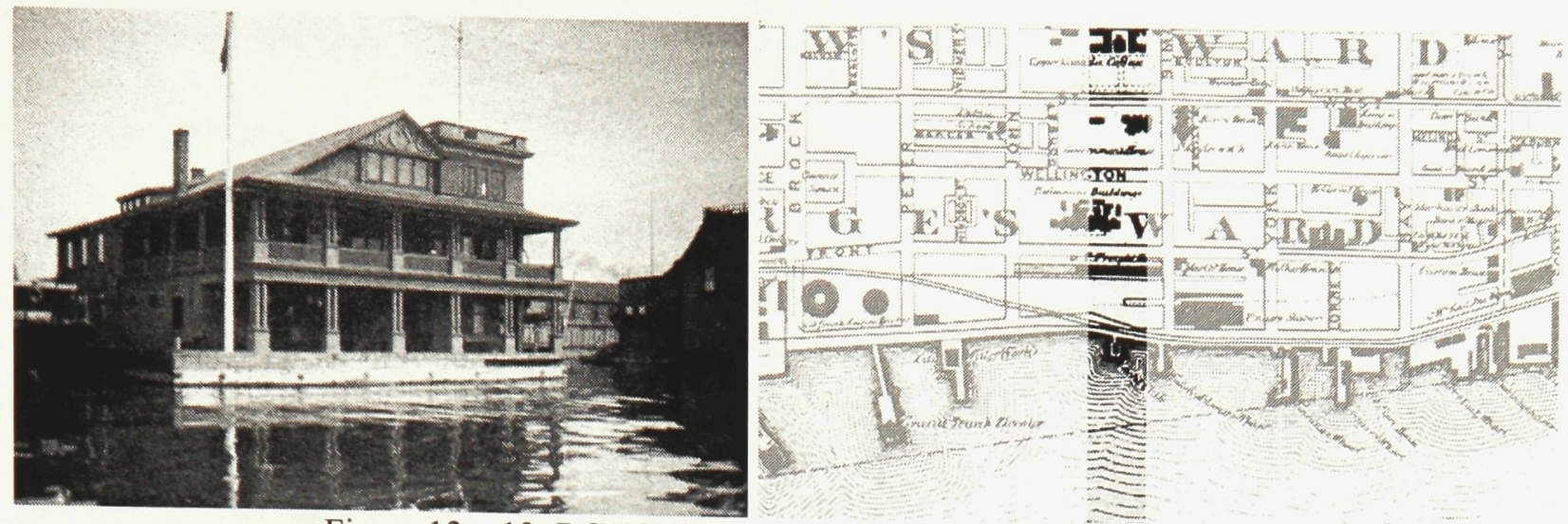

Figure 12-13: RCYC clubhouse at foot of Simcoe street -1897

numerous piers stretching away from the growing city, became the ideal place for the architecture of the clubhouse, among others, to be away from the urban condition and engage the tranquility of the lake. The RCYC, like the city, still lacked a confidence autonomous of the British Empire, such that it looked south towards the water- its colonial origins. Meanwhile, in the baffles of the RCYC's lakeside terraces, Toronto's industry had taken hold, and was expanding rapidly. Piers, now bearing the weight of industry, were creeping around the clubhouse, threatening the RCYC's capacity to successfully exist on the outer threshold of Toronto's urban core. The site was no longer a tranquil place just outside the city, but rather buried amidst the evolution of industrial growth.

The Railway Age brought prosperity- and, in the 1850s, the first major southward extension of the shoreline, which began the process of cutting Torontonians off from the lake. Railway and industrial uses expanded dramatically in the latter part of the $19^{\text {th }}$, and early part of the $20^{\text {th }}$ centuries, driving a widening industrialized wedge between the main part of the city and the water. ${ }^{43}$

By 1880 the Grand Trunk rail yard was settling in behind the RCYC, and a trip to the clubhouse soon to involved a sixteen-track traverse, often taking up to thirty minutes and

${ }^{43}$ Canada, Royal Commission on the Future of the Toronto Waterfront, Persistence and Change: Waterfront Issues and the Board of Toronto Harbor Commissioners. Publication No. 6 (Ottawa: Minister of Supply and Services Canada, 1989) 13. 
sometimes at the cost of loosing a limb, literally ${ }^{44}$. By now, the once pleasant waterside site just outside Toronto, was feeling the weight from Toronto's growth and evolution. Aside from the pressures pertaining to the onset of the early years of the industrial revolution, the rising cost of building maintenance and property value, motivated the club's move, once more, to what was then just outside the city's rapid growth.

In the late 1870 's Honorary Secretary Mr. S. Bruce Harman selected the 10-acre, future site of RCYC on the marshy Toronto Islands. Shortly thereafter, famous Toronto

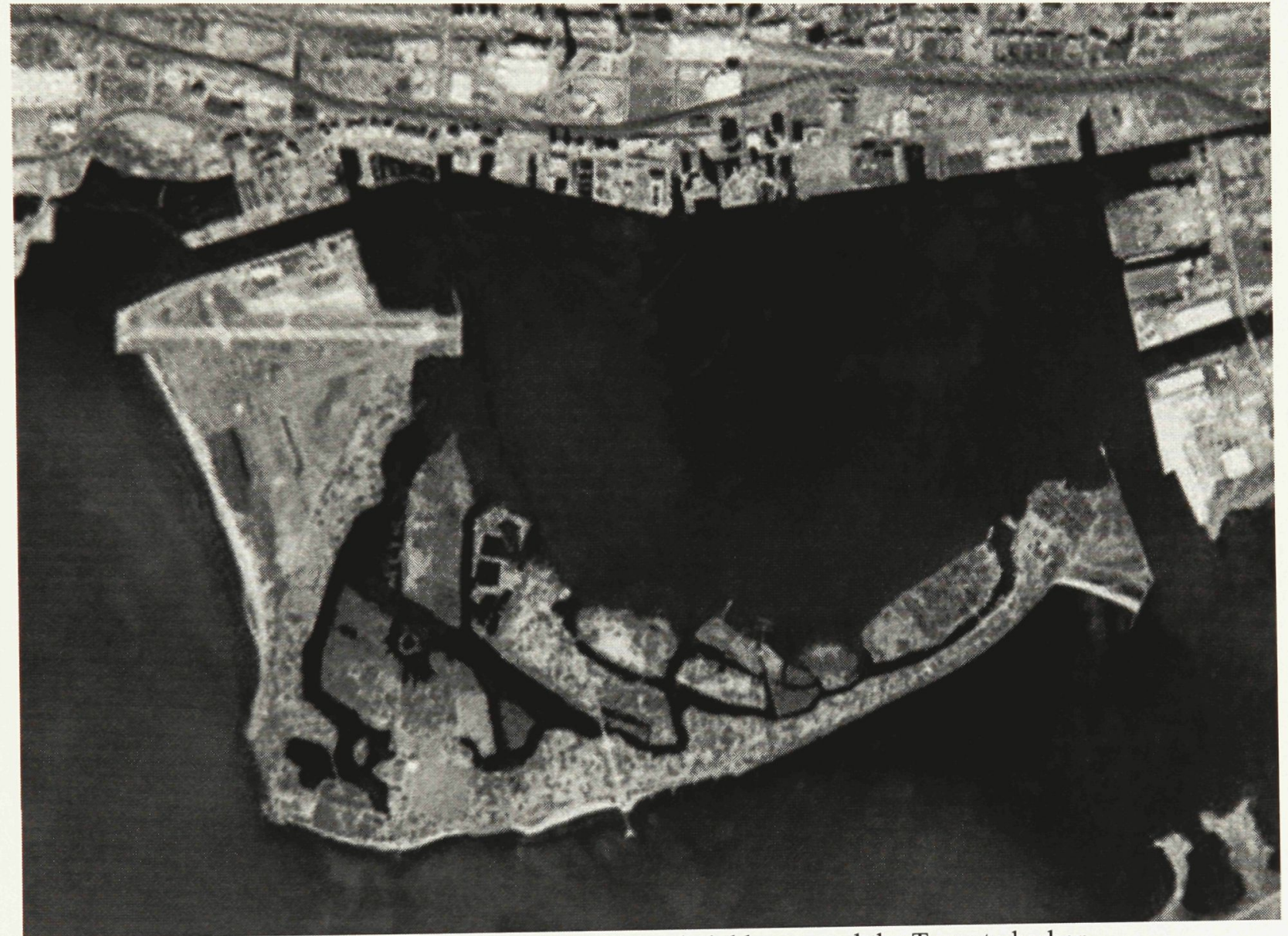

Figure 14: The site of the RCYC island clubhouse and the Toronto harbor

architects Darling and Curry designed the first of the RCYC's island clubhouses on the site which the most recent of the clubhouses still stands today. At the same time, the club

${ }^{44}$ Canada, Royal Commission on the Future of the Toronto Waterfront 14. 
acquired a new waterfront property, stretching even farther out from the city's industry than the previous club. At the end of the pier Dick and Wickson erected an empty

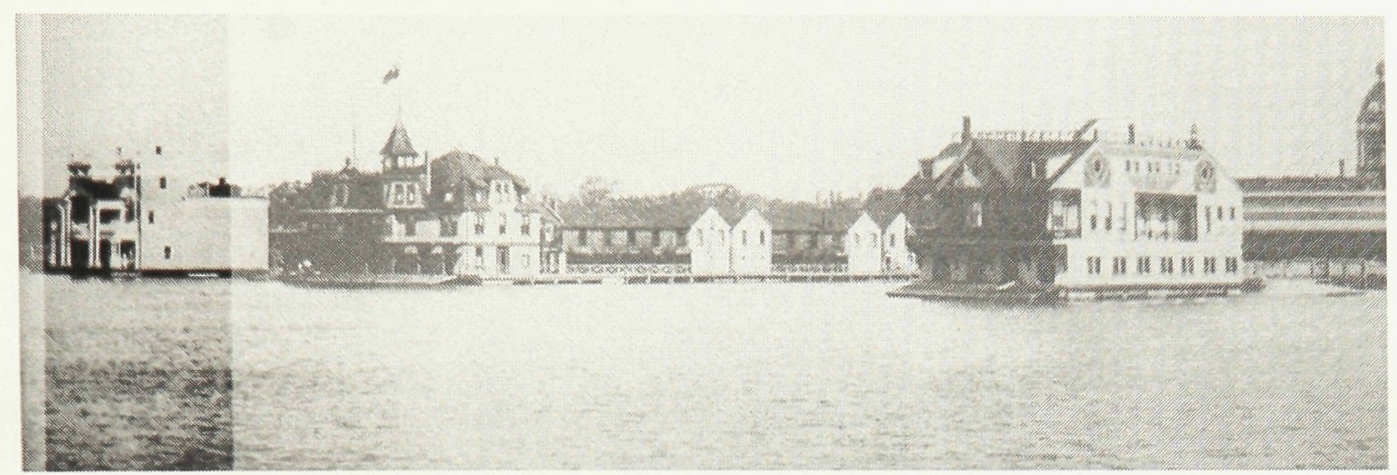

Figure 15: RCYC city station - (Argonaut rowing club far right)

building- four facades to serve as glorified bleachers and the clubs city side ferry wharf.

To the contrary, Darling and Curry's island clubhouse was conceived as the largest clubhouse in the world, in the popular Victorian style of the era. As one of the

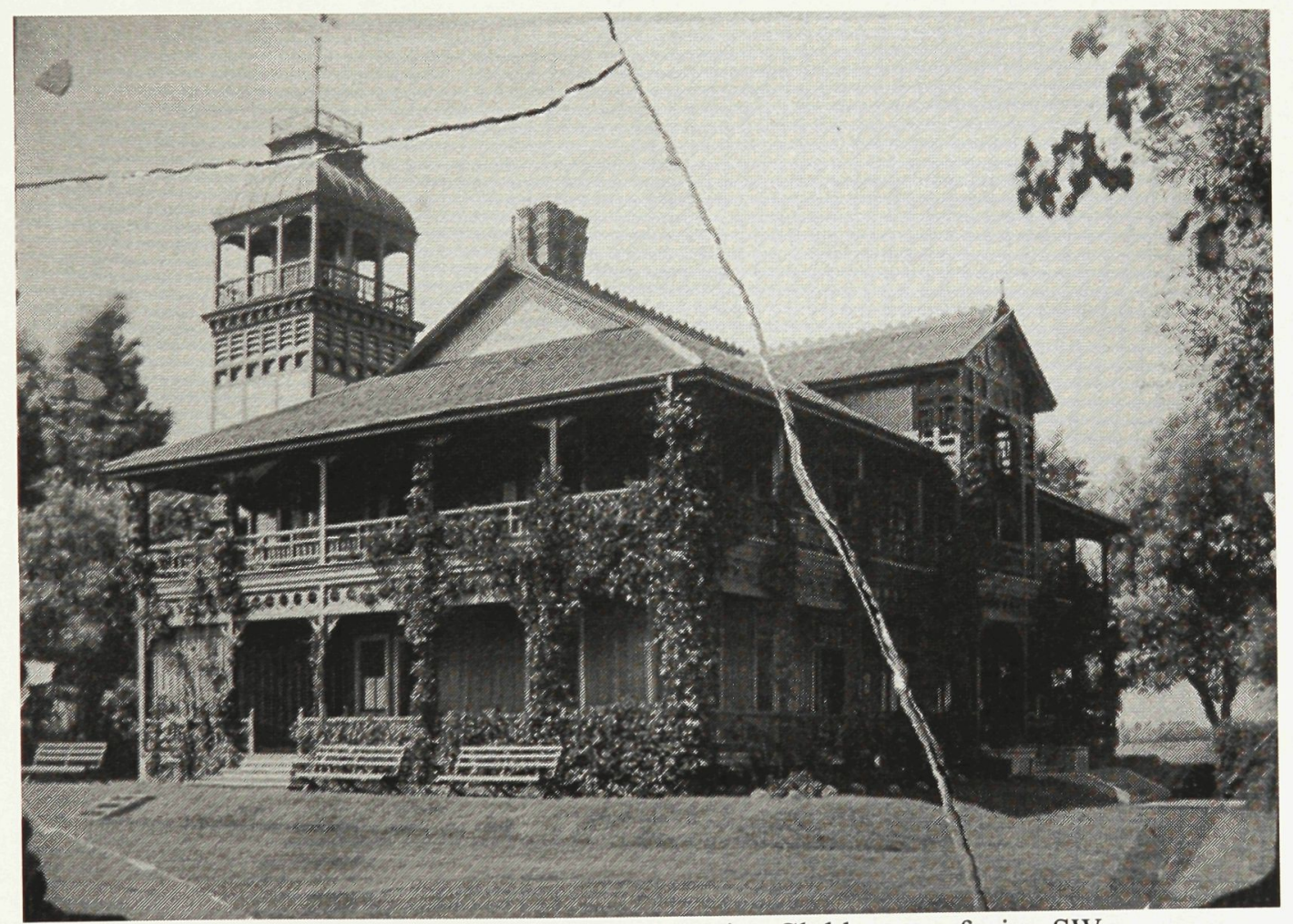

Figure 16: Darling and Curry's Victorian Clubhouse - facing SW

first significant buildings on the islands, shortly to be joined by Hanland's Hotel, the RCYC's new grounds were naturally composed to resemble an English garden featuring 
wandering waterways, and lush green terrain. The growing tranquility, and peacefulness of the island was inversely proportional to that of the growing metropolis across the harbor. However, this was not an entirely new role for the island, ever since the 1790's, Elizabeth Simcoe, the intrepid wife of Upper Canada's first LieutenantGovernor, John Graves Simcoe, went often to her "favourite sands", as she fondly described the islands (or peninsula as the islands then were). Like her contemporaries and generations of Torontonians after her, she went to pick nick on the wild grasses. ${ }^{45}$

Turning into the ideal urban antithesis, the island oasis was responding to an omnipresent yet growing desire to escape the condition of the city; a desire that will significantly develop as the city and the club evolved over the next century.

Regardless, the club's primary façade and center hall plan were oriented towards Toronto; its axis extending into the harbor to, physically manifested in the form of a pier, and accentuating the club's city-centric relationship. In its trans-harbor move, it appeared

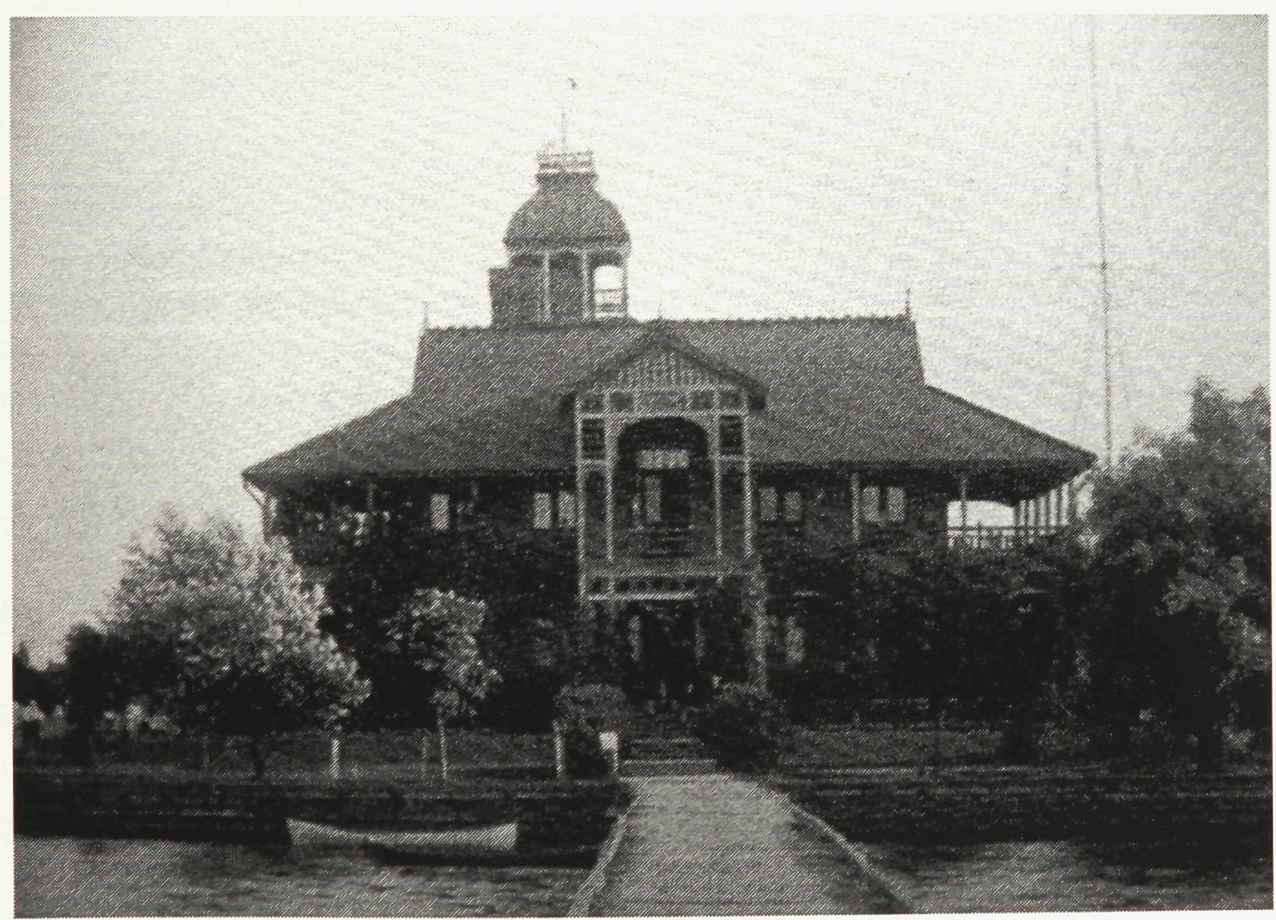

Figure 17: Arrival from ferry along city-centric axis $-\mathrm{S}$ facing

${ }^{45}$ Canada, Royal Commission on the Future of the Toronto Waterfront 9. 
that, the club could only seperate from the city to such an extent before the institution needed to reengage the security that Toronto's economic and relative cultural confidence offered; a dependence that was soon to dissolve as the club's confidence, identity, members, and program evolved. The orientation of the clubhouse, and location of its major programmatic elements (dining, reception, smoking, and billiards), allowed the inhabitants to constantly be reminded of their place in relationship to the city: desirably outside the urban condition, but not disconnected from Toronto. In 1904, an accident burned the clubhouse to ground.

Famous Toronto architects, and RCYC members, Sproatt and Rolph were commissioned to design and construct a new clubhouse on the island in 1906. Sproatt had started a firm in 1893 with John A. Perason, and the firm soon acquired two new partners transforming it into: Darling, Curry, Sproatt, and Pearson. Sproatt's appreciation for Victorian architecture, like that of Darling and Curry's clubhouse, began to change as he severed his ties with the office in 1899 to partner with Ernest Ross Rolph.

Sproatt and Rolph were versed in many styles, designing in Collegiate Gothic for Victoria College and Heart House, in monumental, towered classicism for Canada Life on University Avenue, and in Georgian and Jacobean for clients in Forrest Hill and Rosedale. The clubhouse was one of their very best designs, made all the more special in atmosphere by the gradual approach to it across the harbor. ${ }^{46}$

But with Toronto slipping into the new Edwardian era, a new architecture was taking hold. The white Georgian Classicism of the RCYC's new design is undoubtedly an example of this new style. Its long cool verandas echoed a romantic image of the American south. Gone was the rustic, cottage feel of the old clubhouse for this was soon

${ }^{46}$ Dendy Lost Toronto 46. 
to be the venue for some of Toronto's greatest Toronto social events. ${ }^{47}$ The program of the clubhouse's past, conceived for the gathering of sailors to discuss yacht racing and technology, had shifted. This architecture was a response to new Edwardian need for a social event venue. According to Edwardian Toronto at the time, hotels and restaurants were not yet seen as adequate venues for 'dignified entertainment' ${ }^{48}$ The architecture was the physical manifestation of the needs of Toronto's Edwardian culture at that moment of change, a new architectural form for a new function; a response to its contemporary inhabitants. Like many similar British and American organizations of the time, the RCYC had evolved into the realm of a country club; and Sproatt and Rolph's new architecture was an expression of the club's ever changing character. " ${ }^{49}$ "It was an ideal of country living, and represents the other, more personal, side of the prosperous, self-confident, and often bombastic classicism of Edwardian Toronto." 50

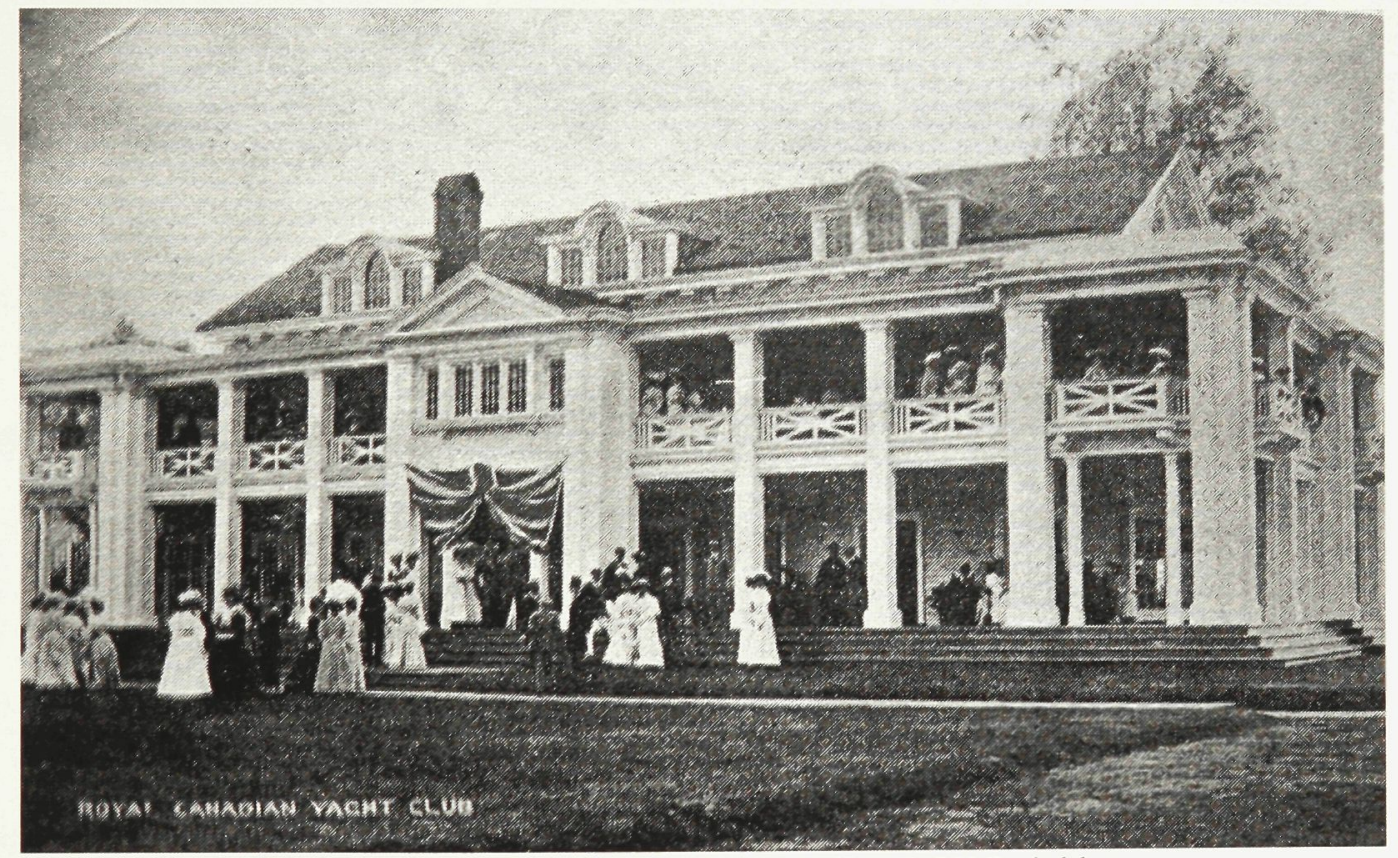

Figure 18: Sproatt and Rolph's Edwardian RCYC clubhouse

\footnotetext{
${ }^{47}$ Dendy Lost Toronto 46.

${ }^{48}$ Dendy Lost Toronto 46.

${ }^{49}$ Dendy Lost Toronto 46.

${ }^{50}$ Dendy Lost Toronto 46.
} 
The 1909 fire retired the Victorian style and city-centric relationship and offered RCYC and its architecture an opportunity to completely readdress its relationship to Toronto. By the 1920s Toronto's shoreline had been plundered by industry; train tracks and smoke stacks had established themselves as the dominating elements of Toronto skyline. With growing confidence, the RCYC, now a considerable Toronto institution, turned its back on the city, and in a colonial move echoing its architectural heritage, turned to engage the tranquility of its island site.

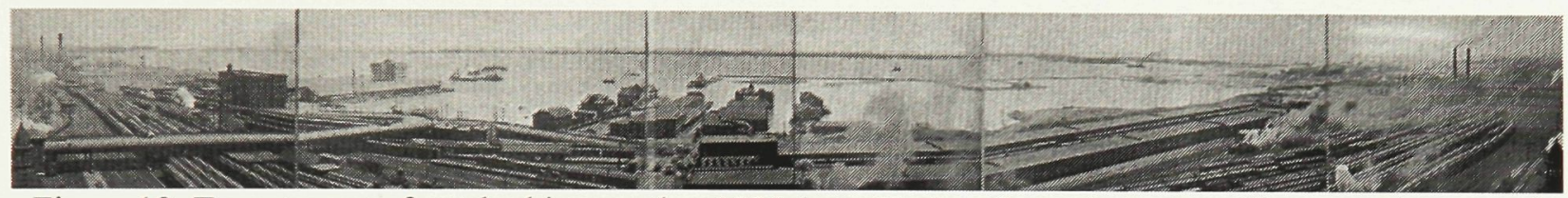

Figure 19: Toronto waterfront looking south - 1924 (note Harbor Commissioners office on a pier second section from the left)

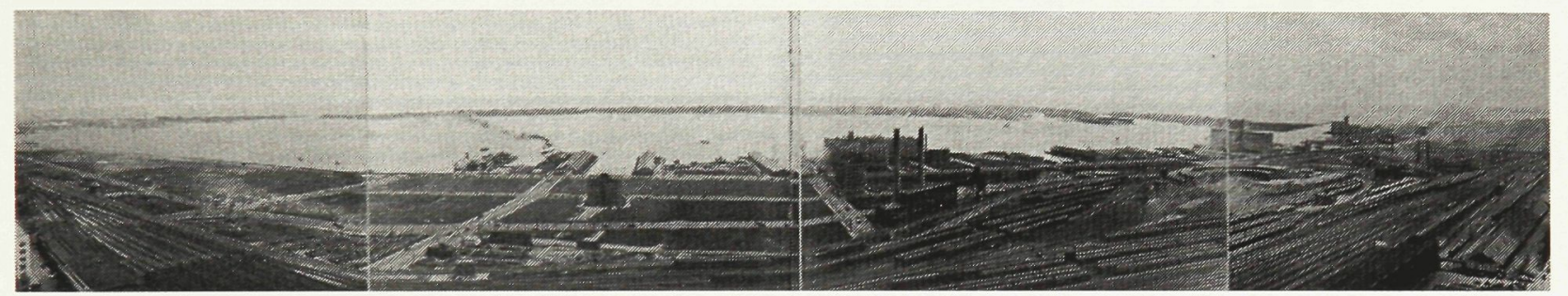

Figure 20: Toronto waterfront looking south - 1934 (Harbor Commissioner's office now marooned by landfill second frame from left)

The 90-degree rotation if its primary façade and axial-plan denoted the new presence of the "country club" in the architectural program of the clubhouse. Its new land-centric orientation further distanced the club from its bustling industrial counter-part. The club, now almost completely detached from the city, was, and still is, linked only by the ferry and its members, who are continually changing with the city, use the island as an escape from time to time to recover their equilibrium. The ferry ride established an undeniable notion of urban departure heightened the experience of escaping the complexities inherent to living in a metropolis. The ferry further perpetuated the experience of being 
just outside of the city's influence. The same experience had been established in the original 1869 clubhouse when it stretched out from the city at the end of a pier. Since then, each new clubhouse progressively distanced itself from the city to the extent demanded as a response to the growing densifying nature of the metropolis

\subsection{Between Architecture, Program, and the New Inhabitant}

These transformations do not claim that this new social presence at the club had replaced the tradition of yachting upon which the club was founded, but rather acknowledges that, with the majority of the boats still moored on city side, the architecture's primarily concern was to respond to the growing non-sailing aspects of the RCYC's evolving program. Regardless, the members were still deeply engaged in the exploration of yachting. In 1912, the club had proven victorious at the Great Lakes Championship in Chicago (now the Canada's cup). Two years later, the P-class sloop Valiant was in the Welland canal on its way to Toronto from Chicago to avenge America's loss when war was declared. With Britain's ultimatum to Germany, the competition was put on hold, and the highly trained crew of Canada's defending yacht Ahmeek, along with every other crew at the RCYC, rushed to form units in the Canadian Expeditionary Force to fight the war. Four hundred and fifty members of the RCYC, including all three hundred of the able active sailors, volunteered to go to war, and the Ahmeek, along with almost every other yacht in the club's fleet was abandoned to swing idly at their moorings. Slowly the fleet vanished, as the yachts, ironically including the Ahmeek, were bought by Americans or dismantled and sold so that the lead in their 
keels ${ }^{51}$ could be used for bullets. "Yet throughout the war the club carried on. It was, indeed, a patriotic duty to do so, it meant too much to the men over seas, on the seas and under the seas in submarines, to know that, back in Canada, among the willow trees billowing in their silver-green, and the old blue and white ensign was flying at the yacht club." 52 In 1915 the first of the wounded were arriving home and "the club lawns, an oasis at all times, and particularly in war time conditions which were turning city parks into drill grounds and war gardens, were devoted to the convalescents from the hospitals every morning." ${ }^{, 53}$ Through the five years of war to follow, the notion of the club as an
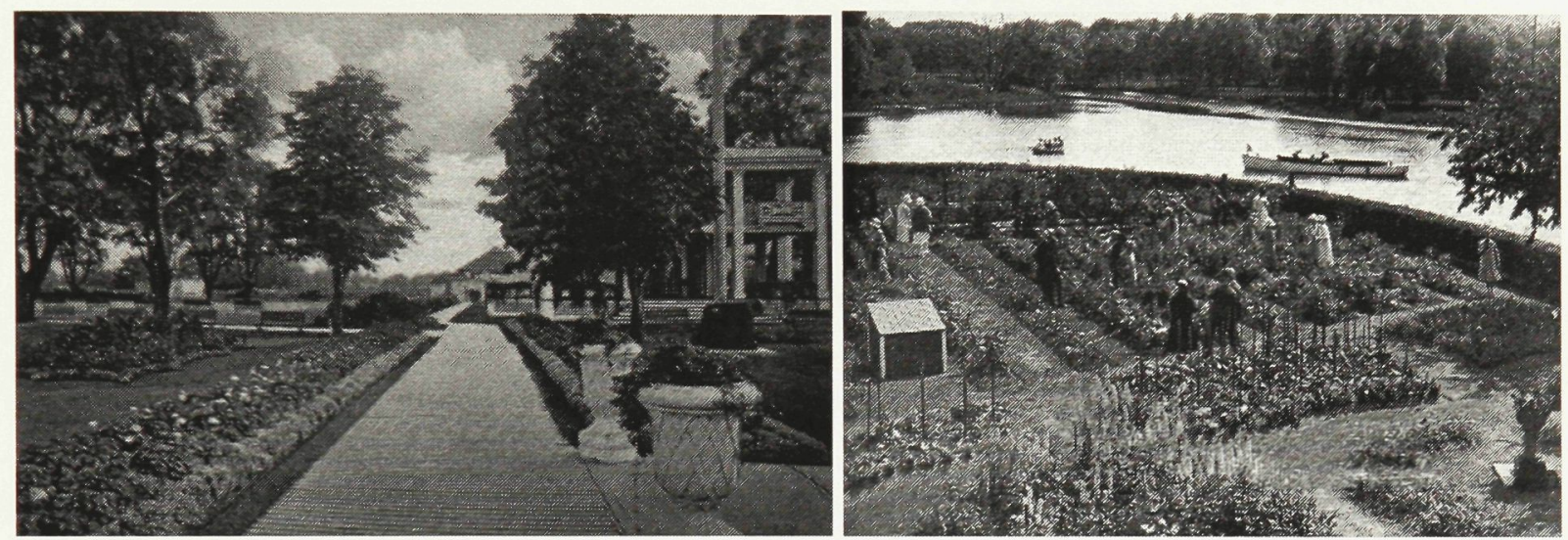

Figure 21: Oasis-like gardens from foot of ferry pier looking towards the Sproatt and Rolph clubhouse Figure 22: The Rose Garden - the clubs most intimate garden behind that architecture on the lagoons

oasis was heightened by the memories and dreams of those who were fighting overseas, and those back home who used it as a refuge from the dirty, industrial, battle-ridden conditions of the city.

In 1918 Sproatt and Rolph's RCYC clubhouse burned to the ground. In its place a temporary one-story veranda was erected for the rest of the season. In the spring of 1919

${ }^{51}$ keel: The structure that hangs centerline off the bottom of a boat, whose base is often caped with lead to increase the boats stability and reduce side slipping while sailing ${ }^{52}$ Ovens, Frank., et al., Annals of the Royal Canadian Yacht Club (Toronto, Roux and Mann, 1937) 13.

${ }^{53}$ Ovens 15. 
John M. Lyle, the man previously responsible for the additions to the 1909 design, designed a new clubhouse. With an appreciation that the Sproat and Rolph design had achieved such monumentality in the eyes of Torontonians, the new design was

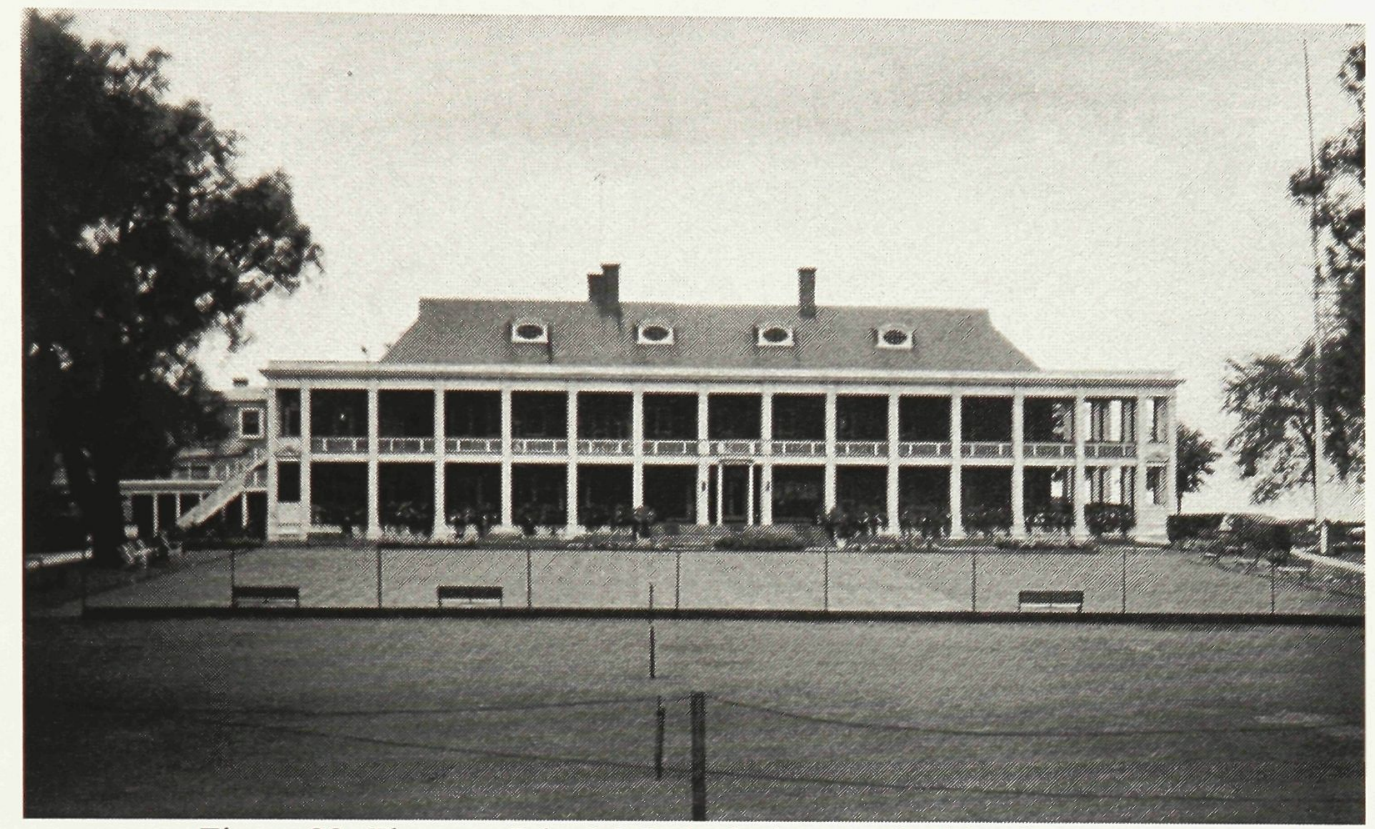

Figure 23: The new John M. Lyle design overlooking its property

conceived as somewhat of a homage to the popular 1909 design. Despite an increase in scale of the primary façade, the clubhouse retained its property-centric orientation. The most significant shift in the design however, was a major addition to the backside of the building, yielding a slightly new shift in the RCYC's city/club relationship. The double height verandas, previously appearing only on the primary façade of the old design now swept seamlessly around all of the buildings secondary façades, that lined a new ballroom whose doors opened towards the city, perpendicular to the property-centric axis of the architecture. The new addition embraced and extend the property-oriented axis initially set up by Sprott and Rolph, yet offering an opportunity for some of the new social program along the axis to face Toronto. At the time of this design, Toronto was beginning to reveal a new skyline no longer exclusively dominated by the monuments of 


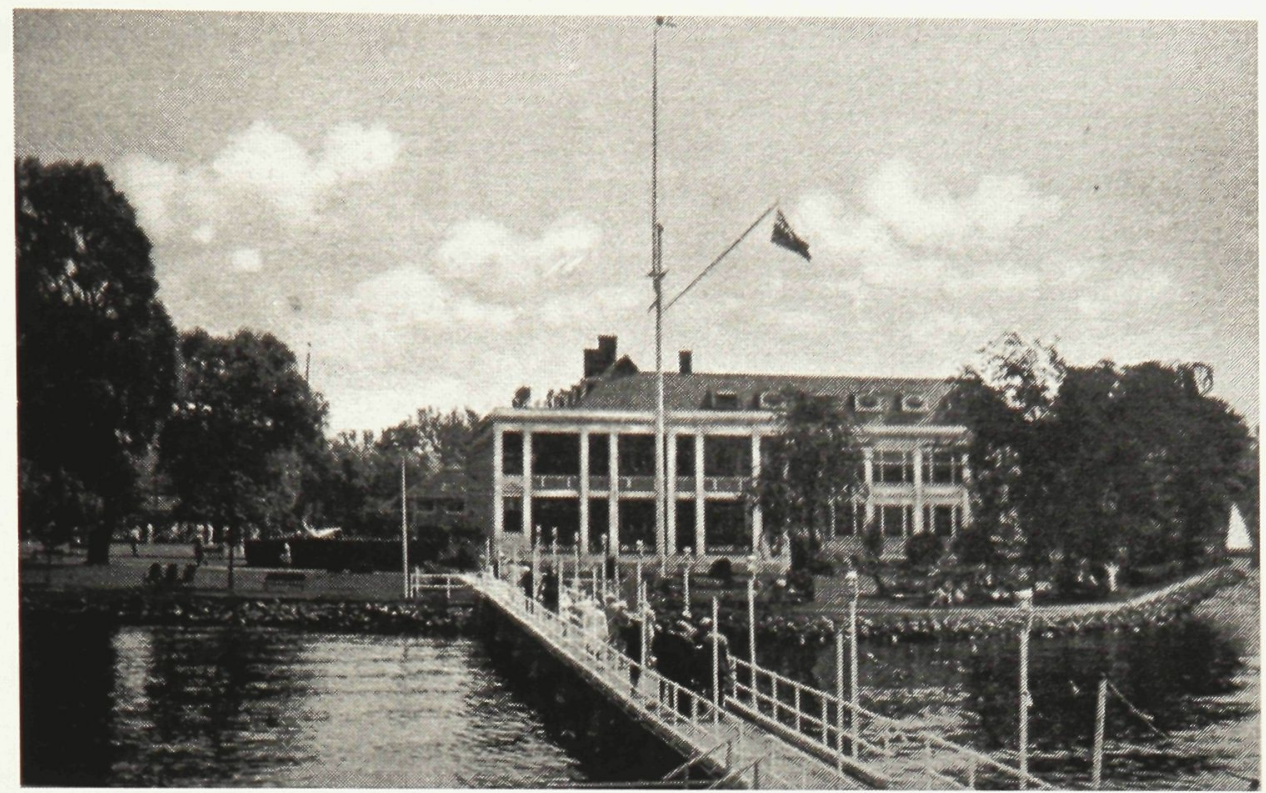

Figure 24: The veranda now lining the entire clubhouse, including the city-facing façade

industry. Although the club's architecture, still undoubtedly engaged its property. It was beginning to reopen a dialogue with the city allowing the inhabitants of the clubhouse an opportunity to better understand the significance of their island oasis through its juxtaposition to the metropolis's growing density and complexity.

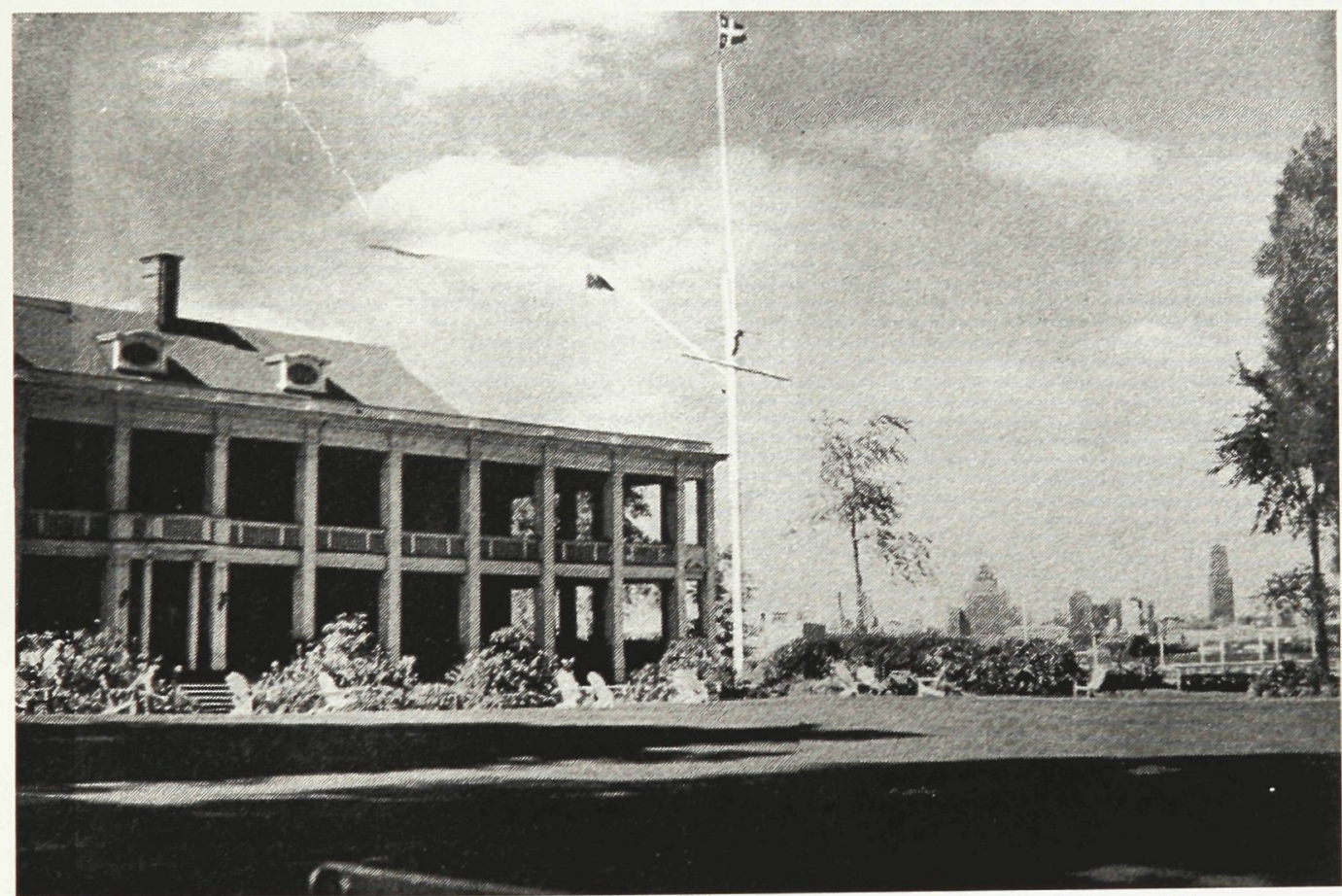

Figure 25: The growing skyline of a city in transformation behind the clubhouse 
The destructive path left by hurricane Hazel in 1954 brought the majority of the fleet from their city-side moorings over to the island, where some of the larger yachts were now keeping berth just off the club lawns. This change, marrying the flourishing social program back to its sailing heritage, added equipment clad sailors back into an architecture whose sweeping verandas were designed to accommodate social gatherings that all too closely resembled the summer evenings of an Edith Wharton's novel. ${ }^{54}$ The addition of the pool in 1934 ironically linked the western and eastern islands. The western island, programmed with all of the club's non-sailing related facilities was clearly separated from the club's men-only eastern island which was filled with the

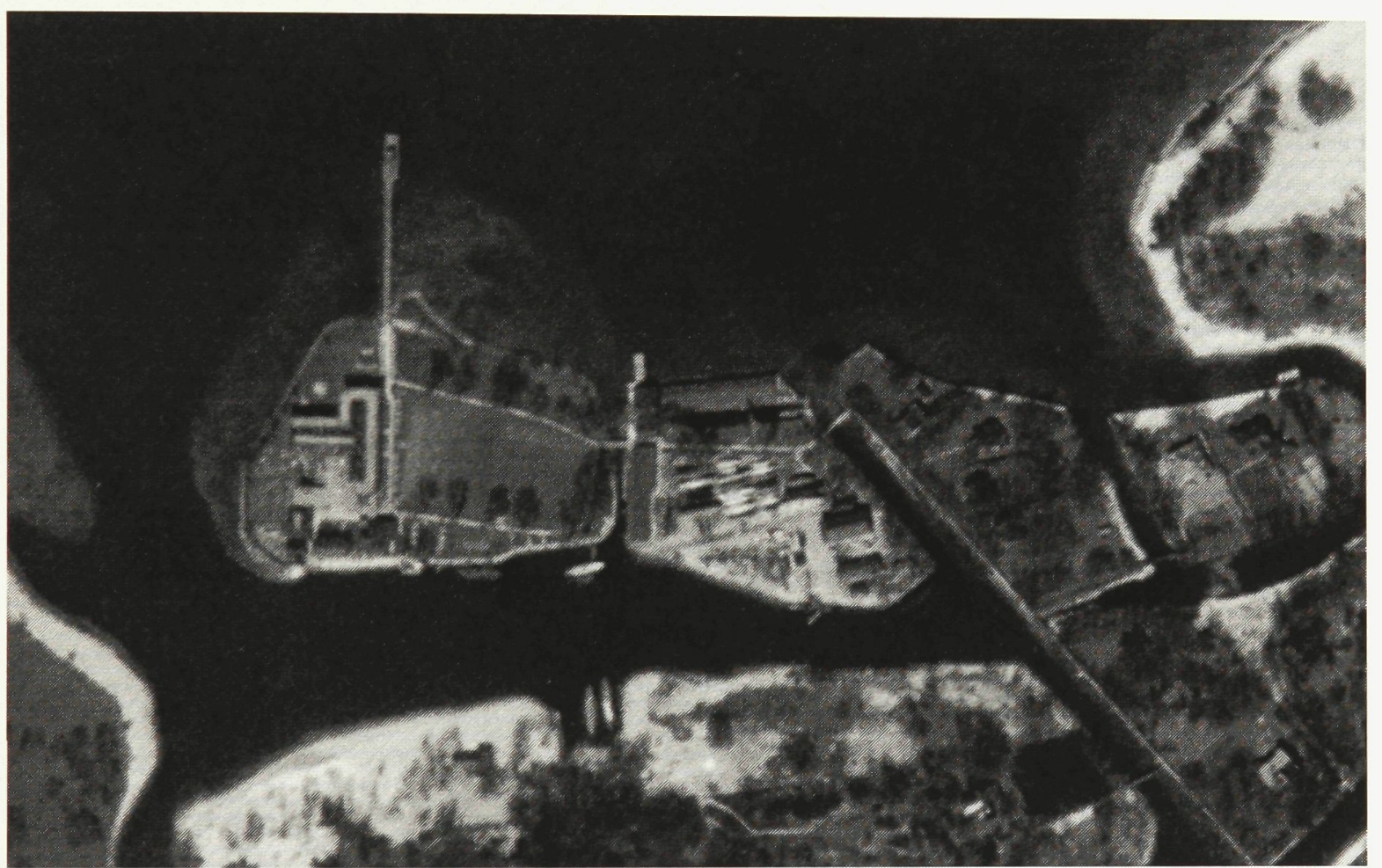

Figure 26: Arial image revealing two distinct islands. The island to the left reserved for the Edwardian programs and the island on the right for all sailing related facilities

club's sailing related facilities including dinghy docks, workshops, and men only private rooms - some with beds. The linking of the separate islands by a pool, and the instalment

${ }^{54}$ Dendy Lost Toronto 46. 
of tennis courts and lawn bowling, denoted the dissolving boundaries between sailing and social aspects of the club. Furthermore, as no women or children were accepted as members until 1960, boundaries separating the sexes were also dissolving.

The elegant, socially-oriented, Georgian architecture of the clubhouse, already strained by transformations that placed the equipment clad sailors, and other athletes, and the socialites in new proximity, now had the further challenge to respond to the family. The Edwardian architecture, looking to the island was becoming a home away from home; an extended living room ${ }^{55}$; a weekend retreat escaping the city and the family added yet another significant programmatic dynamic to the already challenged architecture. The formal dining room was antiquated as much by its stale yellow color and its floral clad accessories. It was by the general deterioration of formality in contemporary culture, that left some of the club's most spectacular spaces mostly

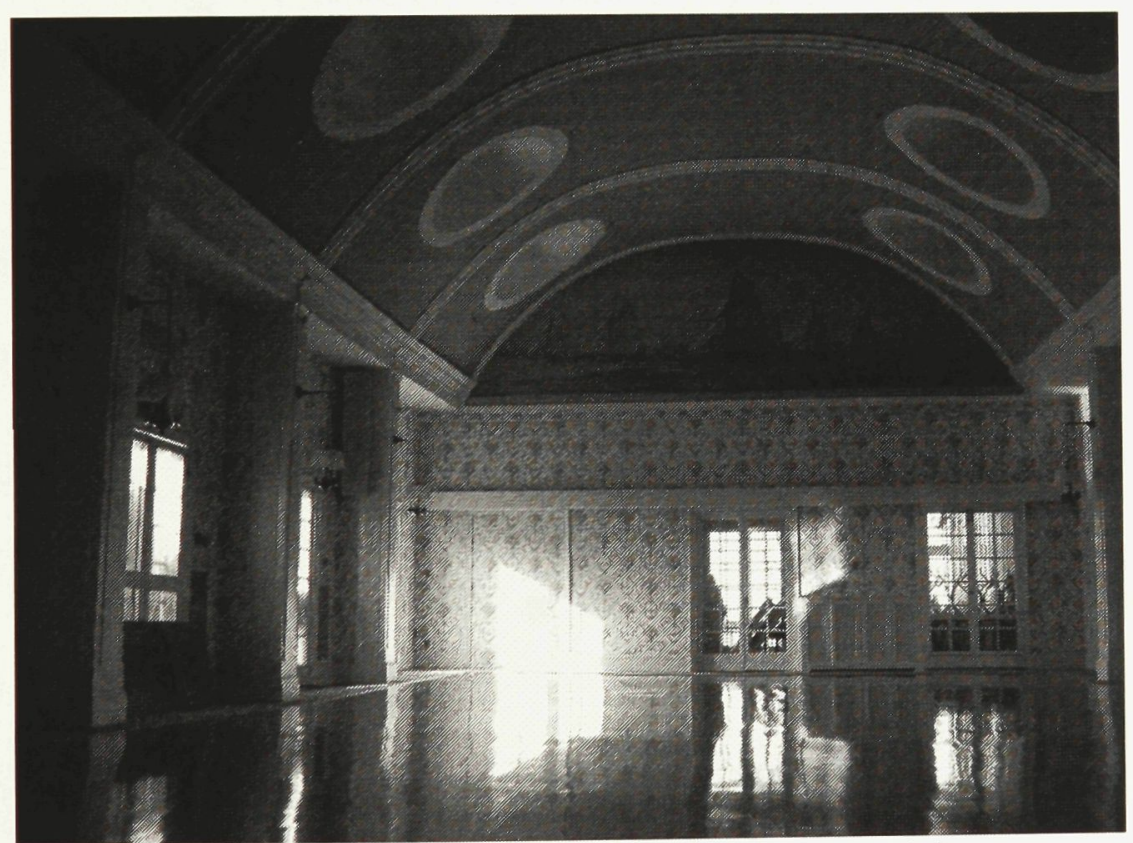

Figure 27: The ballroom - the relic of Edwardian social events

${ }^{55}$ Beattie, Jim. Personnel Interview, Toronto, 16 Sept. 2005. 
unpopulated. The second floor, glorified by its ballroom and sweeping vistas, seems to desperately miss the vibrant Friday night dances of the 30s, as today these spaces are rarely experienced by the club's day-to-day users. These spectacular spaces, once filled by the splendor of the Edwardians, are now inhabited more by memories than people. The small cafeteria / bar, located in the most undesirable part of the club, has become the most familiar space to the architecture's contemporary inhabitants, placing gear-clad sailors, dating teens, young families, tie-loosened professionals, and the club's seasoned members in tight proximity. Fundamentally, the physical architecture is failing to be, as one of the members stated, "the (contemporary) outward manifestation of the inner desires of its contemporary members" ${ }^{\text {56 }}$; similar to Aldo Rossi perception: “... the character of whole nations, cultures, and epochs speaks through the totality of architecture, which is the outward shell of their being. ${ }^{, 57}$ The century old architecture of the Edwardian clubhouse is failing to be the outward manifestation of the contemporary needs of its members.

\subsection{Summary}

Since the conception of the club in 1852 , there have undoubtedly been dramatic shifts in Toronto's condition, the members (evolving citizens of Toronto), contemporary culture, and fundamentally the role of the RCYC. The consequence of this cultural evolution is an antiquated building with awkwardly overlapping programs in an architecture that ultimately was designed to accommodate only one of them 100 years

\footnotetext{
${ }^{56}$ Beattie, Jim. Personnel Interview, Toronto, 16 Sept. 2005.

${ }^{57}$ Rossi 131.
} 
ago. The club's use of multiple sites during the growth of Toronto in the late $19^{\text {th }}$ century, allowed for each new site and each architectural conception, to respond to the club's evolving needs; a product of the people to which the architecture serves being deeply involved in Toronto's evolution. Once on the island, despite the unfortunate loss of glorious architecture from our all too brief history, the fires desecrating the first two clubhouses, ironically revealed an opportunity for the club to completely readdress the contemporary state of Toronto's rapid evolution on a single site. The anti-urban, harbor protected, island site to which the club can attribute a good part of its success as a place of escape, has also paradoxically located the clubhouse's architecture just outside of any pressures applied by the ever-growing, ever-evolving metropolis. Thus it would appear that the island oasis was a place where the architecture too escaped Toronto for nearly a century. Consequently, the Edwardian architecture has lost an essential vitality dissolving into a static monument to the memories to a once spectacular era, an antiquated stage for the contemporary events of the RCYC. 


\section{Between the Architecture and the City}

\subsection{Perceiving Transition}

Our era "seems to be that of space. We are in the age of the simultaneous, of juxtaposition, the near and the far, the side by side, and the scattered.",58

The architecture following the post-modern era is often predicated on a multitude of relationships that manifest and define an experience. The failure of any single architectural entity to engage a dissimilar condition inevitability produces a prosaic architectural experience. By opening a dialogue between unique conditions, through juxtaposition, opposition, or synthesis, the understanding of any single entity is enhanced by the unique traits of its 'other'. On the most macroscopic scale, RCYC's 'other' is the city; on the micro scale, the discourse would exist between the old architectural syntax of the clubhouse, and that of the contemporary intervention. The juxtaposition of RCYC's island oasis and Toronto's dense urban condition, has produced a relationship whose ever-evolving dialogue has been a growing catalyst for the club's success over the past century. An increase in density and responsibility associated with the urban character of Toronto proportionately increases the effectiveness of the club as a place of escape. Escape being defined as the breaking free of the confinement or control inflicted by the innate pressures of the metropolis - Toronto. Similar to Rem Koolhaas' definition of resort as "the nearest zone of virgin nature that can counteract the innervations of urban civilization. A resort implies the presence, not too far away, of a reservoir of people

${ }^{58}$ Foucault, Michel. "Of Other Spaces: Utopias and Heterotopias" Rethinking Architecture (London: Routledge, 1997) 350. 
existing under conditions that require them to escape occasionally to recover their equilibrium." $" 59$

Since its conception, the club's progressive distancing from Toronto's growing urban condition has created a relationship in which each entity has developed relatively through their interdependency. Physically, the club's increasing distance from shore, to pier, to island, has manifested an experience of passage such that it becomes impossible to unconsciously slip from city to club, or vice-versa, without acknowledging their individual traits and importance enhanced through its juxtaposition to the other.

The harbor becomes the fundamental object in establishing a definitive realm in between these contrasting elements $-\mathrm{RCYC}$ and Toronto. For a person making the passage from one to the other, the harbor makes aware the significance of the transition that they are making. In a contemporary culture, the allowance for countless transitions in the city between the spaces of Michel Foucault's heterotopic 'unrelenting opposites ${ }^{60}$ often suppresses the individual potential of each condition. For example, having an office desk in a bedroom would collide the realms of pleasure and work, such that neither could exist autonomously and thus, neither would be optimally effective spaces. The time distance relationship between the two is diminished to the extent that they are no longer separate entities, but rather unite to form a single less clear entity. On the urban scale,

\footnotetext{
${ }^{59}$ Koolhaas 30-32.

${ }^{60}$ In Michel Foucault's essay: Of Other Spaces: Utopias and Heterotopias 'unrelenting opposites' refer to a set of opposites known for their persisting existence despite changing ages. Some of which are: public/private, family/social, cultural/utilitarian, pleasure/work.
} 
there is a similar collapse of realms, as skyscrapers, subways, and Toronto's PATH ${ }^{61}$ allow for boundaries and thresholds to dissolve and blur. It becomes far too easy to slip from one place to another without understanding or acknowledging any single place autonomously, or their relative relationship to each other.

The Seagram building by Mies Van de Rohe creates a schism between two realms by pressing itself to the back two thirds of the site, creating a much-needed break in the overwhelmingly monotonous streetscape. The resulting elevated plaza creates a space of transition slightly detached from the roar of the street becoming a moment of

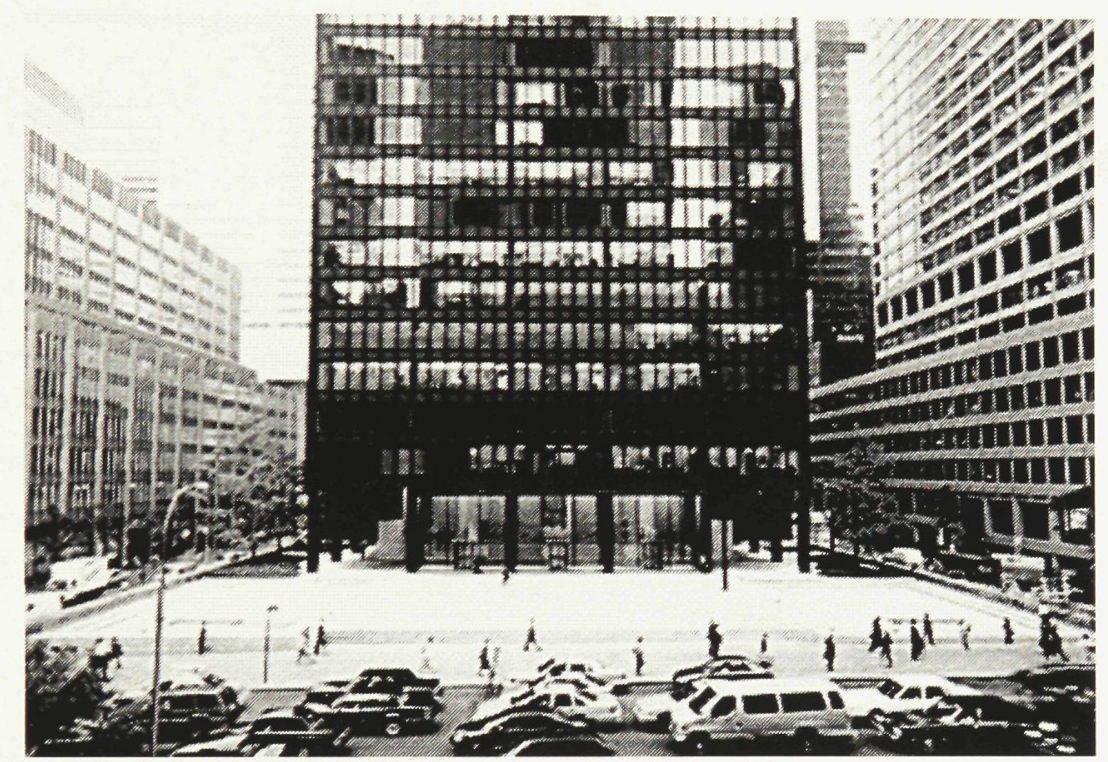

Figure 28: Seagram Tower's urban plaza pressed into the wall of skyscrapers revealing a rare urban plaza transition, between the city and the architecture of the tower, to comprehend and appreciate each element in its own rite, and their relationship to each other. The plaza defines a passage, and denies the possibility for someone to slip from cab to lobby without understanding that there is a transition being made from one entity to another. This moment allows an inhabitant to perceive the tower in its own rite, autonomous from

${ }^{61}$ The PATH is a labyrinth of underground corridors (double loaded), that connect the majority of Toronto's business district; it is notoriously complicated. 
the city but not disconnected. It reveals the relative significance of each entity, as the harbor does for RCYC's island oasis and Toronto's complex metropolis. To quote Pierre Bordieu "Culture is a field made up of a network of objective relations where each position is objectively defined by its objective relationship with other positions." ${ }^{.62}$

\subsection{Crafting the Passage}

Passage can be defined as the realm of transition in between two places. The duration and characteristics of this transition effect the perception of both the place of origin, and the place of destination. The physical characteristics of the transition inexorably affect, through similarity or dissimilarity, the experience of the origin and destination. Metaphysically, the transition offers a break; a moment to draw separation between the two points at either end of the transition such that it provides an opportunity to consider both places at either end of the transition.

The capacity for the passage to manipulate the perception of the origin and destination depends on the defining characteristics: its physical environment, and the duration of the passage through that space - time. In the case of space and time, an increase in either is not proportional to the passage's effectiveness. In other words, if the Seagram's plaza was twice the scale, doubling the transition duration, and sound baffles that were installed surrounding the plaza to heighten the feeling of being disconnected from the street, the effectiveness of the plaza - or passage - would not necessarily

\footnotetext{
${ }^{62}$ Attlee, James. and Le Feuvre, Lisa. Gordon Matta-Clark: The Space Between (Glasgow: Nazraeli Press, 2003) 8.
} 
increase. In fact, in Manhattan, these changes would most likely diminish the experience, as the baffles would too effectively block the street, negating the plaza's relative urban connection, and the time it would take to negotiate the plaza's scale would be disproportionate to the pace inherent to Manhattan. The factor therefore is quantitative not qualitative.

\subsection{The Compression of the Metropolis}

As Toronto grew from town to metropolis, the condition at either end of the passage changed, demanding the passage to evolve respectively. The new scale and condition of the city intensified the RCYC's identity as a place of escape, such that the pier was no longer a distance appropriate to its newly defined end points. Therefore, once the club moved to the island it flourished as a place of urban escape. Ironically, the fifteen-minute passage departs from the northeast corner of the harbor, the only remaining area of Toronto's waterfront still serving the city's industry.

The city side ferry dock, the urban point of departure, is the first point to foreshadow the coming condition of comfort manifested by a familiarity inherent to the club. The gathering on the dock allows for social interaction between friends even before leaving the city, while the trip itself provides time for a person to further shed the stress of being involved in the metropolis as they drift away from the ever flattening city opposing the RCYC's from across the oasis' protective moat. 
During its passage to the island, the ferry's progressive distancing from the city initiates a dimensional compression of the metropolis, which creates a new perception of the cityscape from across the harbor. The harbor separates the city from the club to a distance by which the chaos, manifested by "instability of life in the metropolis" becomes flattened to a placid skyline. That is to say that the complexities of the city, or its growing heterotypic nature ${ }^{64}$, are essentially dissolved. Attributes that define the metropolis, smell, sound, density, speed and so on, are compressed to a two-dimensional image. The island operates as a place to reorient one's perception of the city and urban life. "Roland Barthes claimed that the Eiffel tower changed everyone's understanding of

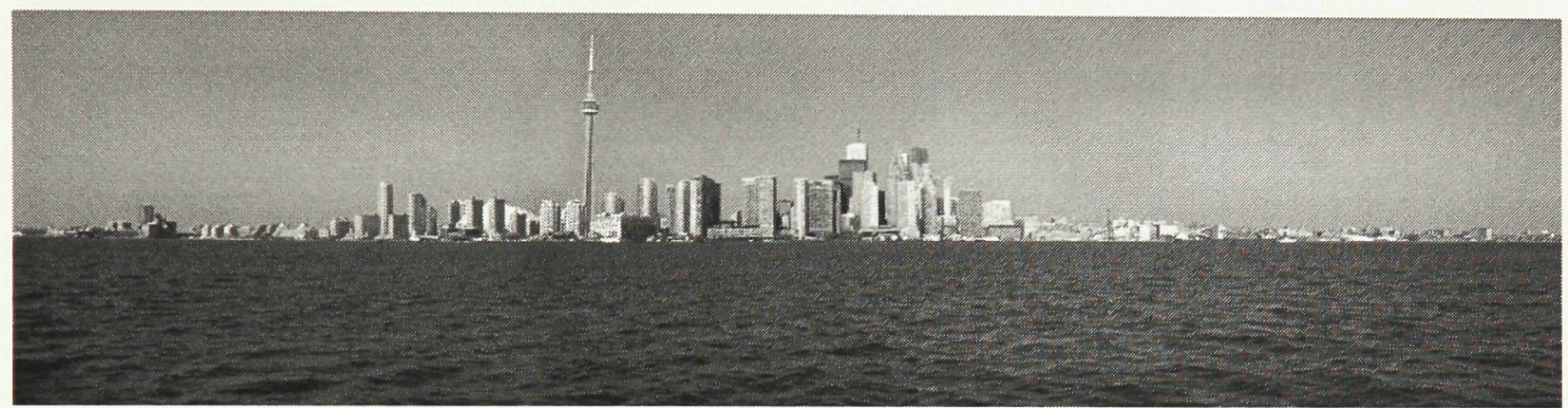

Figure 29: Toronto - the placid metropolis as seen from the island

Paris: a visitor who ascends it becomes part of the tower rather part of the city, and Paris itself turns into and object for contemplation. ${ }^{965}$ However, because the tower is still among the city, Paris still reveals some of its urban characteristics that are attributed to the complexity of the metropolis. While elements like sound and smell are nullified; things like the cars people bustling looping the Arc de Triomphe, and around the complex urban fabric, reveal some characteristics of the city still perceivable from atop the Eiffel Tower. However, in the case of the RCYC and Toronto, the island dissolves all elements

\footnotetext{
${ }^{63}$ Koolhaas 157.

${ }^{64}$ Foucault 352.

${ }^{65}$ Fulford 20.
} 
of Toronto, a towering metropolis severed at the waterfront revealing a two-dimensional skyline. Furthermore, the framing provided by the columns of the sweeping verandas, intensify the already pictorial nature of the city. ${ }^{66}$ Like the flat façade of a skyscraper, ${ }^{67}$ "the monolith [the skyline] spares the outside world from the agonies of the continuous changes raging inside it; it hides everyday life." ${ }^{68}$
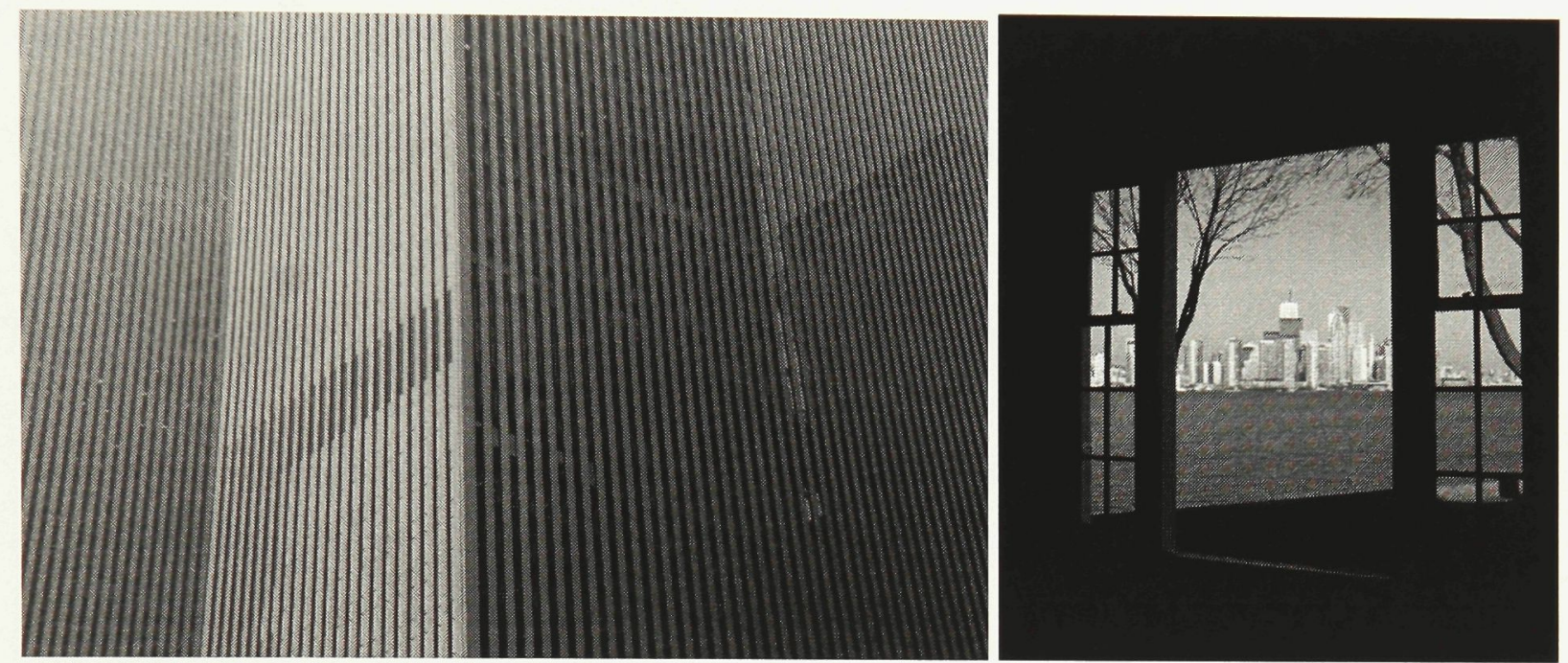

Figure 30: The uniform façade of the monolith - the lobotomy of the container and the contents $-X Y Z$, New York

Figure 31: The pictorial city framed by the columns of the veranda

\subsection{Summary}

The passage through the harbor maintains the inability for a person to 'briefly' visit the club. Like the plaza in front of the Seagram Building, it restricts a quick-slip from one space to another. The harbor lengthens the space of transition to a point that a visit to the island is inevitably an event. Going to the island clubhouse can never be as

\footnotetext{
${ }^{66}$ Beattie, Susan. Personnel Interview, Toronto, 19 Sept. 2005.

${ }^{67}$ From Rem Koolhaas' retroactive manifesto for Manhattan, Delirious New York. He discusses the skyscraper as a single plot repeated vertically whose façade (form) has been completely severed from its function. The façade fails to even remotely allude to the infinite complexities that may exist between the 100 floors of potentially unrelated program trapped in the sky scraper.

${ }^{68}$ Koolhaas 101.
} 
spontaneous as dropping into a coffee shop for a monetary pause to escape the pressures of the metropolis. Instead going to the island is a trip, an event... one must pack a bag, dress accordingly, time the ferry, and be prepared to commit the time necessary for the event of urban escape. The existence of the passage imposes the nature of an event onto the experience of the RCYC, and like going to the theater, one becomes physically and mentally prepared for the event of escape that is essentially not common to the realm of the metropolis. The clubhouse becomes the stage on which the pleasures of escaping the city can be performed while Toronto is successfully diminished to a backdrop hung behind the antiquated theater of urban escape. 


\section{Liberating Traditional Spaces}

\subsection{Away from Le Mathematique Raisonable}

A century long transformation of social dynamics, is made visible in the traditional spaces of the RCYC's Edwardian architecture. In the rare moments where one might inhabit these spaces, the experience is significantly inhibited by the existing syntax's incapacity to engage the needs and nature of the contemporary user; an individual sculpted by a century of cultural and social evolution. The following text will explicate the theories of artist Gordon Matta-Clark as a means to interrupt and reorient the antiquated Georgian syntax by redefining its thresholds and dissolving boundaries. It will reveal the nature by which an intervention can reorient and investigate new potential for a frozen architecture.

Despite studying architecture under Le Corbussier, in the 1938 journal article, Minotaure Gordon Matta-Clark's father, Roberto Matta Echaurren, speaks about what he refers to as "Mathematique Sensible - Architecture du Temps". As an artist deeply interested in the space of the surrealists at the time, he was opposed the modernist ideology governed by a mathematically ordered, rectolinear understanding of space. Falling into the realm of the surrealists, his work was the antithesis of Le Corbussier's geometry that gave birth to Mathematique raisonable, an anthropomorphic architecture based on the modular man. Roberto Matta's understanding of space was motivated by the 
“...non-rationalized subject. A malleable ever changing subject its every psychic turning was mirrored in architectural transformation." 69

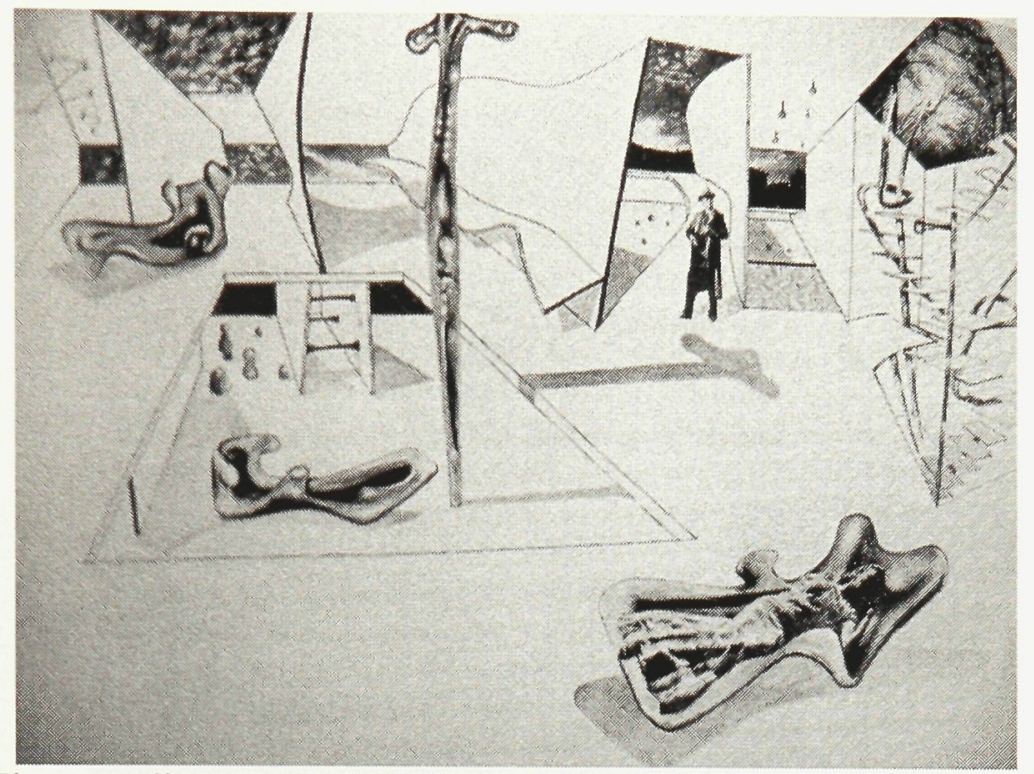

Figure 32: The surrealist spaces of the idiosyncratic inhabitant - Painting by Roberto Matta

We now begin to understand the foundation by which Gordon Matta-Clark developed his perspective of architecture and understanding of space. Like his father, he too "would reserve particular venom for the modernist program" suggesting that the modernist home was "a machine not for living...the virgin machine he [Le Corbussier] wants us all to live in. ${ }^{70} \mathrm{He}$ acknowledges the modernist space as a space without history, and fundamentally without character. It is in this understanding that MattaClarke's appreciation for artifacts, architecture included, reveal a record of time and memory metaphysically embedded in material. When speaking of the artifact titled Food (1971) he says: "the artless drops of paint and bent hinges, and the tired, brittle warp and

\footnotetext{
${ }^{69}$ Lee 7.

${ }^{70}$ Lee 9.
} 
weft of its support... are deeply evocative of phenomena that stands in excess of the thing proper." ${ }^{71}$

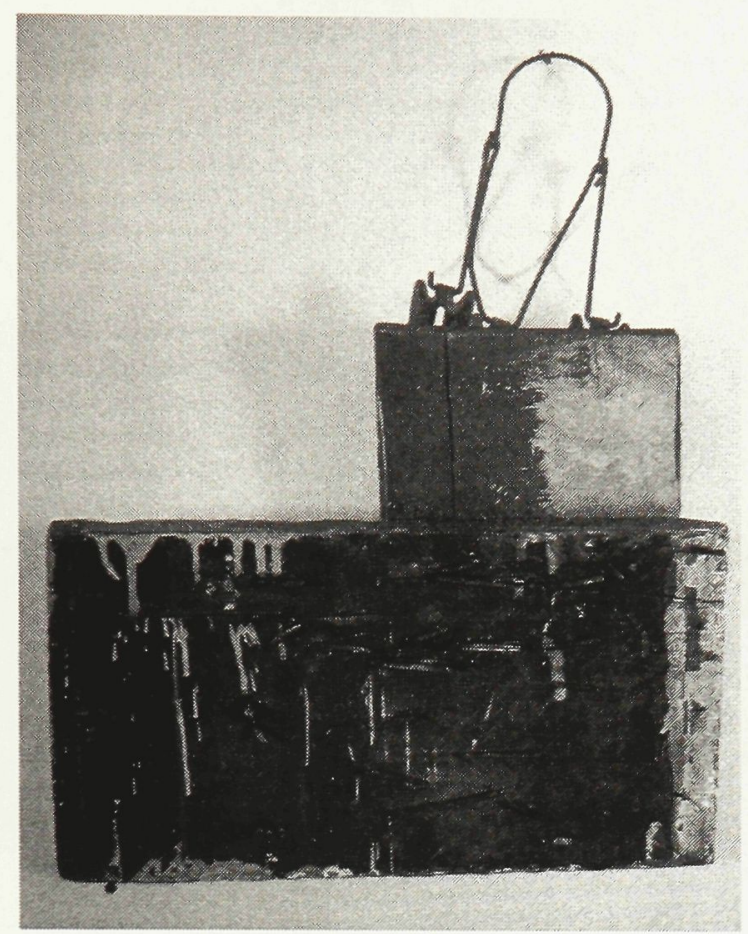

Figure 33: Food

The role in the intervention then is to reveal a new understanding of the artifact, that is to say, the intervention must evoke a new reading, or reorientation of the architectures space and place within contemporary culture. If however, the intervention fails to successfully reveal a new reading of the traditional object then the object will remain what it already is, a century old artifact of memory, still detached from culture. In Matta-Calrk's project Bronx Floors (1972) he cuts square floors sections out of apartments to challenge traditional understanding of the spatial syntax of the apartment; but when the sections of the floors were placed in a traditional gallery as an autonomous object, it was reoriented vertically on end, and suspended off the floor. This gesture

${ }^{71}$ Lee 40. 


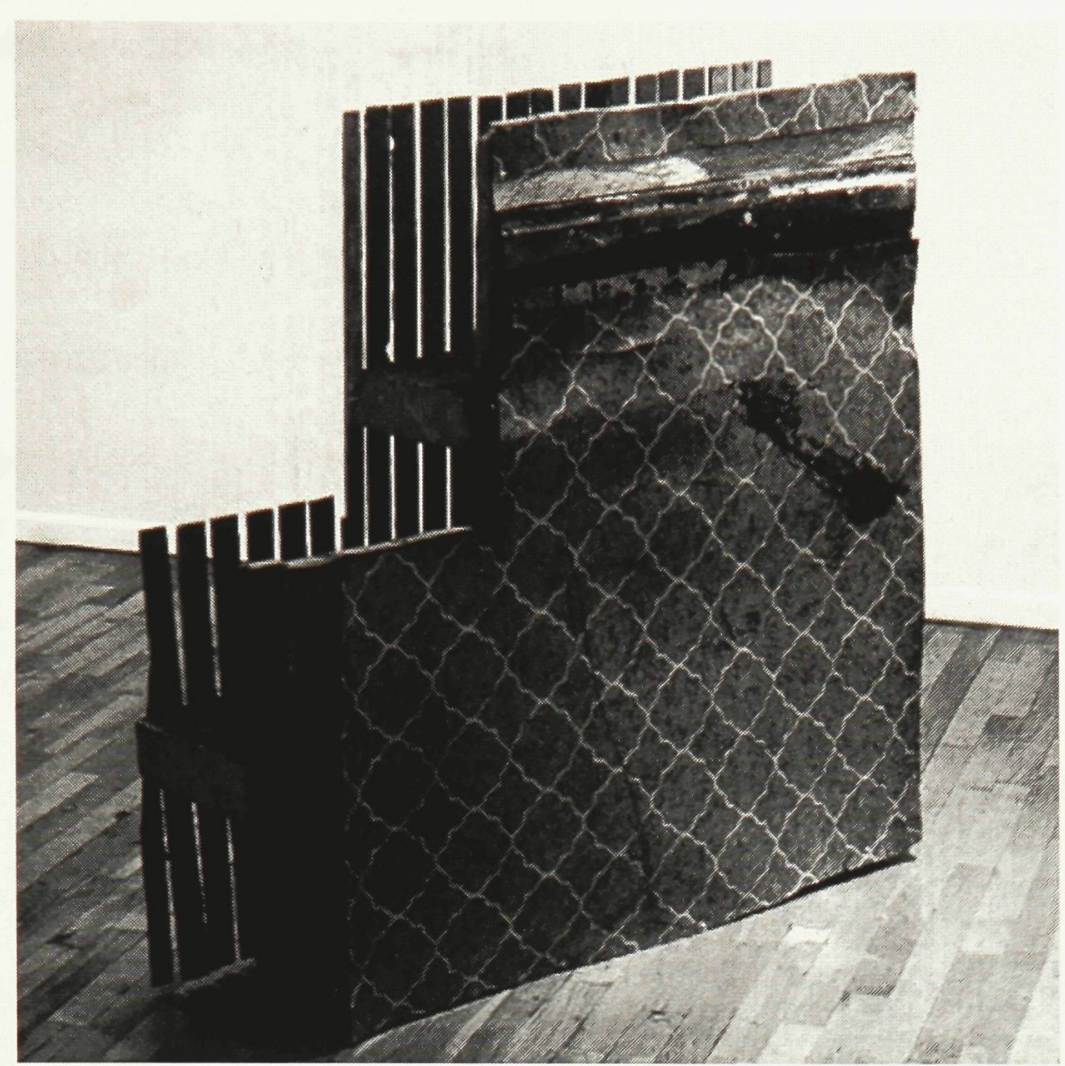

Figure 34: A floor section from Bronx Floors as seen in gallery

transformed the object from its traditional understanding as a two-dimensional surface for walking on into an object for contemplation; the inverse to Roland Barth's perception of the Paris from atop the Eiffel Tower. ${ }^{72}$

The garish linoleum surfaces that covered the floorboards, intended less to be studied than stepped upon, were now made the objects of certain visual scrutiny, each layer a kind of historical stratum to be discerned and parsed by the careful spectator. The interior system supporting the floor is now exposed to vision as well, revealing the heavier joists and a section of the ceiling below. In preserving these structural elements along with the linoleum surface, the apparently flat dimensions of the floor fragment expanded outward, so that which was once architecturally oriented along a horizontal axis was now flipped within the space of the gallery. ${ }^{73}$

It is made clear that the reorientation allows for a new way to understand the floor fragment as something beyond that of its previous identity. New life for an artifact, born

${ }^{72}$ Fulford 20.

${ }^{73}$ Lee 77. 
out of a reorientation of the viewer's perspective; a new engagement with a once mundane relic.

\subsection{Dissolving the Boundary}

This idea of viewing and revealing, is further manifested in an idea that stems out of Matta-Clarks participation in the voyeurism and performance of high-rise living in Manhattan; windows are as much for looking in as out. The 'private' events of day-today life are put on display, and the 'intimate' refuge of the domicile is exposed. The juxtaposition of 'private spaces' dissolves its protective boundary, opening a dialogue between traditionally isolated spaces. An experience of dynamism is injected into the architecture, as "privacy takes on a semi-public dimension as permeable and open to spectacle. ${ }^{.74}$

In 1974, the side facade of a typically suburban house in Niagara Falls NY, was sectioned into nine equal portions of a box. As they were removed, slowly one by one, Mata-Clark aggressive liberation started to shatter the container of the private spaces within what could be considered the most protected icon of autonomous living, the suburban home. Titled Bingo, the project focuses on the undoing of the seductive myth cultivated by the isolation suburbs: the cult of privacy. ${ }^{75}$ Fundamentally the most "intimate sphere" ${ }^{, 76}$ of life, the private domicile, has its outer shell cut away to the public street, thereby bleeding public and private. In addition, the removal of the autonomous

\footnotetext{
${ }^{74}$ Lee 28.

${ }^{75}$ Lee 23.

${ }^{76}$ Lee 23.
} 
skin, traditionally responsible for separating and monotonising the relationships between the programs within in the home, celebrated and dynamised the relationships between the interior programs. It liberated the prosaic space inherent to the traditional suburban box by introducing a new perspective to read the architecture.

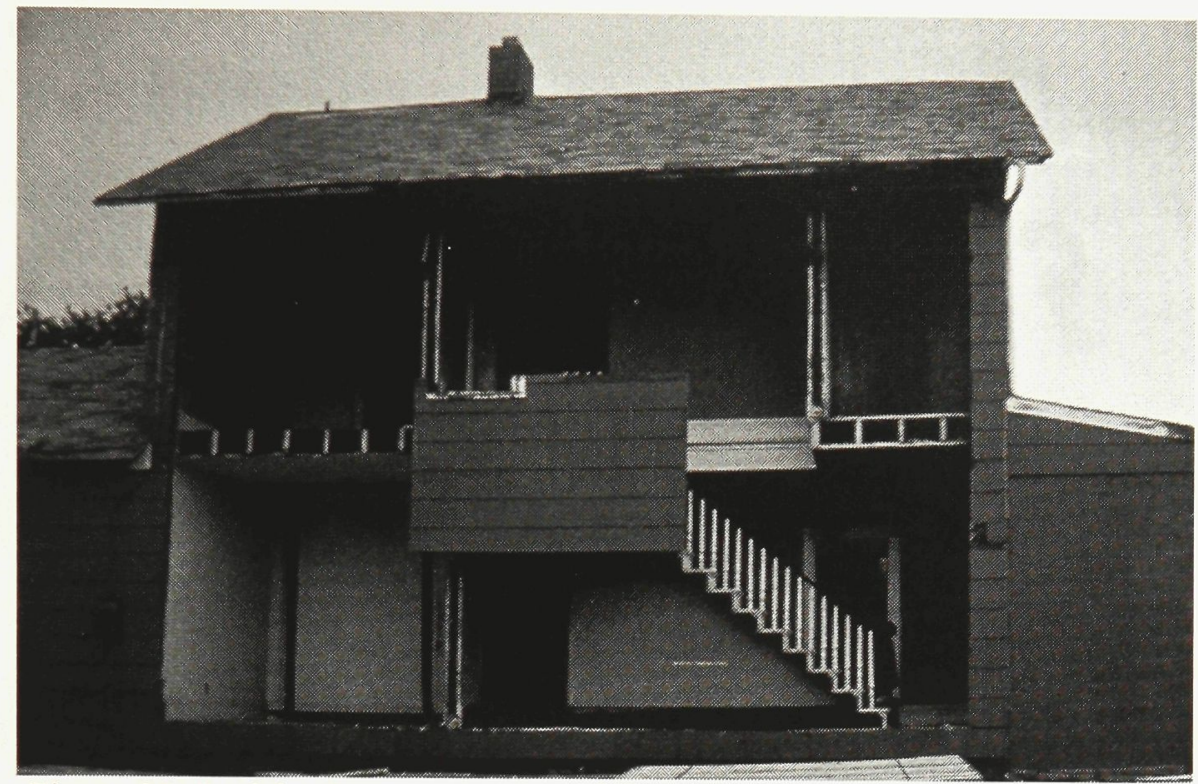

Figure 35: 8 of the 9 squares removed from the suburban container in Bingo

\subsection{Interrupting the Syntax - Reorienting Traditional Order}

As his work evolved, the notion of allowing spaces to bleed into each other by undoing their boundaries appropriately began to permeate the façade as his interventions and started to engage the core of the architecture. The square floor cut (Bronx Floors), beyond being an object in a galley, was more importantly a void, bleeding programmatic realms together in both plan and section. As the beginning of very complex cuts to follow, the interruption of the a mundane, rational system of ordering space was soon to engage the floors, walls, ceilings, windows and doors equally, intending to address the antiquated architectural syntax by reorienting the order of the space and it relates to the body and itself. 
I think that they [the projects] are all different versions of some kind of preoccupation with the dynamic. The thing that I would really like to express is the idea of transforming the static, enclosed condition of architecture of a very mundane level into this kind of architecture which incorporates... this sort of animated geometry or this animated, tenuous relationship between void and surface... [It implies] a kind of kinetic, internal dynamism of some sort. ${ }^{77}$

It must be understood that the intention was not to just cut open traditionally rectilinear spaces and link them together; but rather, the intervention becomes an interruption that is "not merely a question of engaging with a physical structure, but of "juggling with syntax', picking apart the grammar of architecture phrase by phrase." ${ }^{, 78}$ Matta-Clarke's intervention offers the prosaic syntax a new life, and thus, a new relationship to its place, by injecting a contemporary dynamism into the antiquated architectural spaces.

The new intervention establishes a syntactical juxtaposition between past and present, revealing to the inhabitant, a discourse with time and evolution. Culture manifests one architectural syntax for inhabitation, and evolves beyond the capacity of the architectural syntax. Contemporary culture abandons that syntax while manifesting a new syntax, and the new syntax is inserted disrupting old syntax, such that the spaces are revitalized for contemporary use. The dialogue of opposition reflects the nature of social evolution manifested in physical architectural space. "A tension between the new and the primordial or obsolete would animate the history of the site." ${ }^{, 79}$ This dialogue however, transcends that which exists between the two syntaxes by further reorienting the inhabitant's relationship to the architectural spaces; a new set of relationships for a new

\footnotetext{
${ }^{77}$ Lee 389.

${ }^{78}$ Attlee and Le Feuvre 45.

${ }^{79}$ Lee 188.
} 
inhabitant. By perceptually disturbing the fixed axiality of the building's construction ${ }^{80}$ his intention was to challenge the inhabitant's understanding of space and loci within the discourse produced by the two syntaxes. The resulting space "deprives one not only of the perpendicular axis by which architectural space is commonly regularized, but also the conventional disposition of ones body within it." ${ }^{, 81}$

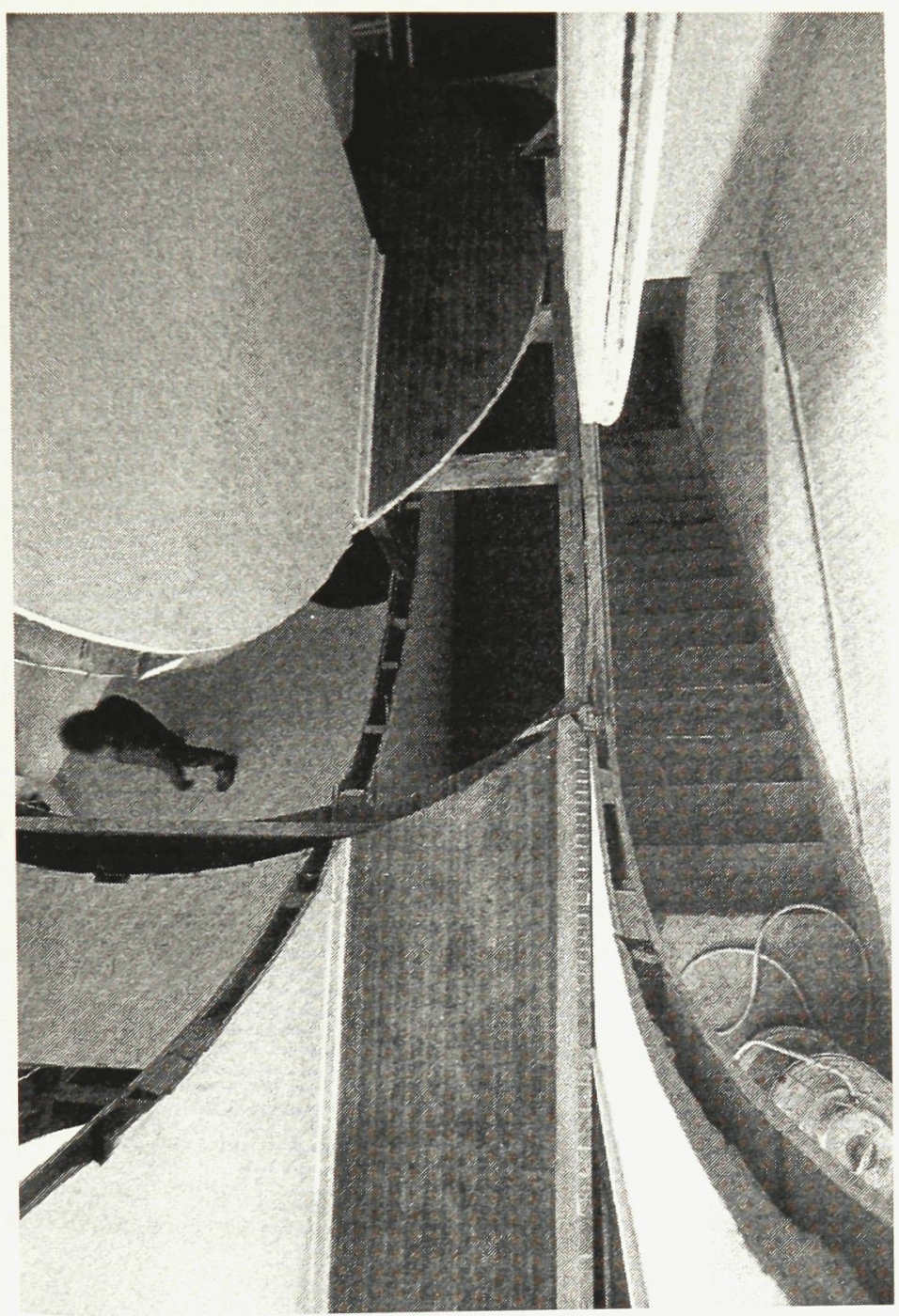

Figure 36: Circus

${ }^{80}$ Lee 157.

${ }^{81}$ Lee 157. 
Matta-Clark's cuts reveal a dynamic discourse about the nature of resolving time, evolution, and place in physical junctures between structure, surface, and void of both the 'new' and 'primordial' syntaxes. However, the omnipresent existence of the void and edge, define the new space of inhabitation, asking: is the inhabitant's loci within contemporary space of the void, produced and defined by the cut?

\subsection{Inhabiting the Void}

"Matta-Clark's exposure of the joists and floor complex further reveals how the cut performs a two-fold operation, consolidating and defining the form at the same time as it undoes it. ${ }^{, 82}$ It was the destruction of the traditional threshold, the blurring boundaries between spaces, syntax, and the building section; it was the liberation of history by evolution. The blurring of space, program and syntax was dually the destruction of the threshold, and an exploration of the void. A cut in the floor, (Bronx Floor) for example, was intended to disrupt the threshold between spaces in plan by removing the floor under the doorway; it further dissolved a sectional threshold manifesting a special dialogue in the vertical axis. As his explorations evolved the cuts became more complex the space body relationship started provoking, what Pamela Lee refers to as, "Kantian sublime vertigo." 83

\footnotetext{
${ }^{82}$ Lee 157.
}

${ }^{83}$ Lee 138 . 

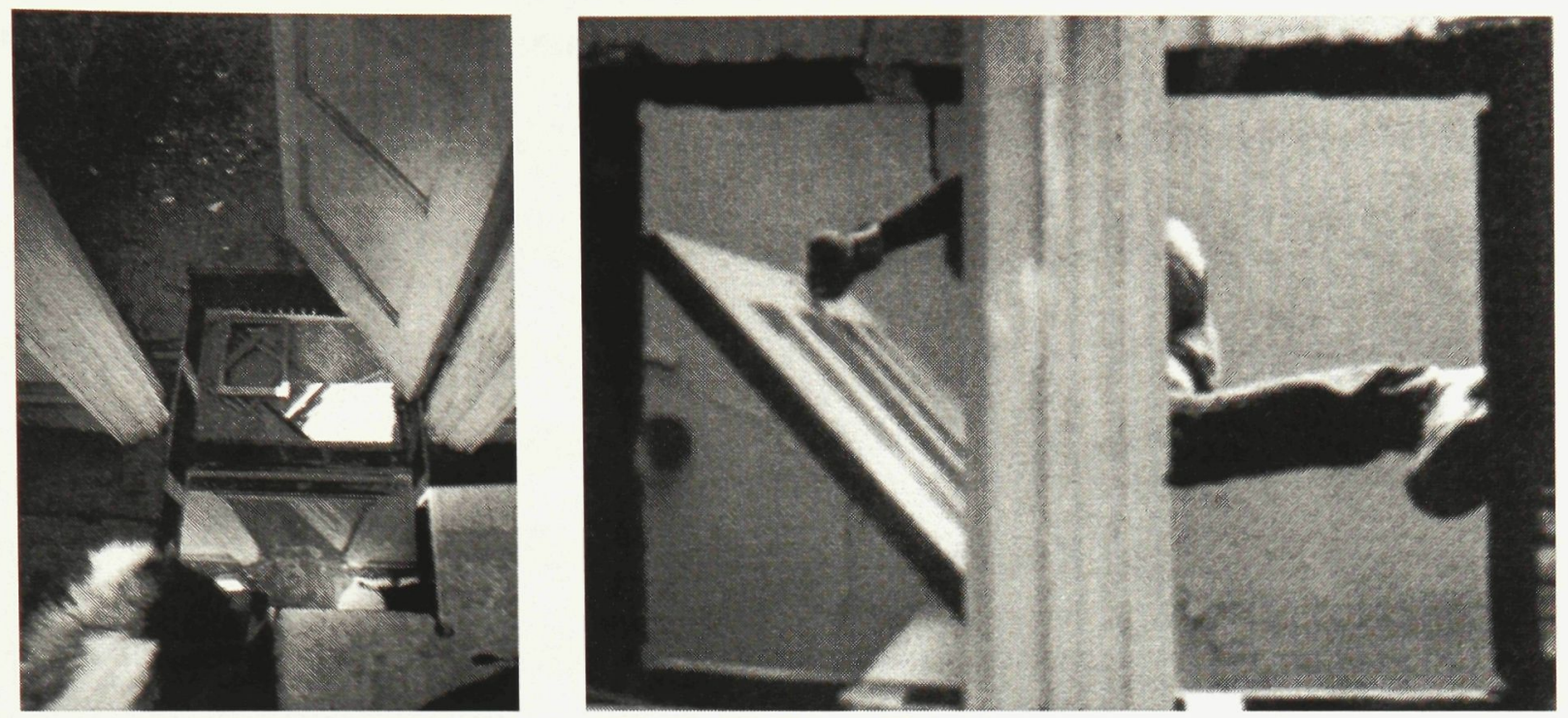

Figure 37: Bronx Floors

Figure 38: Bronx Floors - Threshole
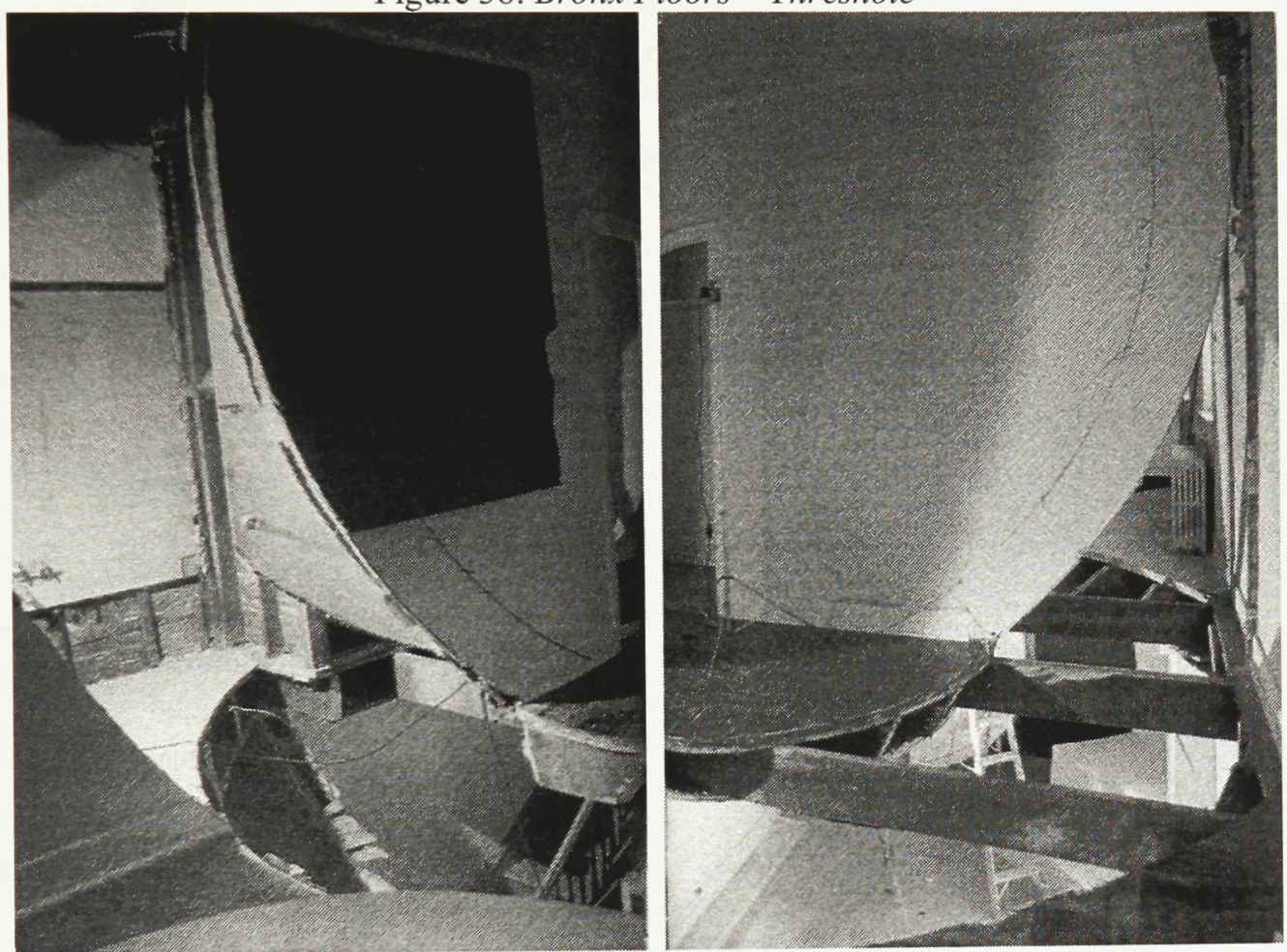

Figure 39: Circus

Accompanying this unsettling feeling of the sublime, made present by the complete destruction of the walking plane, which humans depend on, is the desire to lookup - a feeling of spatial ascension. This ascension is furthermore, the spectacle opposing the point of discomfort inherent to Kantian sublime. They are "interruptions 
into the architectural mass unsettling the very act of spectatorship in the viewers passage through the space. ${ }^{\prime 84}$ The spaces of Matta-Clarke are by no means intended to be a pleasant walk through a 'renovated historical space'; they are contemporary spaces revealing dramatic space body experiences engaging time and place via syntactical juxtaposition, revealing through the destruction of threshold, and spatial reorientation through disorientation. "This kind of dynamism, experienced through the confrontation with 'real time', is not that of the subject strolling casually, easily through the phenomenological space. We are far away from the free plan here; in anything, we have now given way to a free fall." ${ }^{, 85}$

"Beauty is associated with that whose form can be apprehended, the sublime is associated with the formless, that which is unpresentible in sensation" ${ }^{986}$ The sublime was a heavily explored idea in the $18^{\text {th }}$ and $19^{\text {th }}$ century; however, the post modern, Kantian, understanding of the sublime was investigated in its association to aesthetic and generally comprised of two components. First, displeasure revealed through an experience of the incomprehensible, denoting the mind's limited sense of experience. The second, a feeling of pleasure revealed through the power of the mind acknowledging the spectacle. ${ }^{87}$ This would suggest that the impact of the void in Matta-Clark's Circus would reveal to its inhabitant a two-fold experience: pleasure, via the comprehension of the spectacle; and displeasure, via the incomprehension of spatial disorientation.

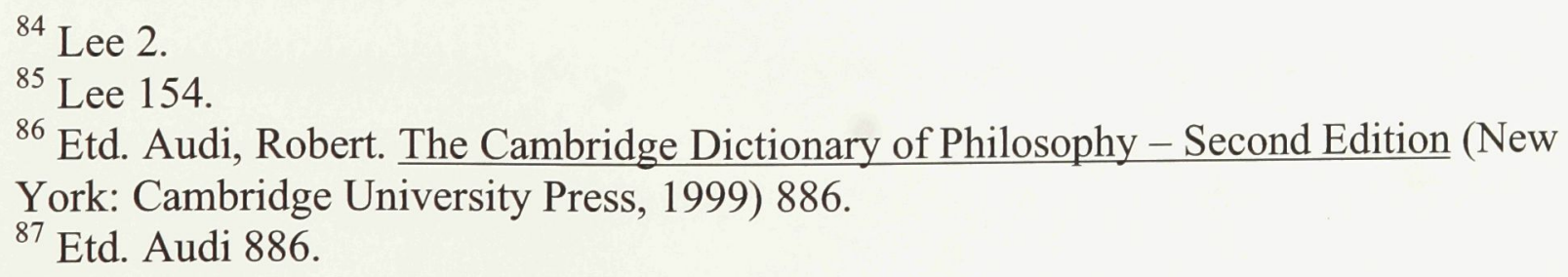




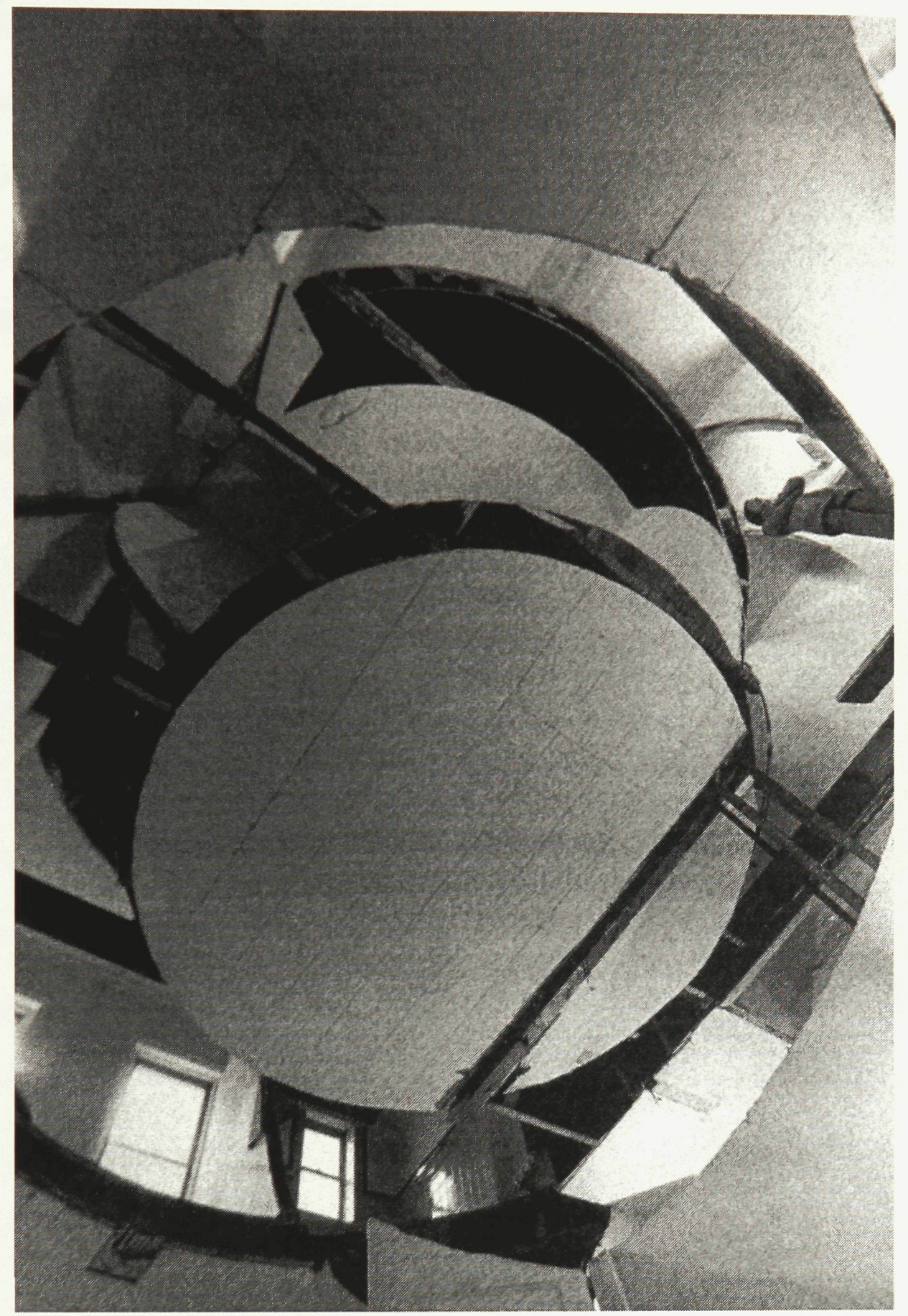

Figure 40: Circus

According to Gilles Deluse "the feeling of [Kantian] sublime is experienced when faced with the formless or the deformed (immensity or power). ${ }^{, 88}$ Then deformation of space is the resultant of the complexity of negative space, and new thresholds of the cut

${ }^{88}$ Deluse, Gilles. Kant's Critical Philosophy (Minneapolis: University of Minnesota Press, 1996) 50. 
edges; while formlessness, is the product of dissolving the boundary between the physically inhabitable and the uninhabitable. In the mind of the inhabitant, the Kantian sublime "confronts subjective relationship between power of imagination and demands of reason." ${ }^{89}$ As the realms of object and void collapse into a single entity, it is a challenge to the inhabitant to define their existence in the paradoxical ${ }^{90}$ non-place, as "the room appears to be an island marooned in a sea of abstinence." ${ }^{91}$ As inhabitable and uninhabitable realms blur and bleed into each other to a point of displeasure, the revilement of the Kantian sublime suggests that, in the discourse between object and void, the void of interruption prevails. In Circus, the intervention dissolves the historical monolith to the extent of displeasure.

In its capacity to induce a feeling of Kantian sublime, Circus reveals a set of experiences that are far from the understanding of the traditional architectural space, allowing the antiquated architectural syntax to transcend the time and evolution that stripped it of vitality. The intervention has liberated the traditional syntax transforming architecture from traditional container to an object ${ }^{92}$ of spectacle to challenge even the most contemporary inhabitant.

\footnotetext{
${ }^{89}$ Deluse 51.

${ }^{90}$ Paradoxical in that despite the suggestion of inhabiting a void, a space of non material, there is very much an understanding of the body being part a place defined by history: the existence within old building itself.

${ }^{91}$ Lee 157.

${ }^{92}$ Lee 59.
} 

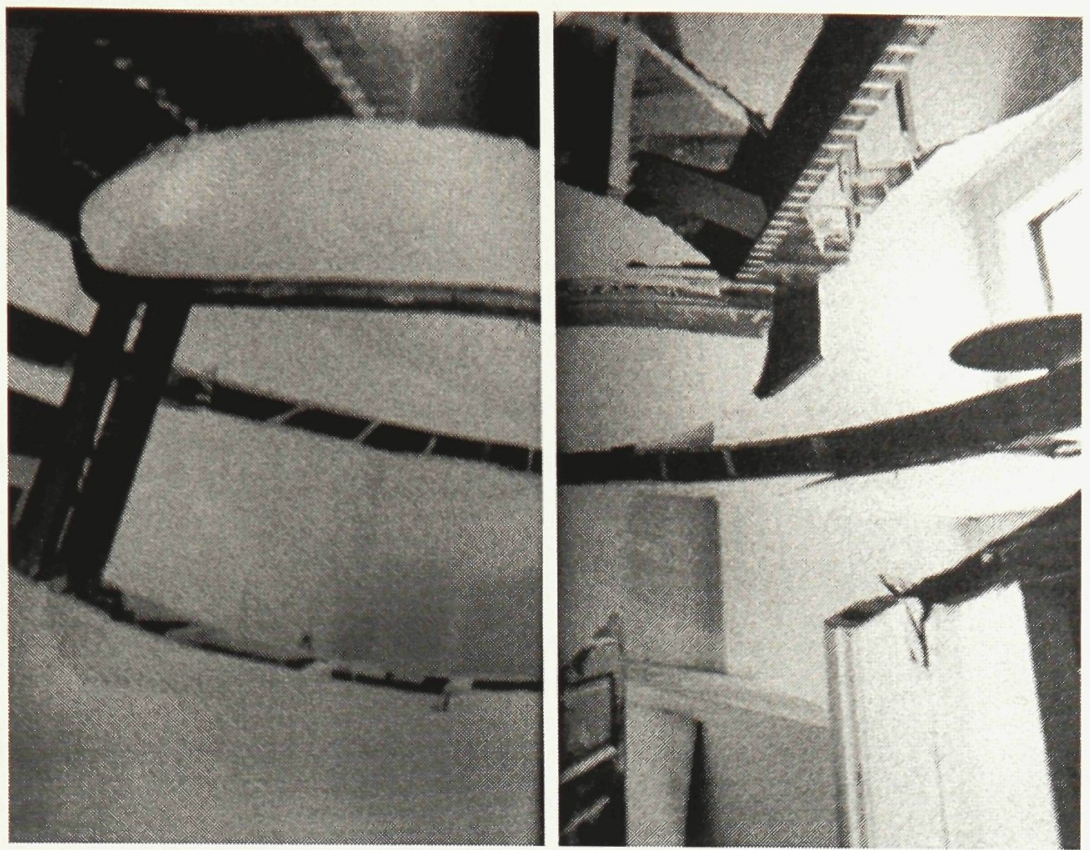

Figure 41: Circus

\subsection{Summary}

Born into a general disbelief in the modernist ideology, Matta-Clark's understanding of space transcended that of traditional architectural making. His work revealed a way of making new space via surgical operations on the body of architecture. He found that the notion of reorientation was fundamental in transformation; a new perspective offered a new understanding of the object through the dissolving of the container. His intervention would insert dynamism into the static, creating a dialogue, through the juxtaposition of traditional and contemporary architectural syntaxes, with the capacity to denote a transformation in the culture that necessitated the space. By dissolving boundaries and thresholds he undoes traditional space, manifesting an overwhelming negative space, or contemporary space, that challenges the nature of the architecture body relationship by revealing the spectacle of the sublime. 
However, in the overwhelming sublime, it should be noted that neither the discourse revealed by syntactical juxtaposition or the void itself, could exist without the historical framework; the nature of complexity can only exist when juxtaposed to the mundane. This underlying idea of historical frameworks providing the basis for contemporary exploration is analogous to the idea that character and identity, innate to history, generate the present and the future. The present could not exist without the past.

It must also be acknowledged that Matta-Clarks's work was temporal installation art. It had no architectural program, and thus existed as an inhabitable object. It should be further noted, that a shift in the nature of an architectural program can further inform the nature by which spaces are reshaped. Regardless, through a reorientation of tectonics he adds dynamic to the prosaic static, allowing for the spaces to be reengaged by breaking it free from the confinements of history and reattaching vitality to antiquated architecture. 


\section{Reorienting the Edwardian}

\subsection{Two Systems of Transformation}

Alluded to in both the texts of Aldo Rossi and the Work of Gordon Matta-Clarke, the notion of architectural subtraction reveals a spatial void in an existing framework which allows for an opportunity to read the existing architecture in a new way. This thesis proposes two fundamental systems by which to operate on the monument such that it may be reoriented towards the contemporary inhabitant. The first system involves the making of incisions to create voids in the existing architecture. The incision interrupts the traditional spaces, allowing new architectural relationships, manifested by the void, to inform methods upon which to reengage the antiquated spaces and programs with new architecture. The second system embraces the already existing axial system of ordering to inform the orientation of the contemporary syntax. The new intervention thus becomes the transformation of system that is, and always has been, inherent the existing clubhouse and the predecessors on its island site. Essentially, the two phases can be reduced to first, the cutting away of the existing architecture to isolate the spaces of interest and create a void for the intervention; and second, the insertion of a profoundly ordered contemporary architecture that can reorient the existing Edwardian spaces.

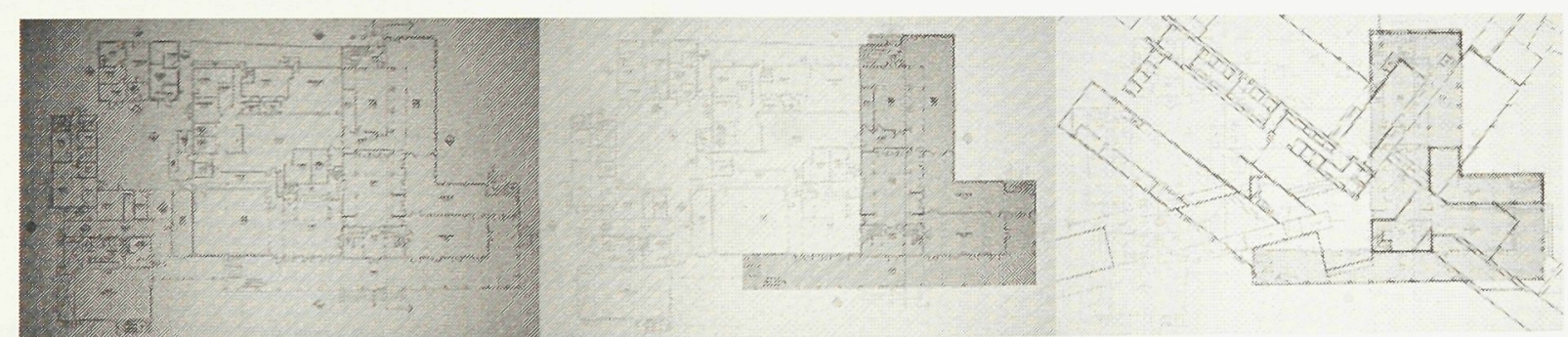

Figure 42: Existing plan / Plan of interest after removal / New architecture layered onto existing Edwardian Architecture 


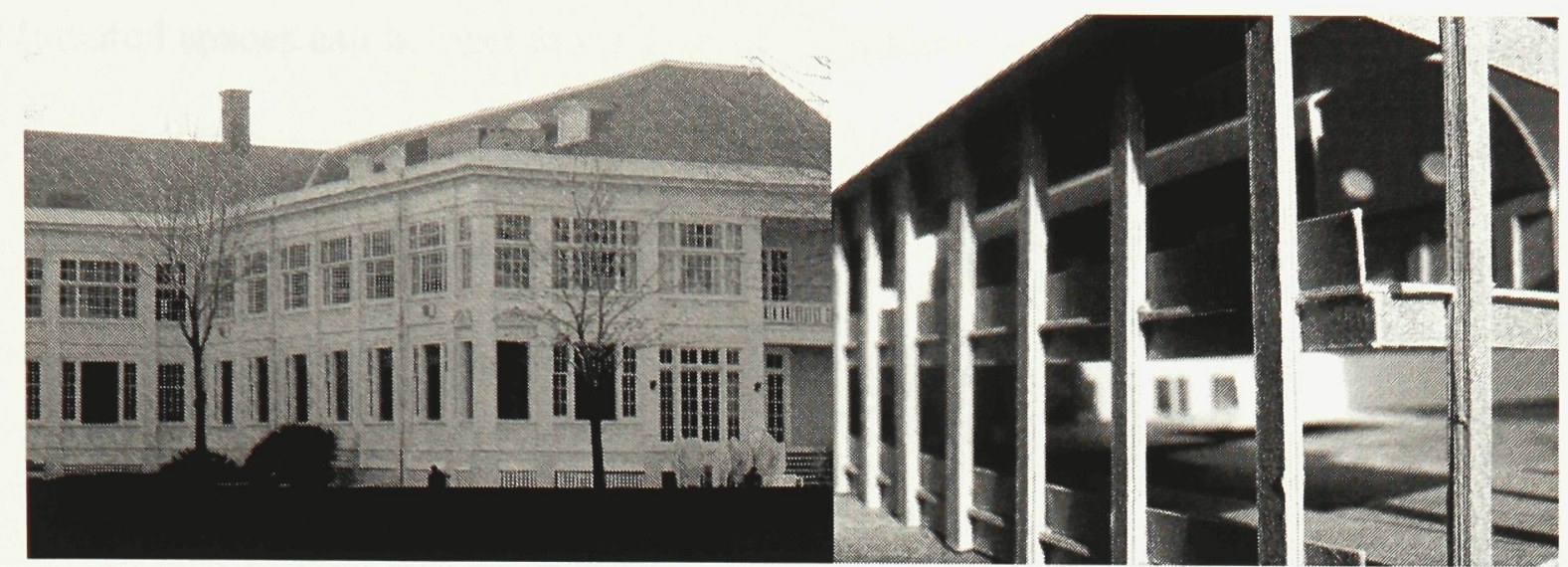

Figure 43: Existing NW corner of Clubhouse / Same corner after subtraction revealing a floating ballroom

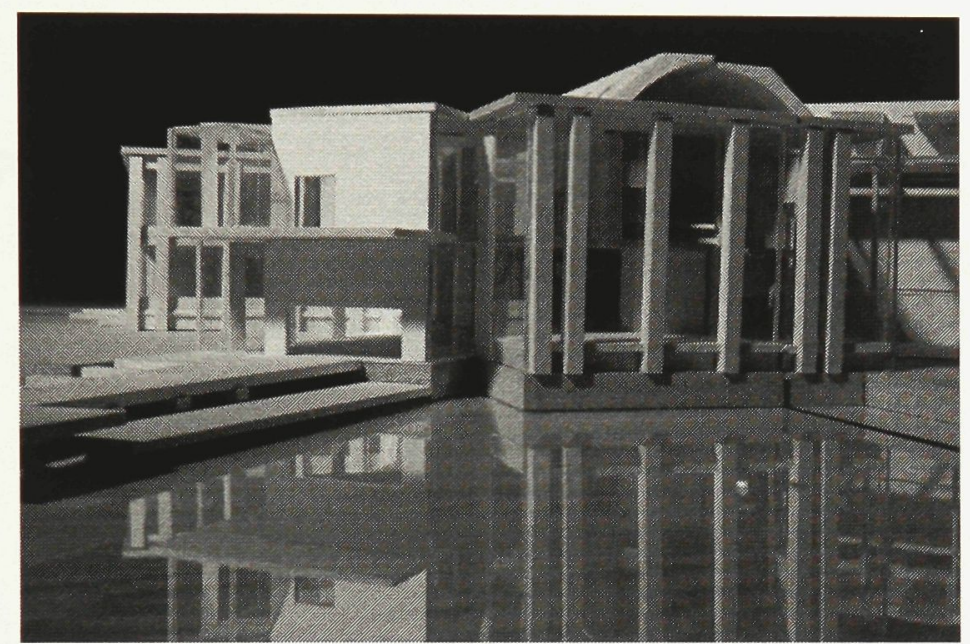

Figure 44: The new axis punching through the façade dissolving in a pier

\subsection{Three Perspectives}

Recent cultural transformation has seen a decline of formality through the flattening of social hierarchy, transforming the way in which contemporary culture engages its built environment. The rigidly defined spaces and programs of the RCYC, frozen by the architectures incapacity to transform with its Torontonian inhabitants, still adhere to the traditional relationship between service and served. The intention of the design is to explore the boundaries of these spaces by reorienting the architecture, such that it may reengage its contemporary inhabitants. This transformation will be provoked through a transformation that dissolves boundaries by undoing the existing spaces revealing a discourse of juxtaposing thresholds. The architectural transformation of the 
antiquated spaces can be read through three characters that have forever played essential roles in the functioning of the club, but have, prior to this design, been hidden in the depths of Edwardian service space. Having vital roles in the club and its storied history, the Chef, the Gardener, and the Dock Master will go through a shift that will challenge, transform, and ultimately revitalize the archaic spaces of the clubhouse.

Socializing and entertaining, and eating and drinking have seen numerous transformations through out the ages. As the RCYC was conceived as a venue for Edwardian socializing and entertaining in Toronto the heart of the RCYC clubhouse, the ballroom, is thus subjected to similar architectural transformation. It is at this moment in the architecture where the Chef and the Bartender have linked the age-old social event, predicated on eating and drinking, to the architecture. Furthermore, sailing itself has had a long past with consuming alcohol, as rum has strong association with both the British Royal Navy and Pirates. Privateers used it as a valuable trading commodity, but the British fleet grew a particular affinity for rum after the Royal Navy ceased Jamaica in 1655 ; and the relationship since only been strengthened by things such as Robert Louis Stevenson's Treasure Island.

The relationship between alcohol and the social event, however, was established centuries before by the Greeks. In the Late Archaic age dining was to be followed by a 'symposia', derived via Latin from the Greeks the word 'sumpotes' literally meaning 'fellow drinker', the event was predicated on the consumption of alcohol leading to 'intellectual pursuits'. Later, in $4^{\text {th }}$ century BCE, the symposium was an event exclusively 
for intellectual dialogues, but in Plato's book Symposium he focuses on the 'intellectual drinking party'. Wine to the Greeks was a means to transcend into an intellectual surreal space, of escape defined by a feeling of floating and existing outside the realm of daily life.

Deeply rooted in the history of sailing and the social event, eating and drinking have justified and occupied the heart of the RCYC's architecture. It is this moment in the clubhouse, supported by chef and the bartender, that will be subject to the transformation motivated by the flattening between service and served. They are the characters that have historically supported the programs and spaces that define the events of the RCYC, and in the new design will inversely become the spectacle in their respective spaces.

As the boundaries of the traditional realms of the Edwardian architecture begin to dissolve and overlap, a relationship between the thresholds of the spaces is opened, allowing the programs to transform. However, since the conception of the island clubhouse, the Dock Master has been the guardian of the club's most fundamental threshold existing between the island and the water. As the sailboats began to make berth off the clubhouse lawns, the inhabitants and programs of the club's social architecture transformed to include the sailor. The sailboat thus became an extension of the architecture and it was the role of the Dock Master to negotiate this new threshold. Despite the introduction of the new programs, the architecture's island site forced the club to always be dependent on the boat for everything required to sustain the club's existence. Most importantly including, the visitors who were constantly arriving and departing via ferry. When arriving by private boat, the Dock Master was literally the first 
person the visitors encounter when arriving on the island, and thus is responsible for mediating the engagement of first of the non-Edwardian programs.

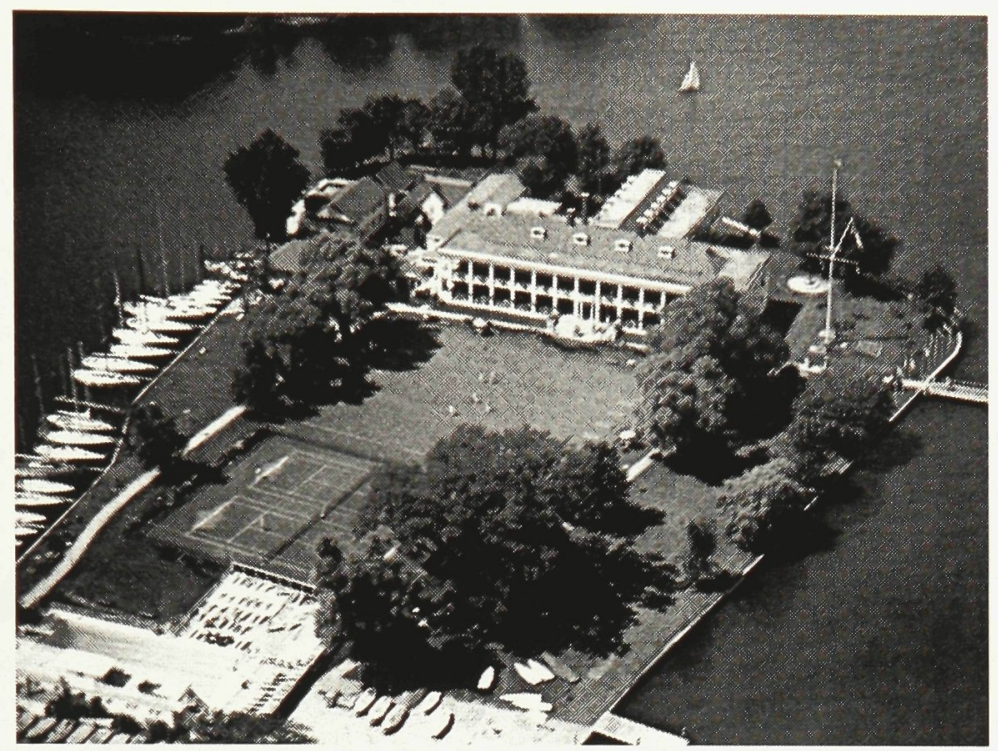

Figure 45: Arial photograph revealing the new programs as they juxtapose the once autonomous Edwardian architecture

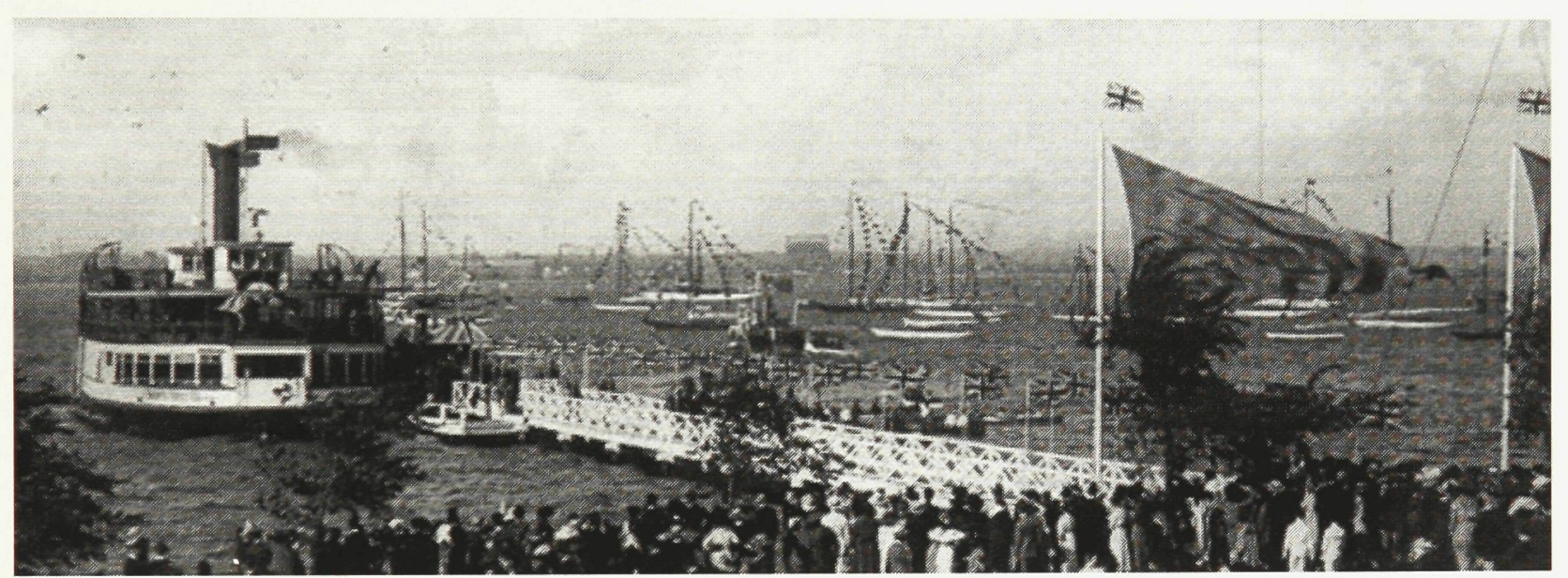

Figure 46: The ferry arriving at the threshold of the island.

Parallel to many similar British and American institutions of the late $19^{\text {th }}$ early $20^{\text {th }}$ century, the programs of the RCYC evolved. The new programs, responsible for transforming the identity of the traditional yacht club, created new thresholds in and around the architecture. The Dock Master then becomes gatekeeper of the new island programs, and master of the thresholds that allow the new programs to engage antiquated clubhouse. 
Aside from the new programs inhabiting and transforming the old architecture, the landscape surrounding the club is still a refection of the initial 1919 design intentions that drove the original architecture of the clubhouse. The design of the landscape embraced the conditions of the island appropriately echoing the manicured nature defined by the British landscapes of the time. The intention was to carefully craft the landscape to insulate the architecture from the surrounding conditions, affirming its autonomous place among 'nature'. The domain of the Gardener propagates the buffer that protects and encourages the introverted architecture, framing it as a formal object placed in its oasislike landscape. He manifests a space autonomous from the city, and like Frederick Law Olmstead's carefully cultured Central Park in Manhattan creates the illusion of being elsewhere. The pinnacle of the landscape is the highly manicured and intimate rose garden. The idea of retreating to the garden is deeply embedded in history and the notion of intimacy furthered by the roses association to Eros, the Greek god of love, lust, and sex. The rose is then the icon of the landscape's most intimate place of escape. A contemporary transformation of the rose garden can be seen in moments such as Le Corbussier's roof garden at Villa Savoie, where the ground plane is transplanted vertically to a new plane and grafted onto the architecture. As the curator of the landscape, the Gardener transforms the architectural veil, to a dynamic landscape that dynamically reveals the intentions of the new architecture. 


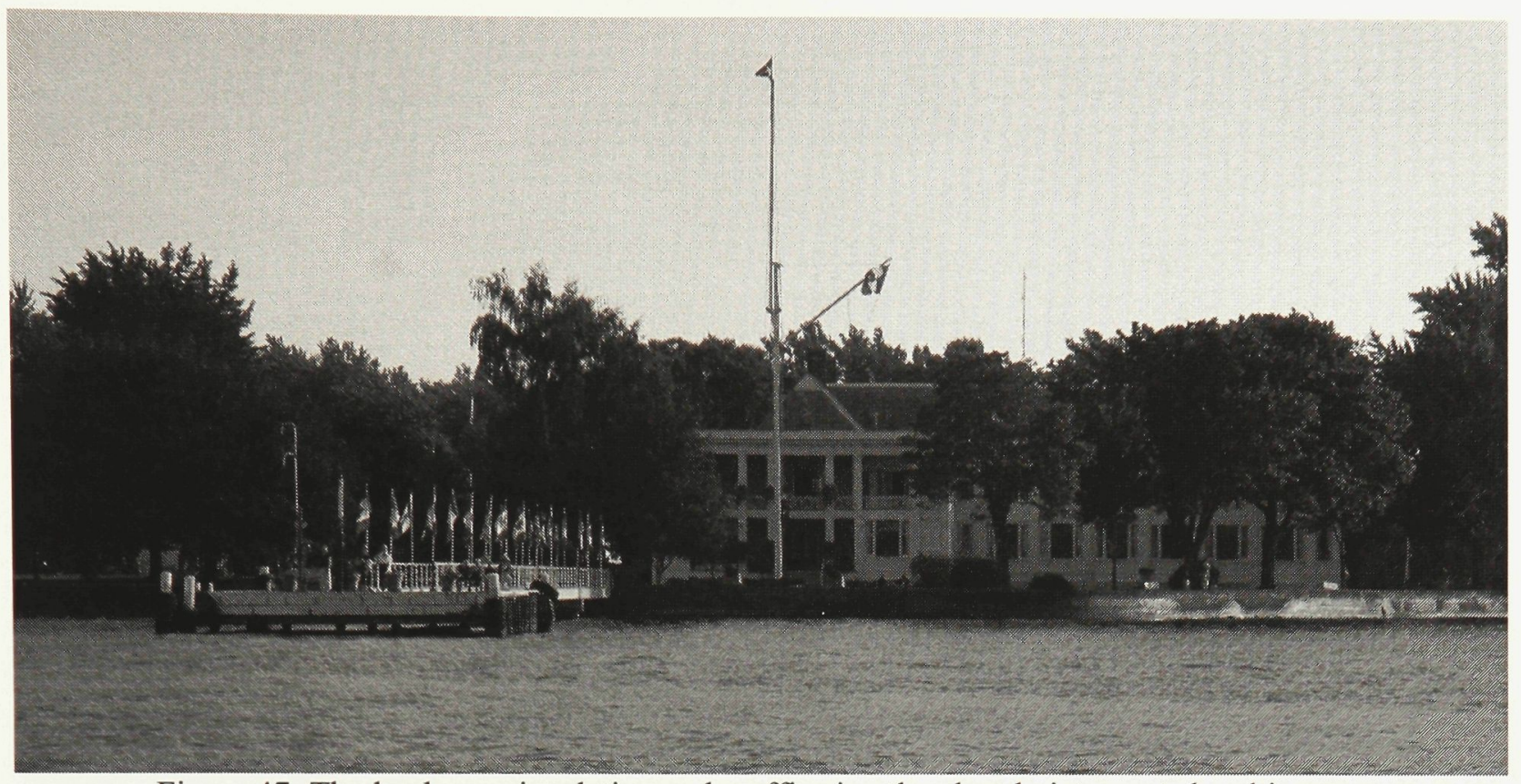

Figure 47: The landscape insulating and reaffirming the already introverted architecture

The Ballroom is the protected relic of social space and the heart of the Edwardian event-based architecture. It is the icon of the buildings's incapacity to evolve with culture. Set along the now severed property-centric axis, the dead space of ballroom extends out to include its 'lobby' that is further bracketed by the symmetrical staircases unfolding from behind the mostly locked main doors of the clubhouse. This region defines the social core of the old architecture. By focusing on the antiquated icon of social space, that once defined the Edwardian architecture, it is translated into what might be its contemporary equivalent. The glorification of the Chef invigorates the ballroom by transforming the formal relic into a more casual and engaging space. A gesture that reflects the changes in the social fabric inherent to people who are to inhabit the space. 


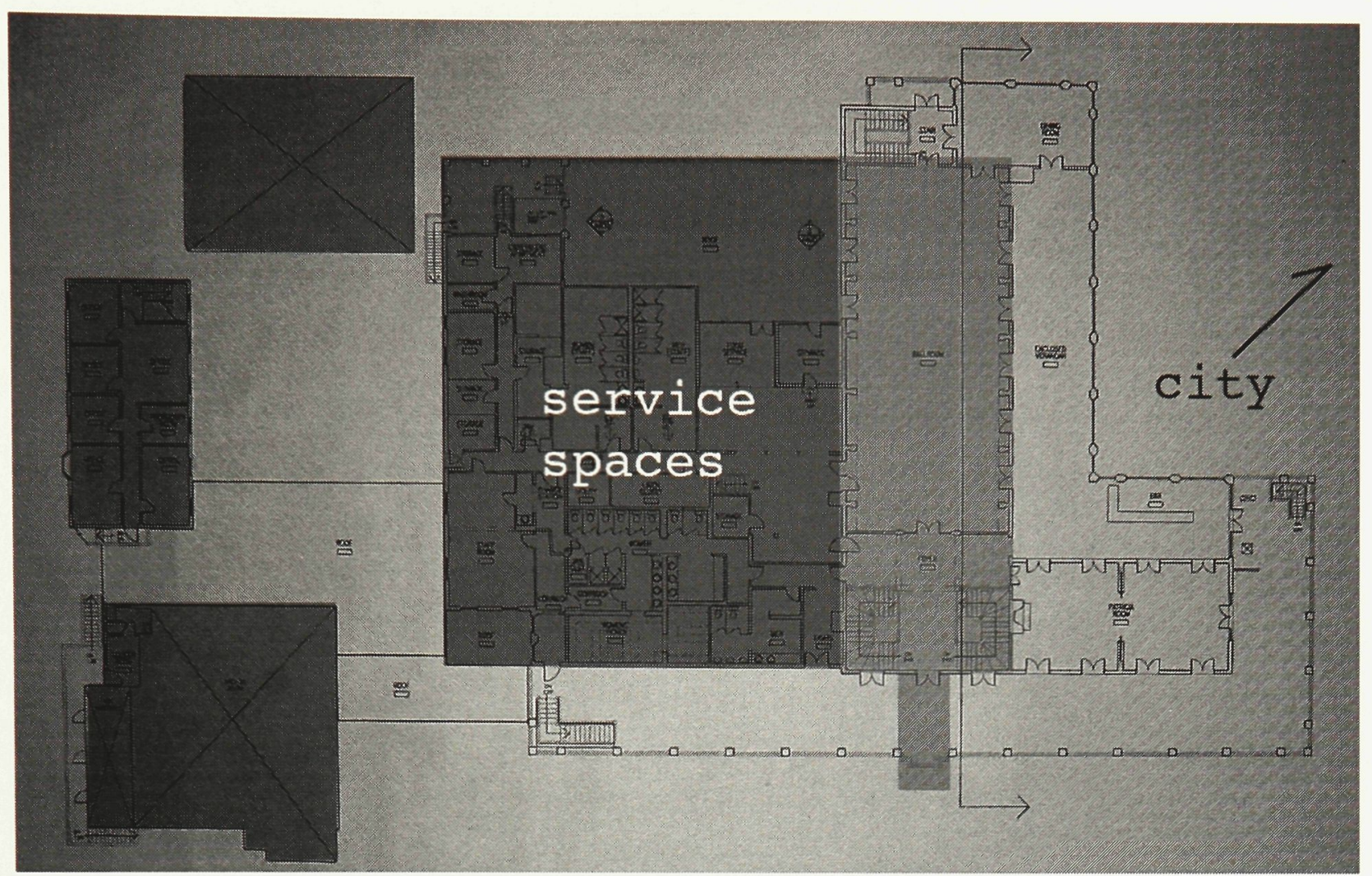

Figure 48: Existing second floor place showing ballroom - services spaces and the Edwardian formal core

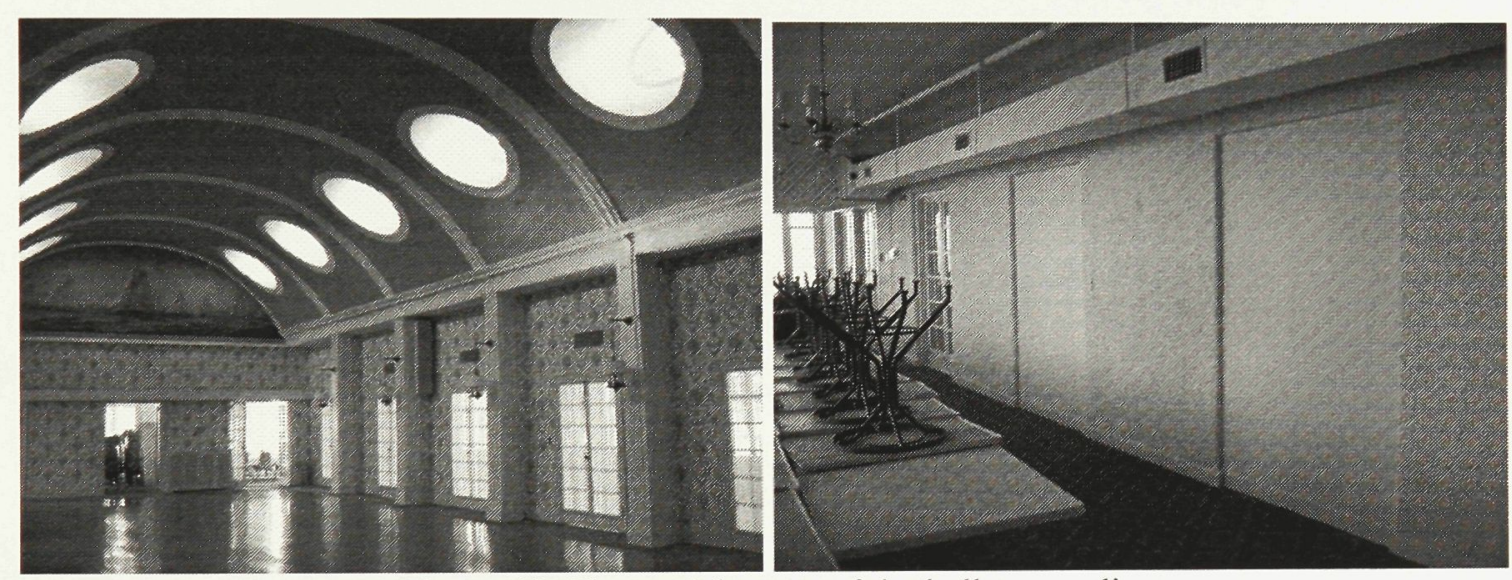

Figure 49: The social space of the ballroom relic

Figure 50: The veranda space between he core of the architecture and the city 


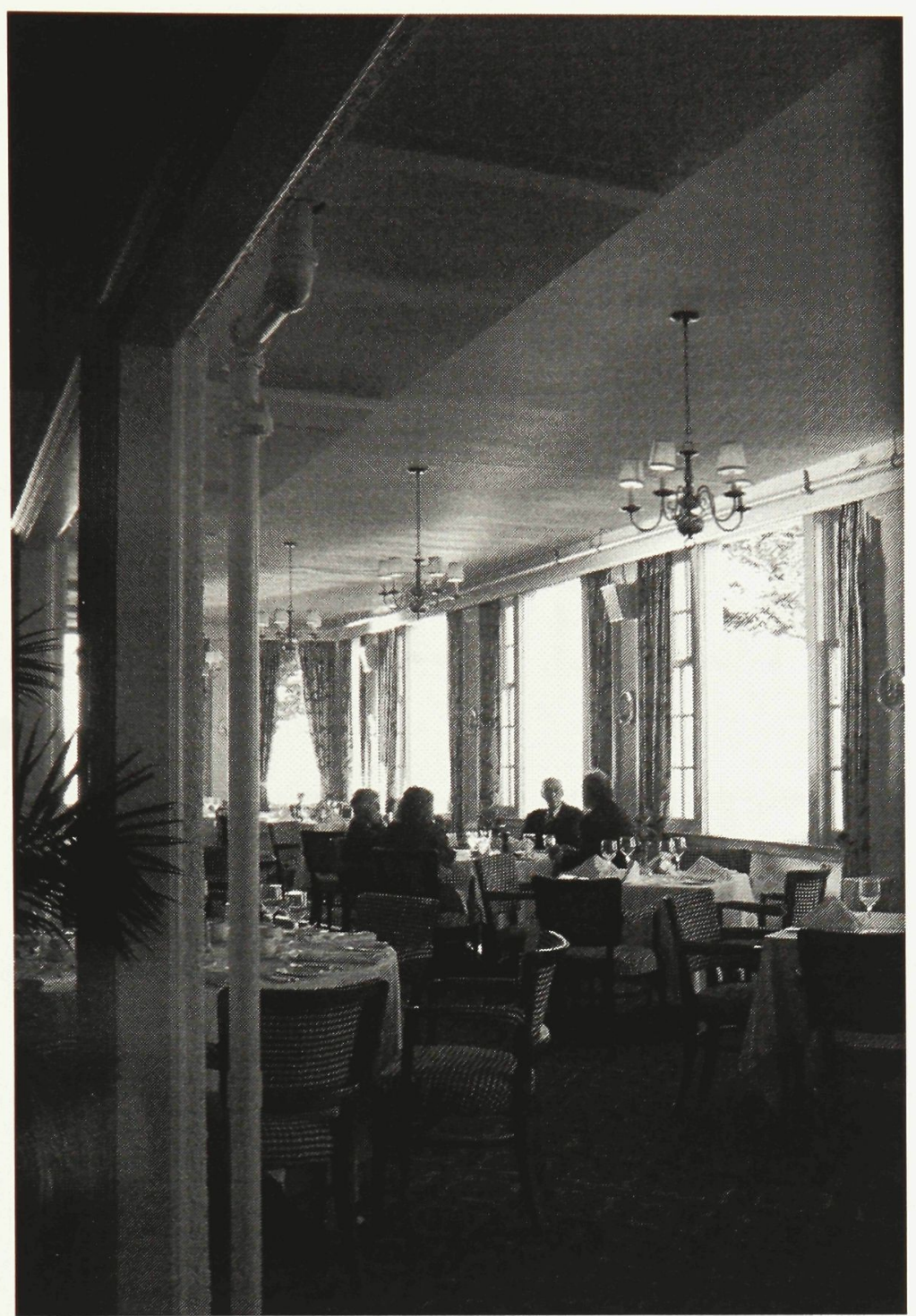

Figure 51: Existing formal dining room in the old outdoor space of what once was a veranda - city facing

The locus of the contemporary reorientation has been defined by a massive skewed cut in the floor under the original entrance for the ballroom. It intends to denote the presence of a new architecture through a shift the formality, the experience, and the perception of these spaces. By sectionally dissolving the traditional boundaries and allowing the programs to bleed into one another the architecture reveals a layered space of architectural evolution. Generating momentum along side the service core on a new axis, the formality of the kitchen begins to dissolve as it approaches the historical syntax of the architecture, where it terminates as the new event of the ballroom. 


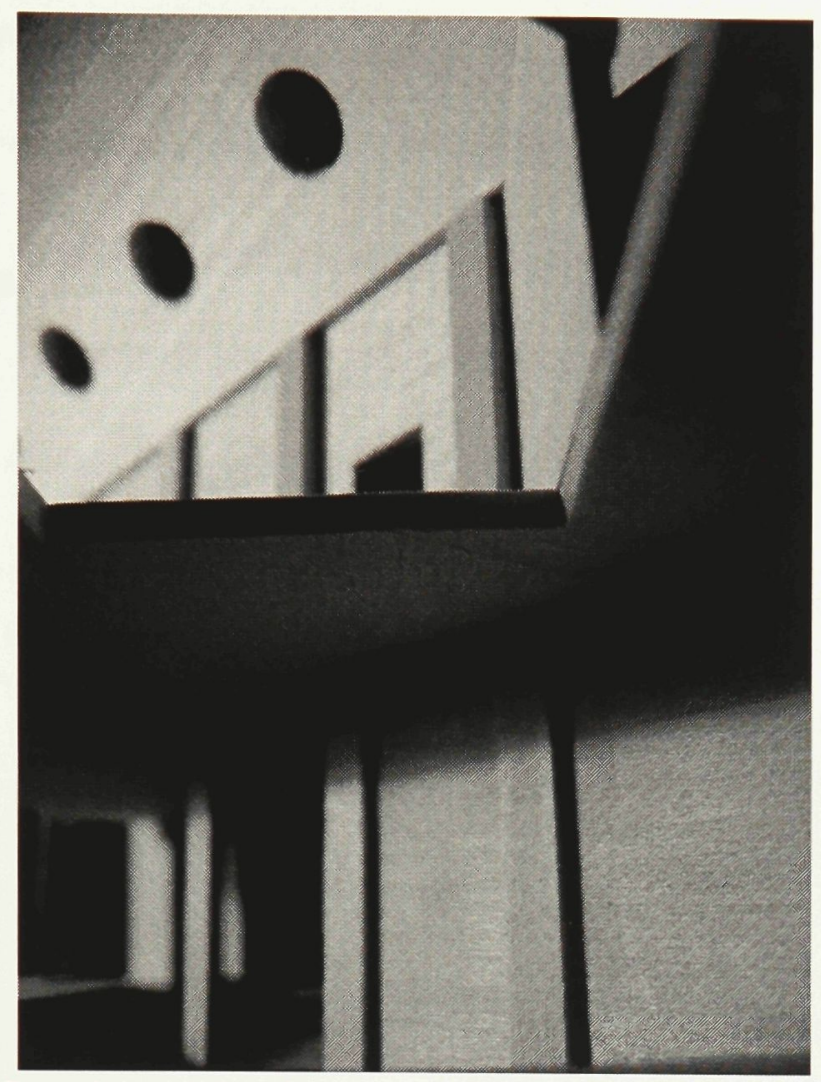

Figure 52: Cut in floor the traditional entrance of the ballroom - the space of reorientation

Through its transformation, the kitchen resolves itself into three stages of revealment. Existing in its most traditional form at the back of the architecture, it is separated from the new event room by the service core and is the space for preparing for the more rare larger events. As it runs along the service core and moves closer to the Edwardian architecture, the boundary of the kitchen begins to dissolve in the casual space of a snack bar as a short-order grill. But once the realm of the kitchen collides with the architecture's core space of reorientation, the tectonics shift, adopting a new axis, and the kitchen ascends sectionally, cutting into the formal space of the ballroom in the form of an event kitchen ${ }^{93}$. Here the traditional boundaries of both the kitchen and the ballroom are dissolved as the surface for preparing is dually the surface for eating. The boundaries

${ }^{93}$ A kitchen where cooking itself is on display and is glorified as a spectacle in the space. 
of the ballroom are further dissolved as the west end of the ballroom is completely removed, allowing the boisterous space of the bar below to bleed into the once, very private, formal ballroom and the rose garden. Furthermore, the west façade is dissolved exposing the once introverted ballroom and its events to the harbor and the city, and viceversa. The landscape mirrors this intention by pulling back the shoreline to the base of the façade uniting the threshold of the ballroom, the façade, the landscape (site), the water and effectively the city.
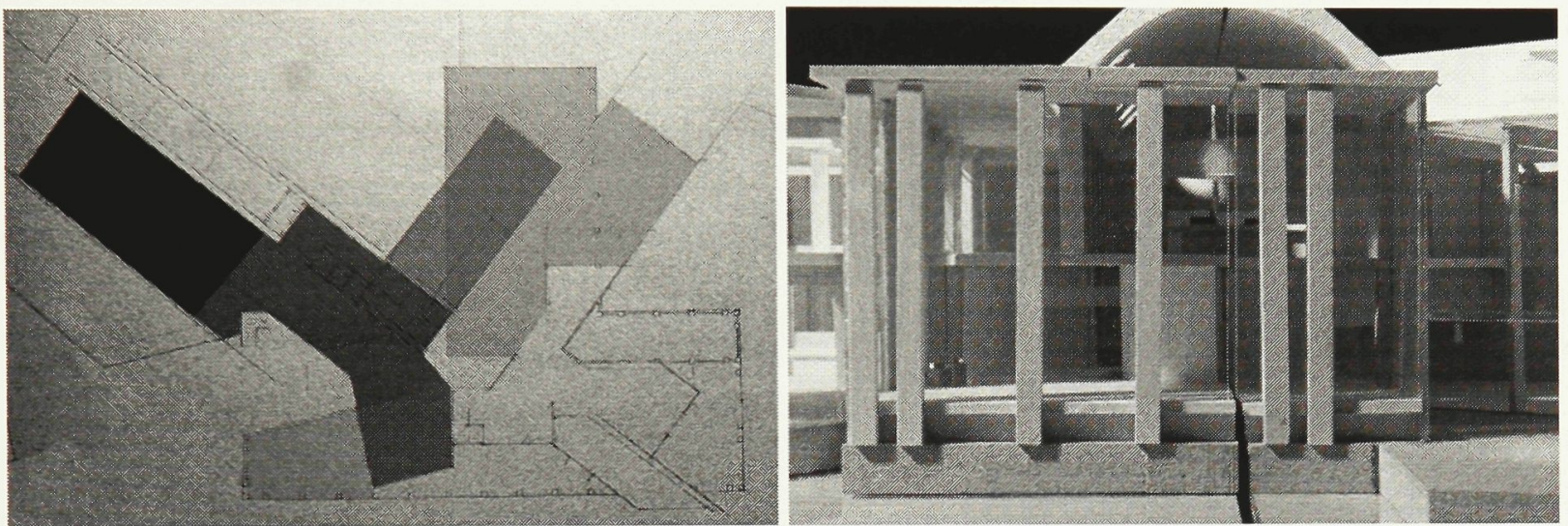

Figure 53: The realm of the cook (black) in transformation as it shifts to engages and interrupt the Edwardian architecture

Figure 54: The west façade as it would be seen from water - dissolving the boundaries of the most protected social relic

By playing with thresholds and dissolving boundaries within the ballroom, the intervention forces the questions whether or not the Chef is a guest in the realm of dining or is the diner a guest in the realm of cooking. The kitchen engages the space on a new axis, skewed from that of the ballroom, shattering the space of the relic, making cooking the contemporary event, and the chef effectively becomes the new ballroom dancer. 


\subsection{Designing for the New Inhabitant}

What was once an icon of social architecture on its own island, clearly autonomous from the sailing related facilities, was now subject to the existence of a more complex set of programs. As these programs are added to the RCYC's infrastructure to accommodate the club's transformed inhabitants, as well as the sailing and athletic programs, a new axis and point of entrance is created in response to the nature by which these people engage the club in a contemporary nature. This new axis, and point of entry, allows the inhabitants to bypass the more socially formal spaces of the club that stem from the ferry axis, occupied mostly by a tie-clad, post-work evening crowd. This entrance, presided over by the Dock master, is an appropriately glorified back door into the Edwardian architecture. The new entrance and axis cuts into the old architecture until, like the opposing ferry entrance, it intersects with the core moment of reorientation. The resultant axis is driven by the ever present socializing and entertaining program inherent to the club, as it reaches, slightly skewed from the historical syntax, towards the water and the city. On the main floor this the program is a casual bar while above are slightly more formal lounges and the aforementioned contemporary dining space in the ballroom. The circulation between these realms then occurs at the core of reorientation in the heart of both the Edwardian and contemporary architecture. 


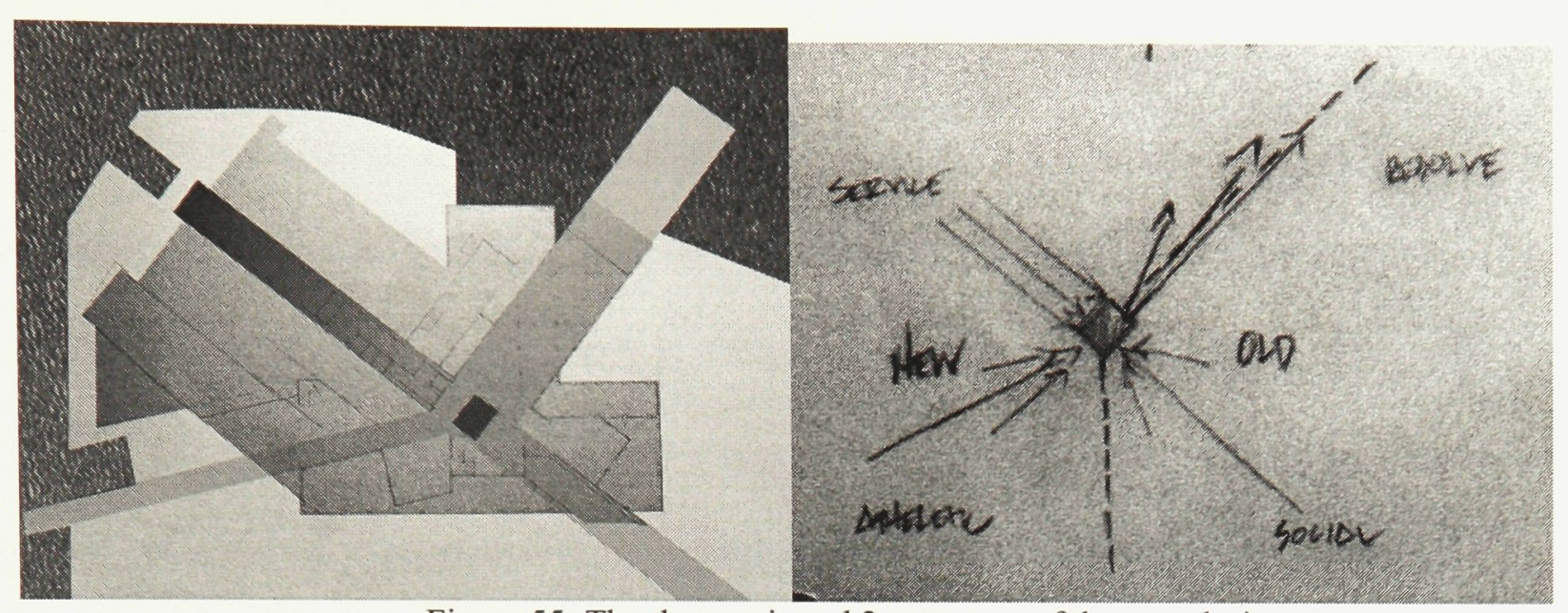

Figure 55: The three axis and 2 entrances of the new design

Figure 56: Early schematic sketch of new design

\subsection{Articulating the Site}

As the intentions of the intervention are to engage and reorient antiquated architectural space and program though the dissolving of boundaries and thresholds, it becomes clear that the landscape must be readdressed through similar intentions, so that the architecture and landscape speak a common syntax of transformation and evolution. By allowing the spaces of the club to bleed out of the architecture and transform elements in the landscape, the club opens an active and dynamic engagement with its landscape, the water, and subsequently the contemporary city. What was once a landscape that framed the city, and was itself framed by the rhythmic columns of the veranda, now becomes and a more complex entity that responds to the shifts within the architecture, effectively becoming a filter for the clubhouse. The three major axis that are established within the architecture, the ferry arrival, the island arrival, and the resultant axis, can all be further read in the landscape. The traditional orientation of the arriving ferry dock's path is intersected by the powerful service axis that originates itself as a service boat arrival slip. After it passes through the core of the architecture, it resolves as the new axis 
for those arriving on the island. Its counter point, the arrival axis for the people already engaged in the activates of the island retreat, originates as a boat slip and pier, which continues to penetrate into the Edwardian architecture through to the core of the reorientation. Together, the two axis resolve to generate a new axis that punches out of the old architecture terminating in a large pier reaching out into the harbor and dissolving in an 'urban beach' 94 ; a response to the purposed ' $\mathrm{HtO}$ ' project ${ }^{95}$ cascading into the harbor from the foot of Spadina Ave. The three axis then separate the landscape into three major components, one off the main façade littered with the post-Edwardian 'country club' programs reminiscent of the property-centric axis. The second is the landscape of arrival, which mediates the club and the city and is bound between the arrival axis, the resultant axis reaching towards the city, and the waterline of the harbor. The third is an homage to the original rose garden. Outside the new event space on the west side of the building, the garden is separated from the rest of the landscape and remains the most intimate part of landscape. The idea of the intimate garden is further transplanted to the top of the service core enhancing it as a place of escape, while revealing its significance through its juxtaposition to the city.

\footnotetext{
${ }^{94} \mathrm{~A}$ term uses to describe the proposed $\mathrm{HtO}$ project on the city side of the harbor - see following note

${ }^{95}$ Purposed by the Municipal Government of Toronto, $\mathrm{HtO}$ is waterfront revitalization project that plays the with the water land threshold. One of the major elements is an urban beach consists of a series of concrete levels, reaching into the harbor, stepping down into the water for sitting and relaxing.
} 


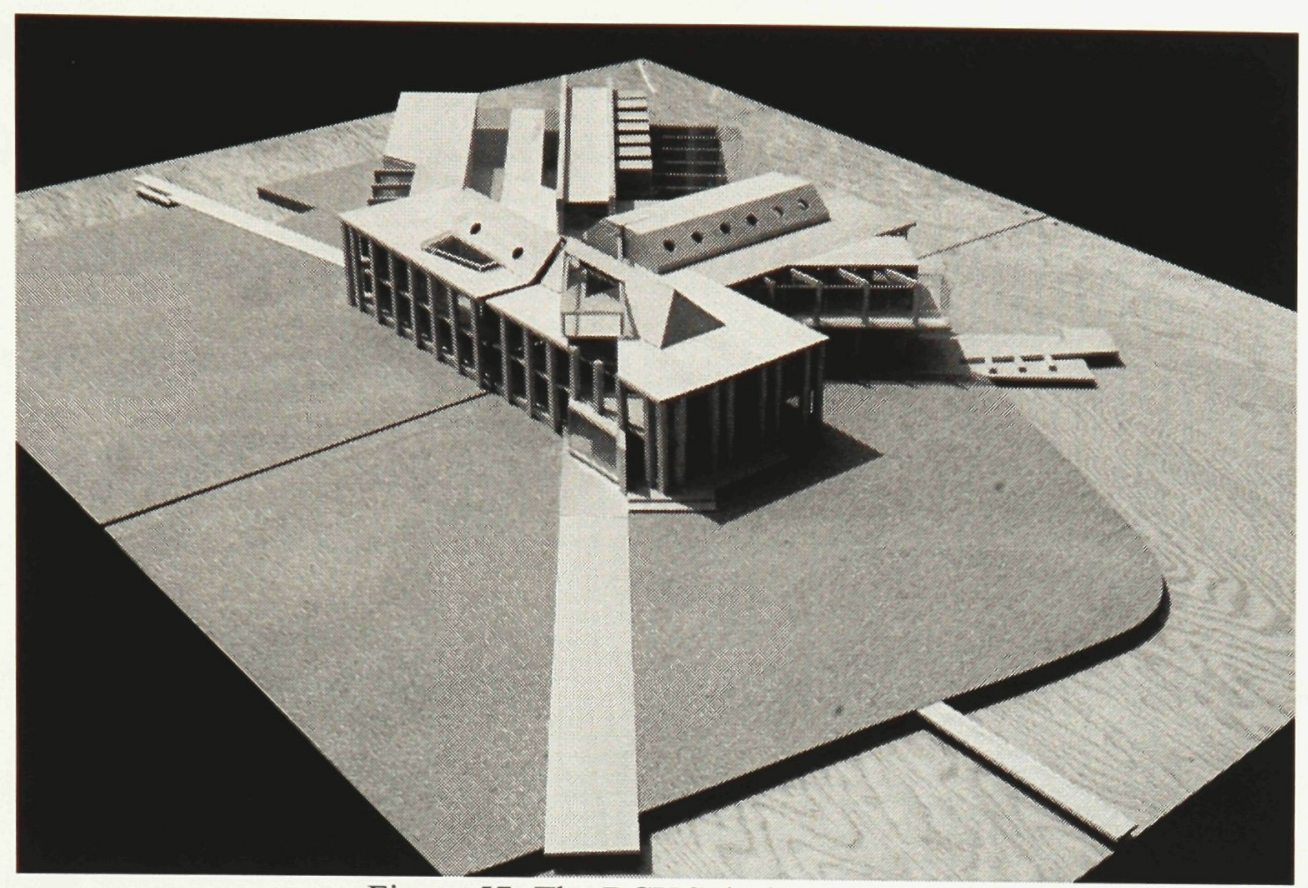

Figure 57: The RCYC design proposal

\subsection{Summary}

The traditional heart of the architecture becomes the focal point for the architectural transformation of the static relic, the space of reorientation for the traditional syntax, antiquated programs, deserted spaces, the architecture city relationship, and fundamentally the architecture culture relationship. All the spaces in the architecture can be accessed from this core space. It is a space for every inhabitant, and is thus the moment where the discourse between old and new is most dense. By using the cultural shifts, inherent to the contemporary inhabitant, as a generator for a new syntax, a physical layering of architecture denotes the evolution of this place. Like a palimpsest, it reveals the invaluable discourse of time, culture, and architecture. 


\section{Conclusion}

The intention of this thesis is to reveal a set of shifting cultural transformations that have rendered the century old Edwardian architecture of the Royal Canadian Yacht Club without vitality; and in turn, use them to generate an intervention capable of reorienting the architecture towards the contemporary culture that it intends to serve.

By embracing the deterioration of formality inherent to a century of social and programmatic shifts within the club, and the culture of the inhabitants; the intervention plays on new relationships between the realms of service and served to revitalize the antiquated Edwardian architecture. The new architectural syntax dissolves the traditional boundaries of the spaces, unfolding a discourse to between typically autonomous programs revealing a new architecture/inhabitant relationship. Furthermore, the juxtaposition of the historical and contemporary syntaxes reveals a layering that makes visible shifting social dynamics; and in turn, tells a narrative of the ever-transforming identity of the RCYC, the inhabitant, and culture as a whole.

This thesis then purposes a method by which contemporary architecture can resolve historical spaces challenged by our rapidly developing culture, allowing these monuments of our past to re-engage contemporary culture. By reacquiring architectural vitality, the spaces of our past will continue to contribute to the events of our cities. They will affirm their place in culture as propelling elements allowing them to be producers of memories rather then becoming parts of it. Their presence revels an invaluable discourse 
between our complex, contemporary identity and the moments of our past that have come to define us.

"Hope in the future is rooted in the memory of the past, without history there is no memory and no knowledge. No projection of the future can be formed without reference to the past. Past, present, future, and memory and prophecy are woven together into a continuous whole. In a clear understanding of our past lies the hope of our future. ",96

-Buckminster Fuller

${ }^{96}$ Rodgers, Richard Architecture: A Modern View (London: Thames and Hudson, 1990) 


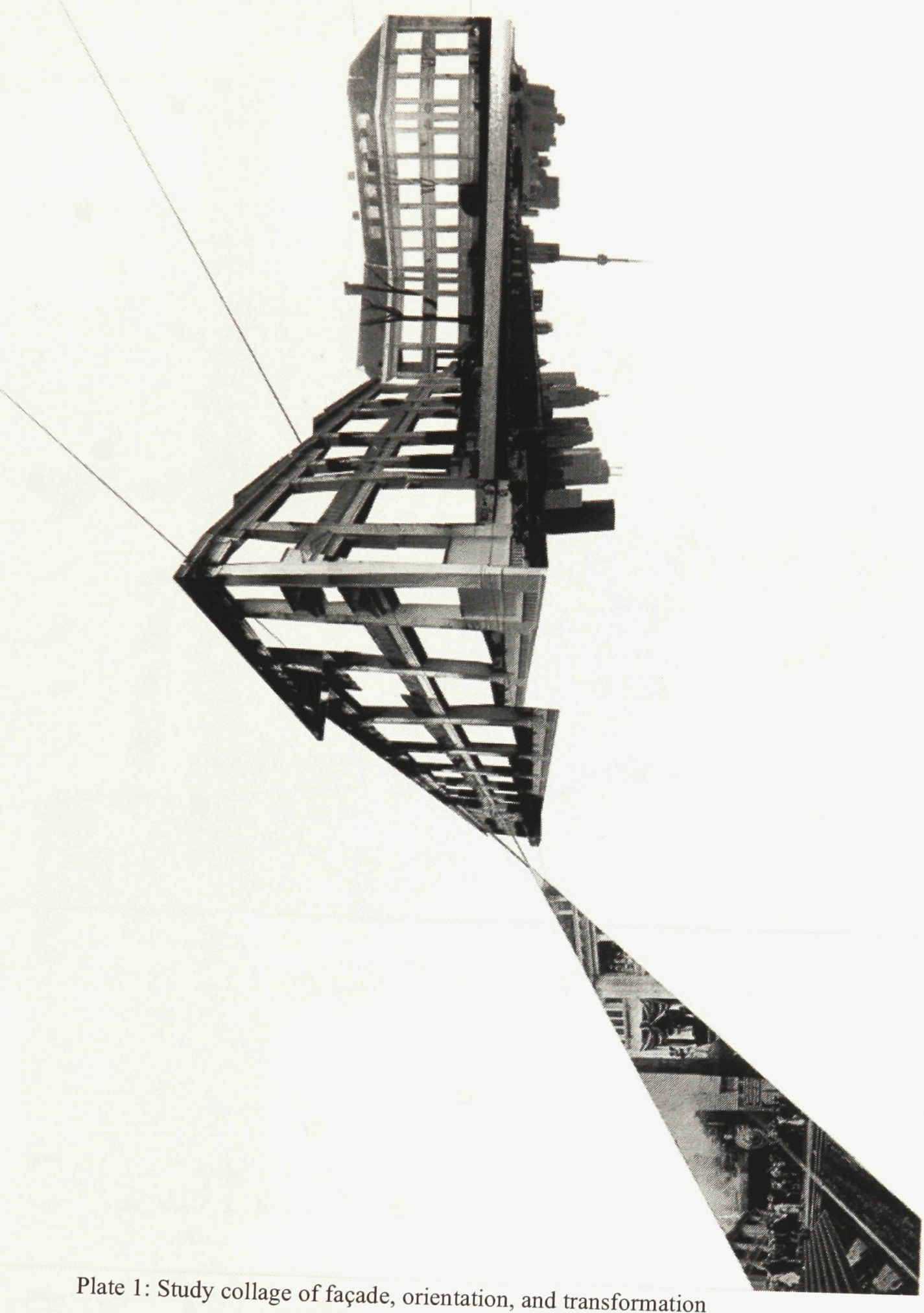




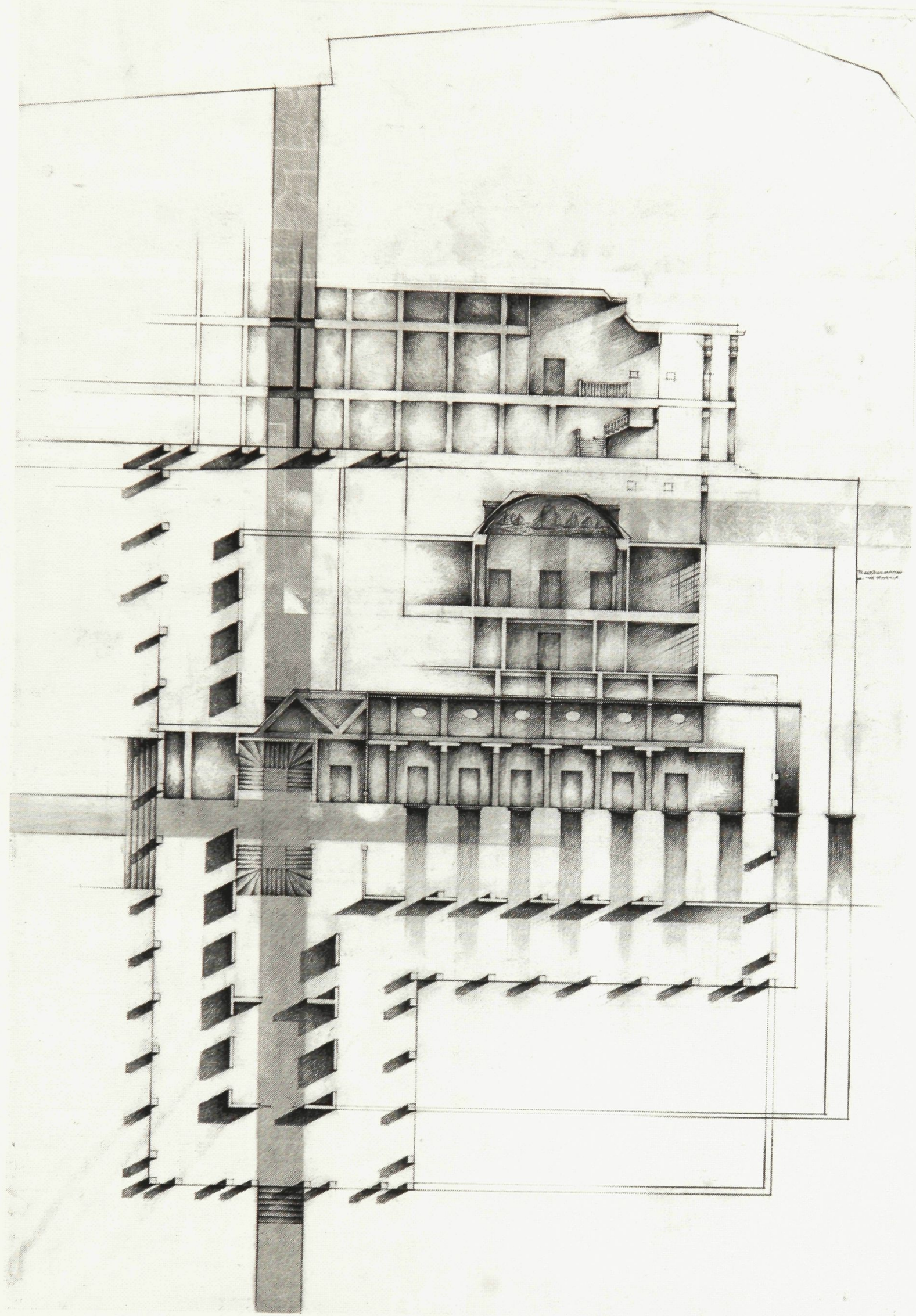

Plate 2: Study drawing of existing building 


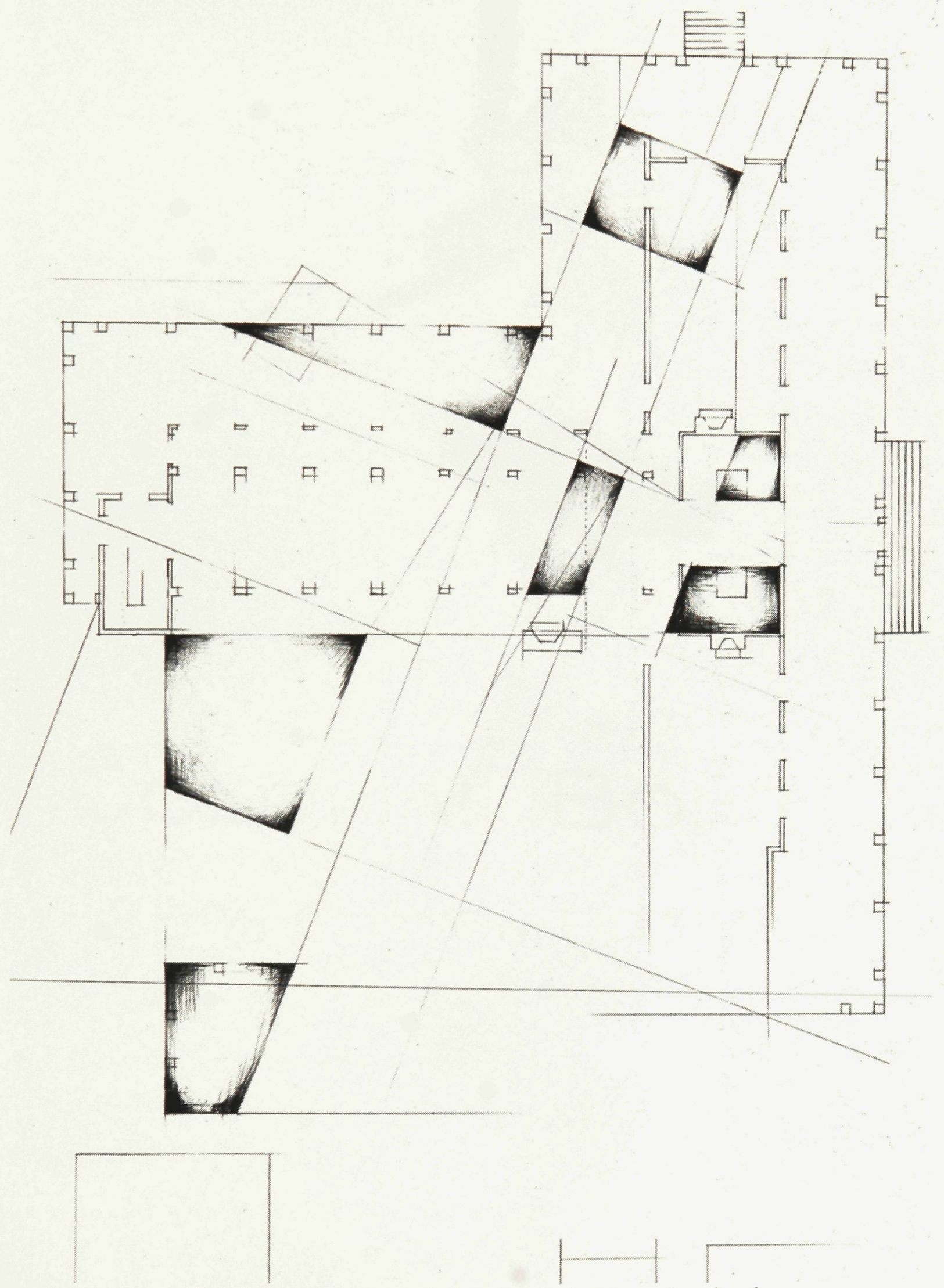

Plate 3: Study drawing exploring areas for incision and exploration 


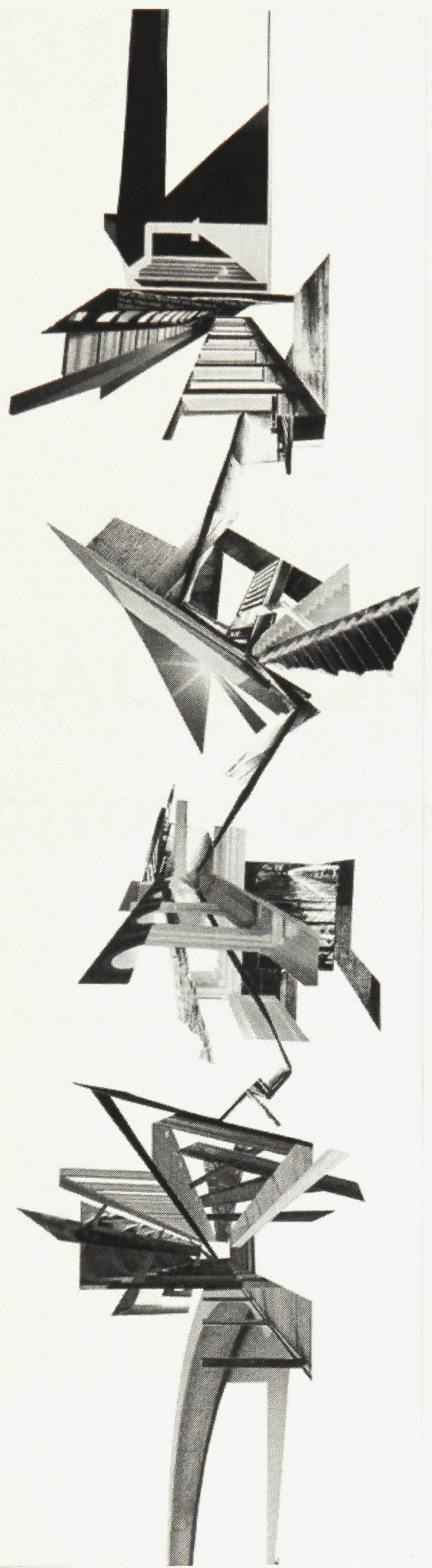

Plate 4: Study collage exploring areas of incision 


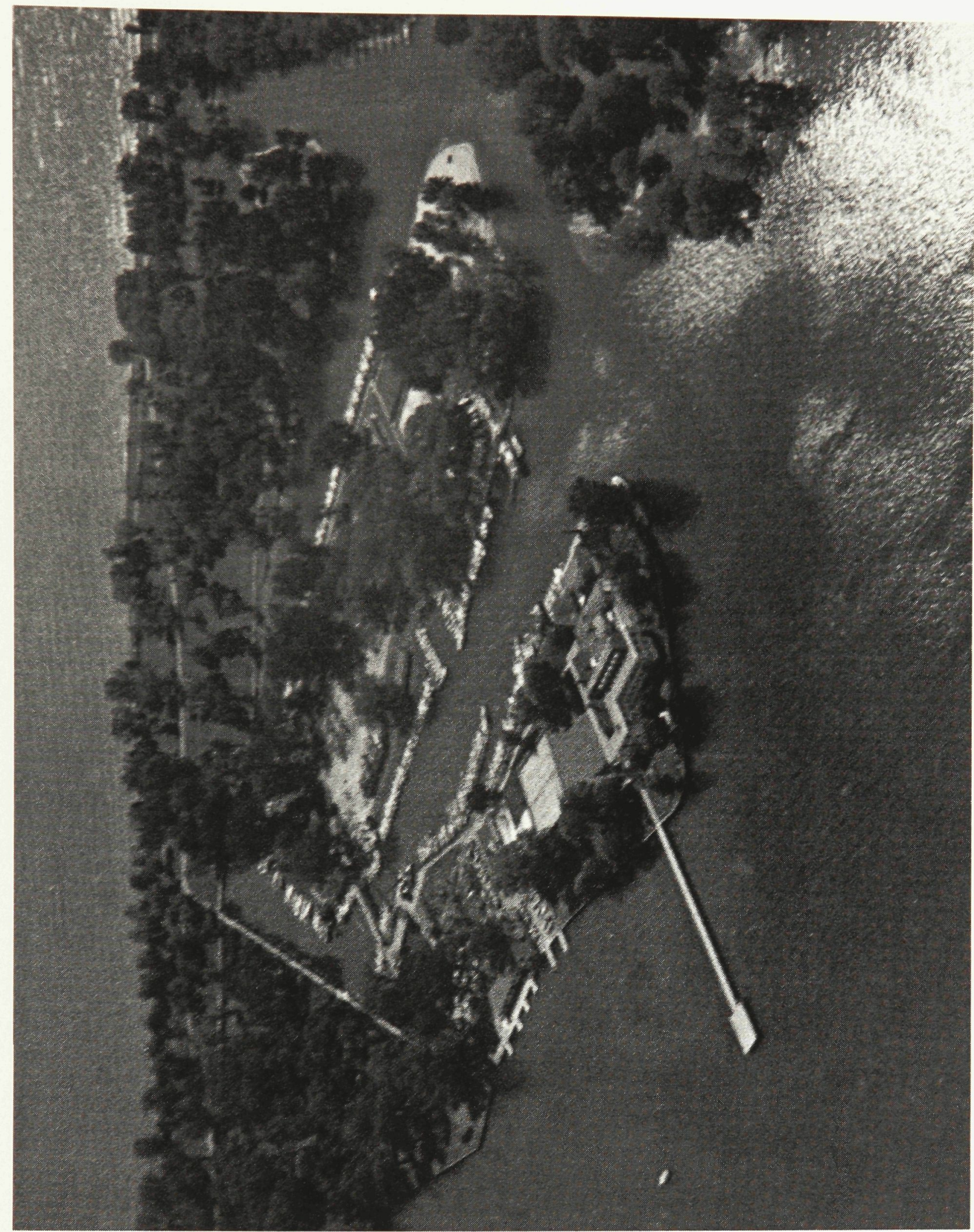

Plate 5: Arial photograph of site - existing 


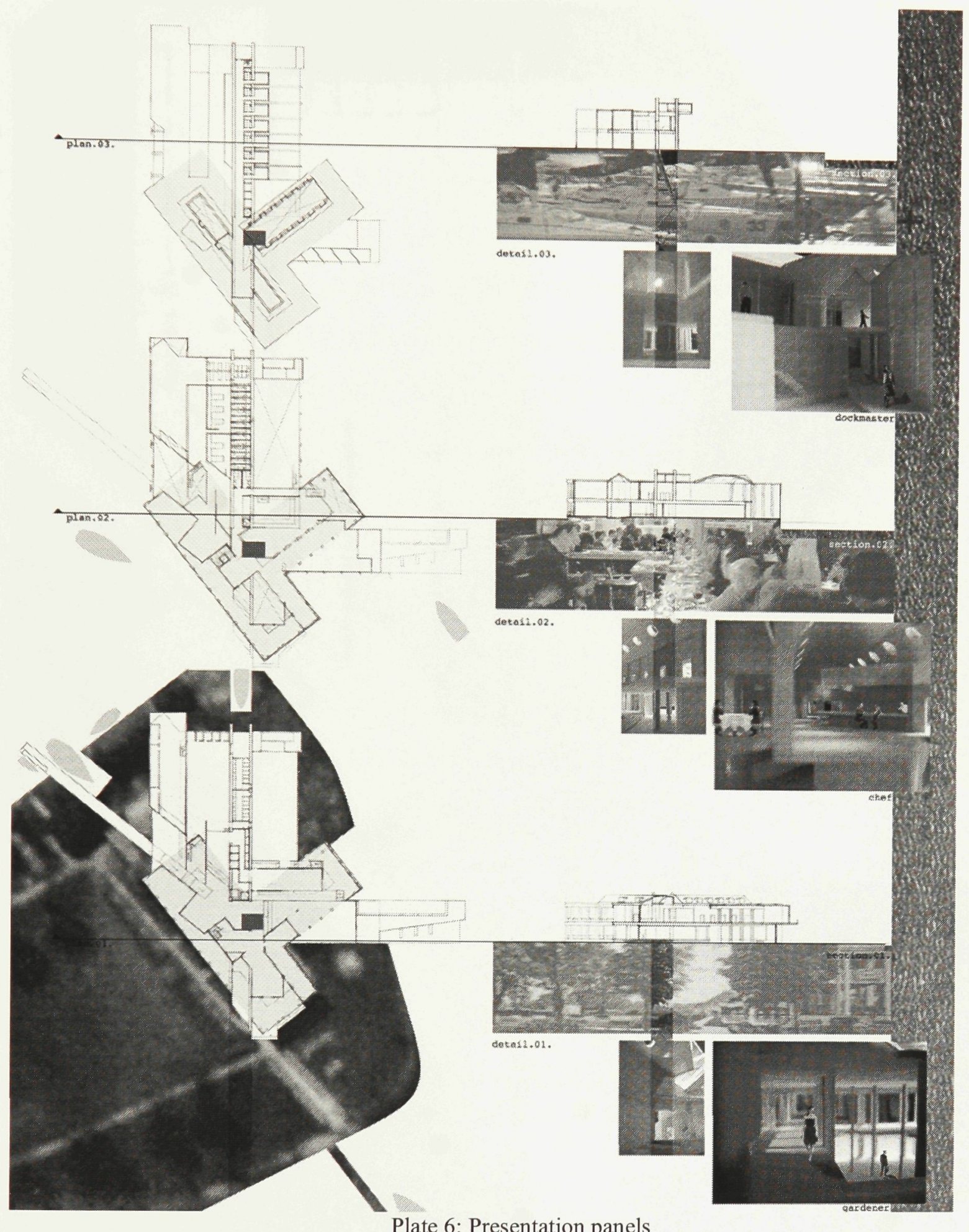




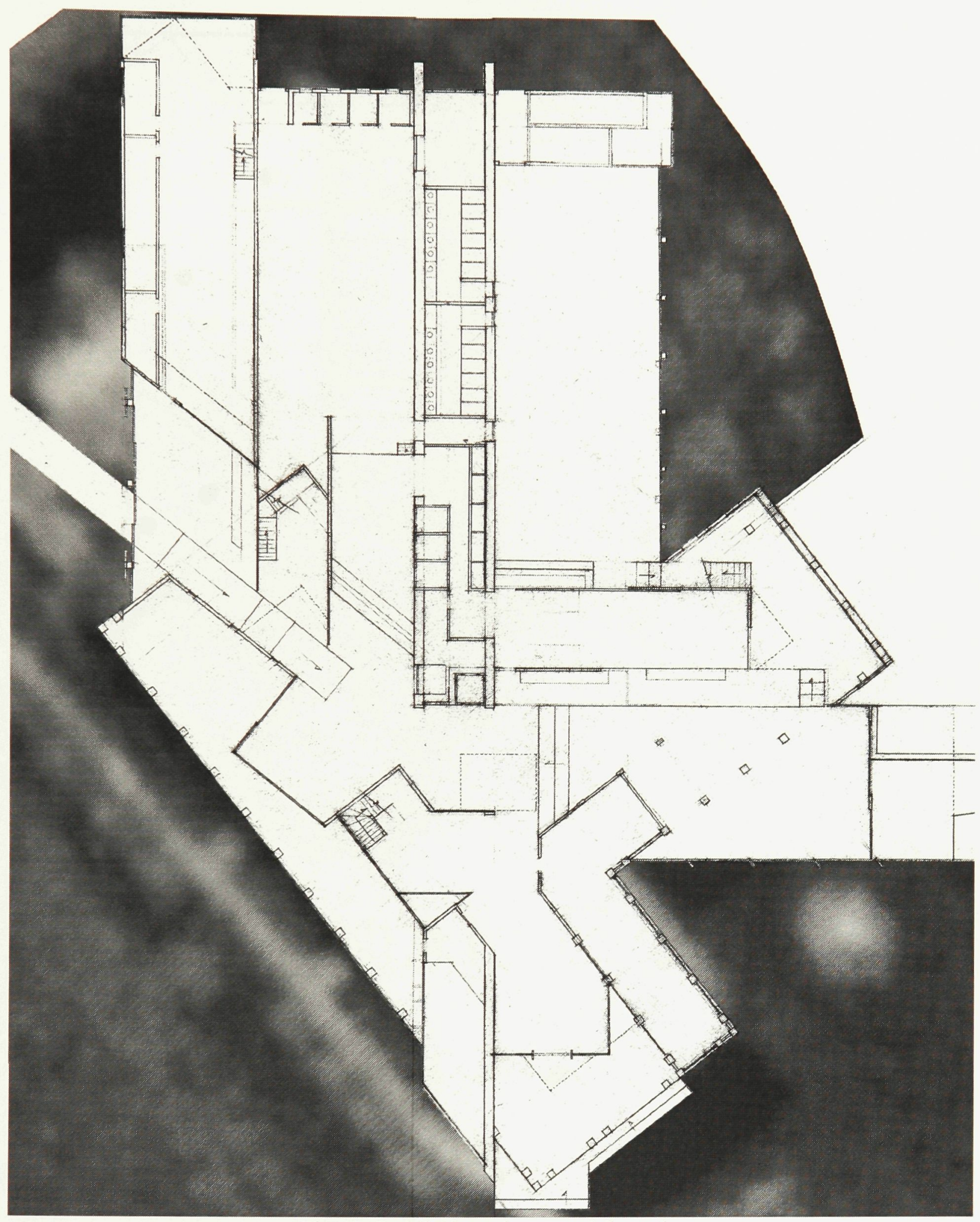

Plate 7: Detail of panel - ground floor plan 


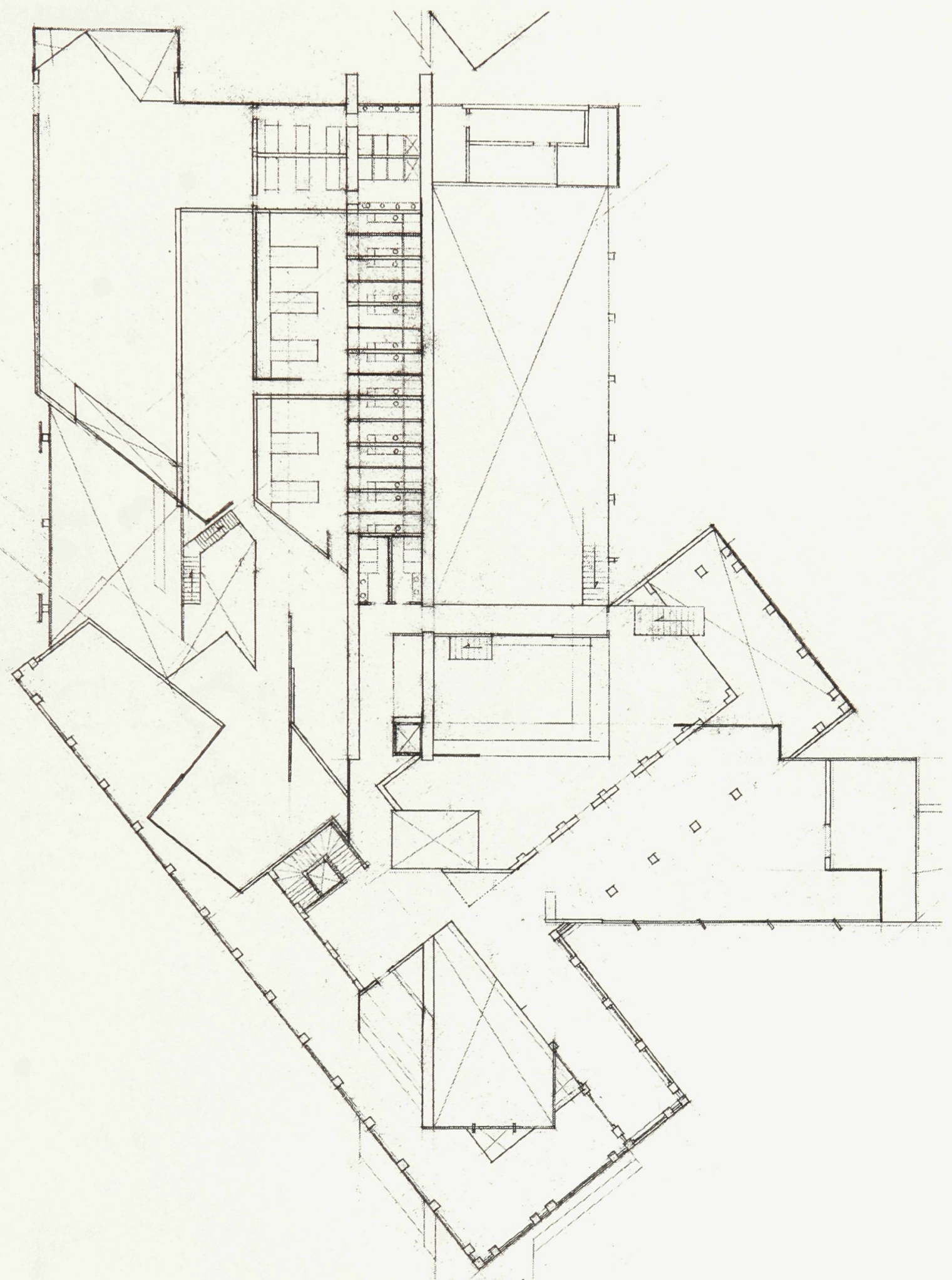

Plate 8: Detail of panel $-2^{\text {nd }}$ floor plan 


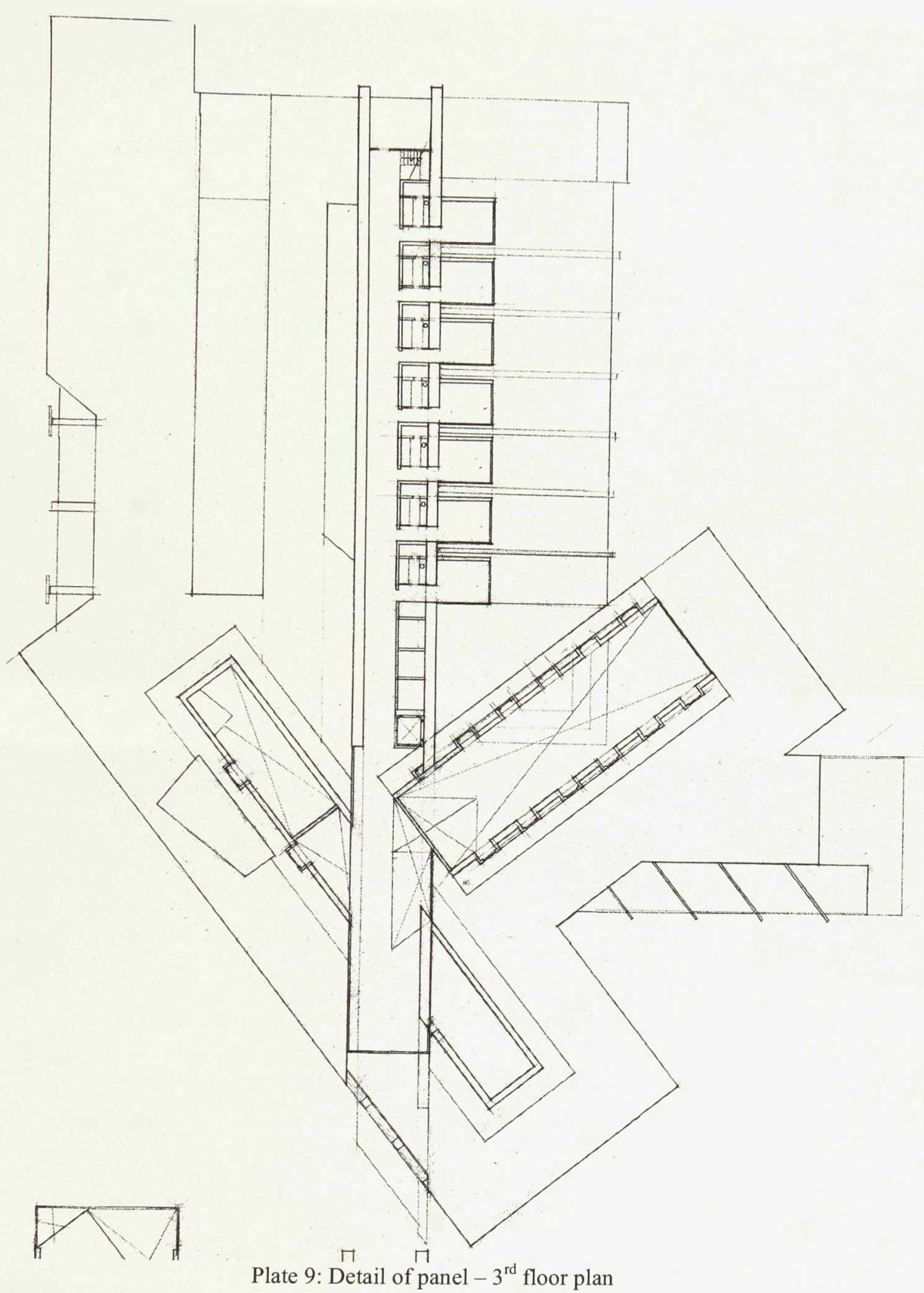

Plate 9: Detail of panel $-3^{\text {rd }}$ floor plan 

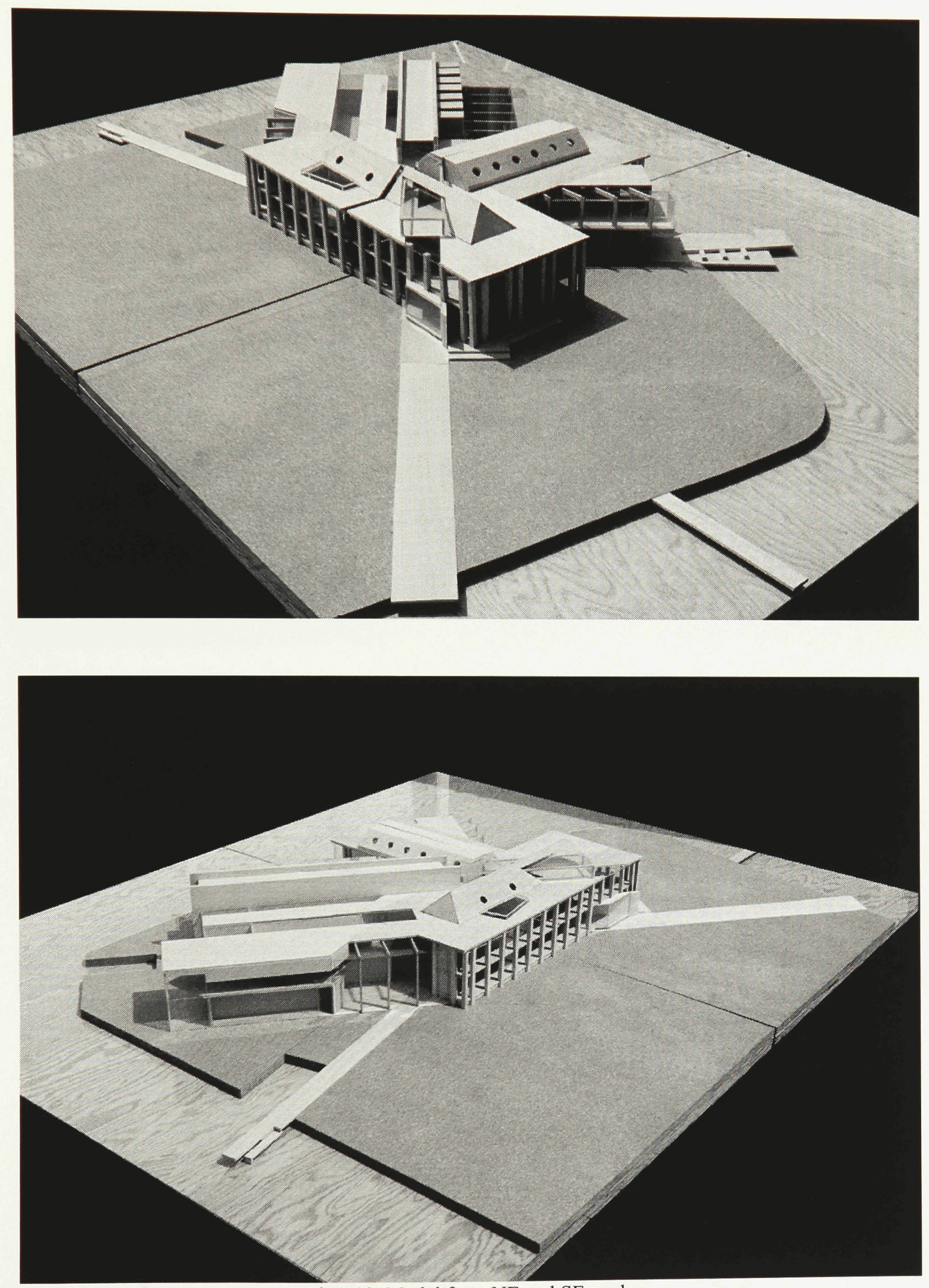

Plate 10: Model from NE and SE angles 

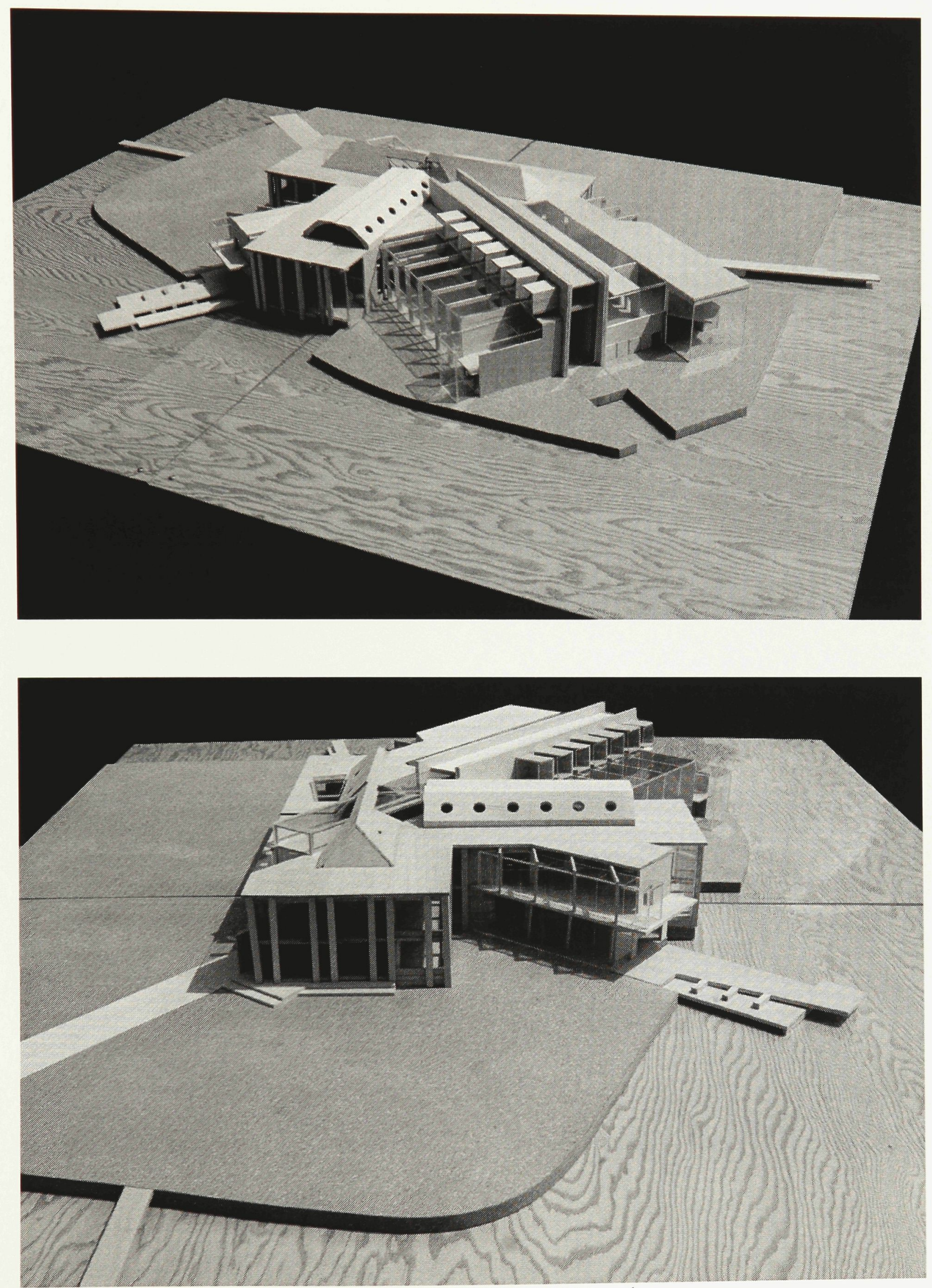

Plate 11: Model from SW and NW angles 

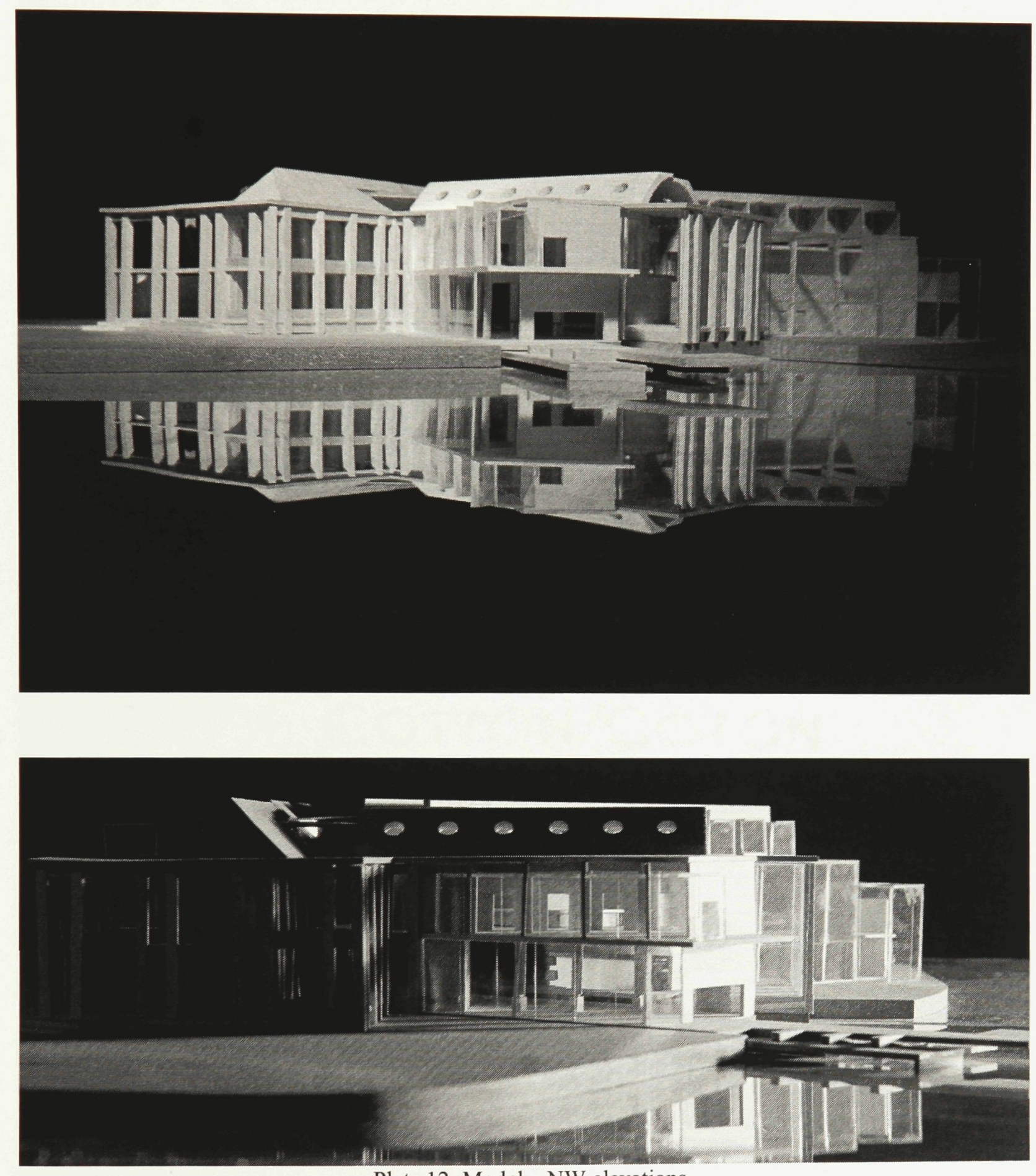

Plate 12: Model - NW elevations 

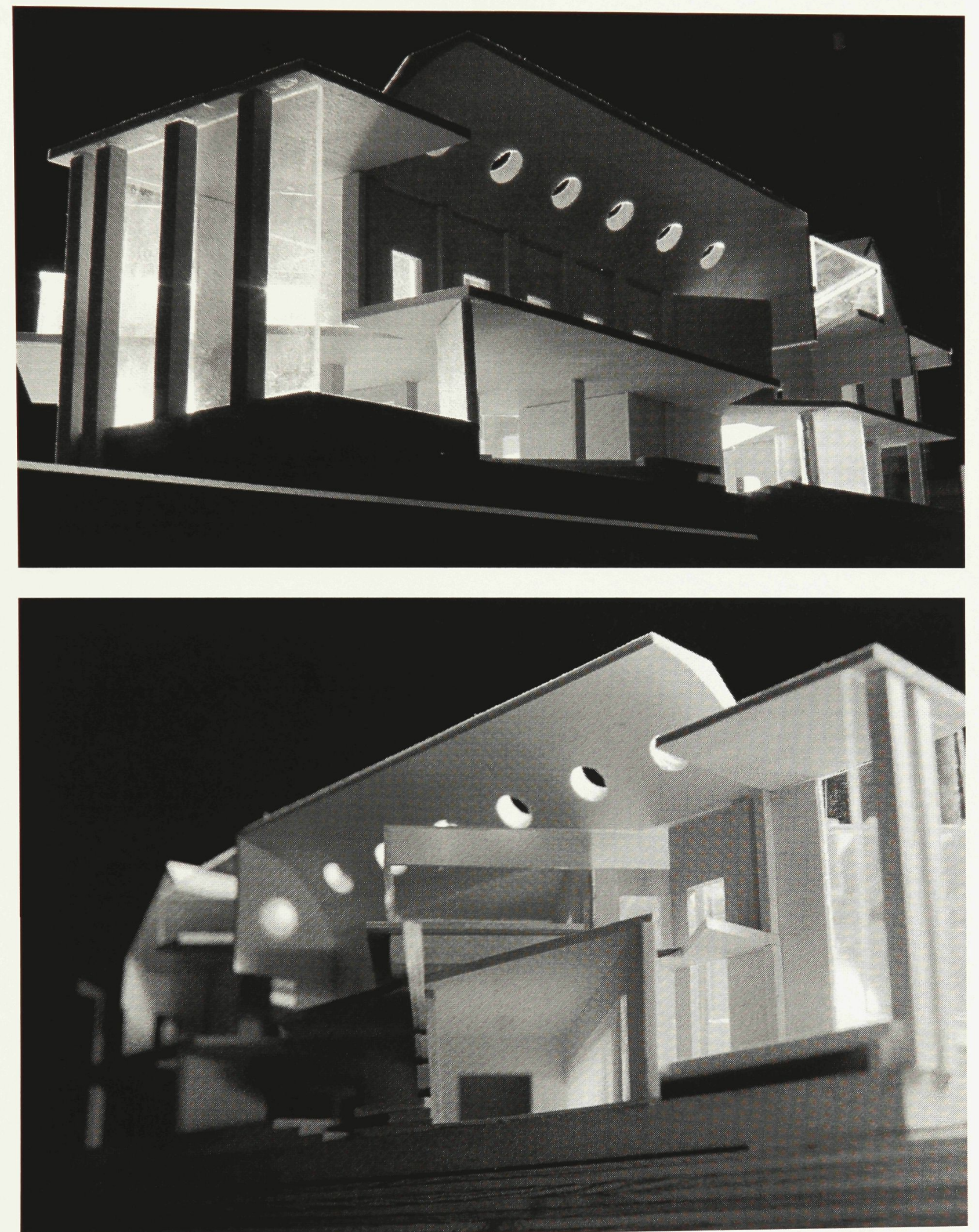

Plate 13: Model section - $\mathrm{N}$ and $\mathrm{S}$ sides 

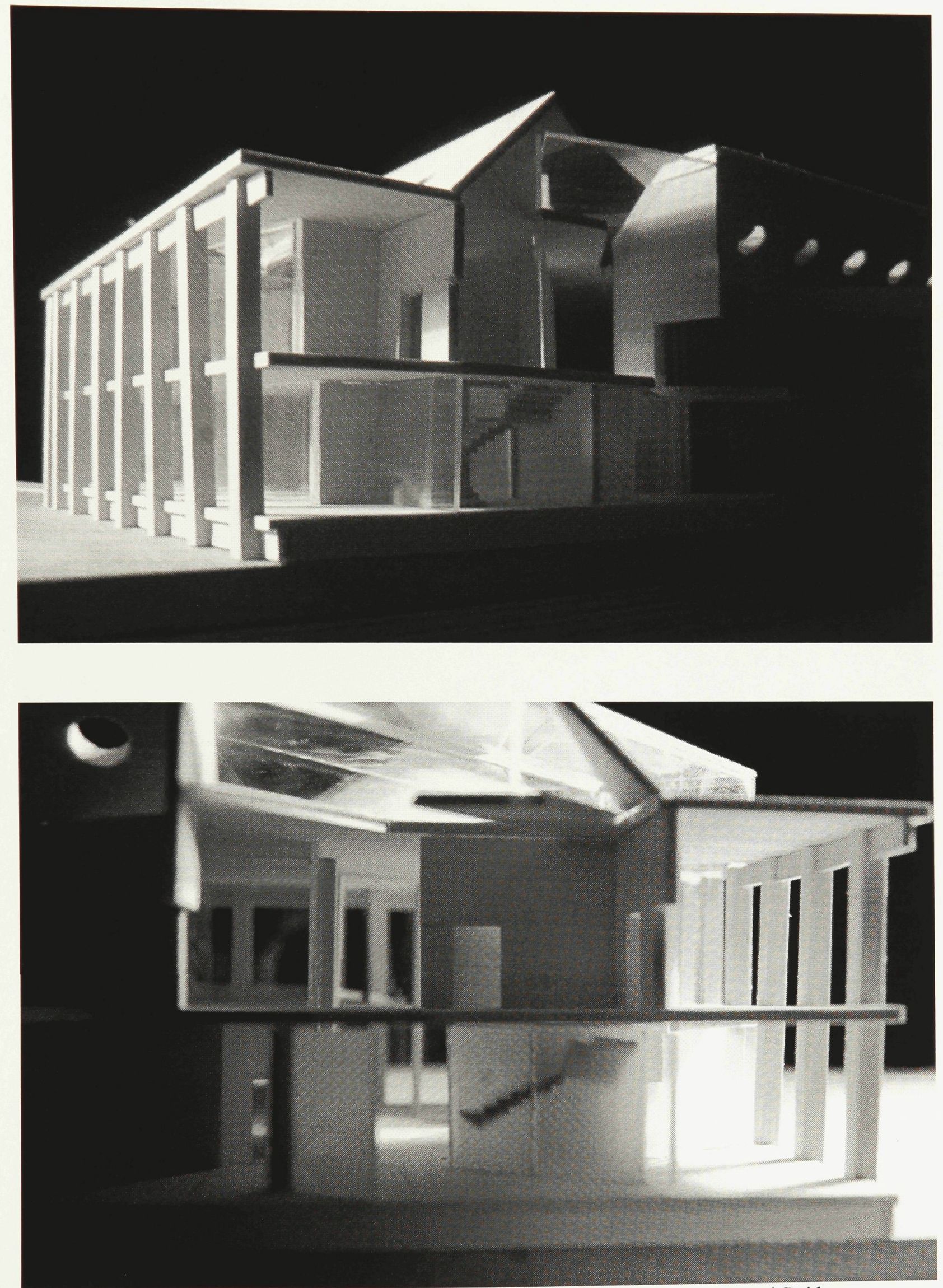

Plate 14: Model section through core of reorientation and circulation - N and S sides 

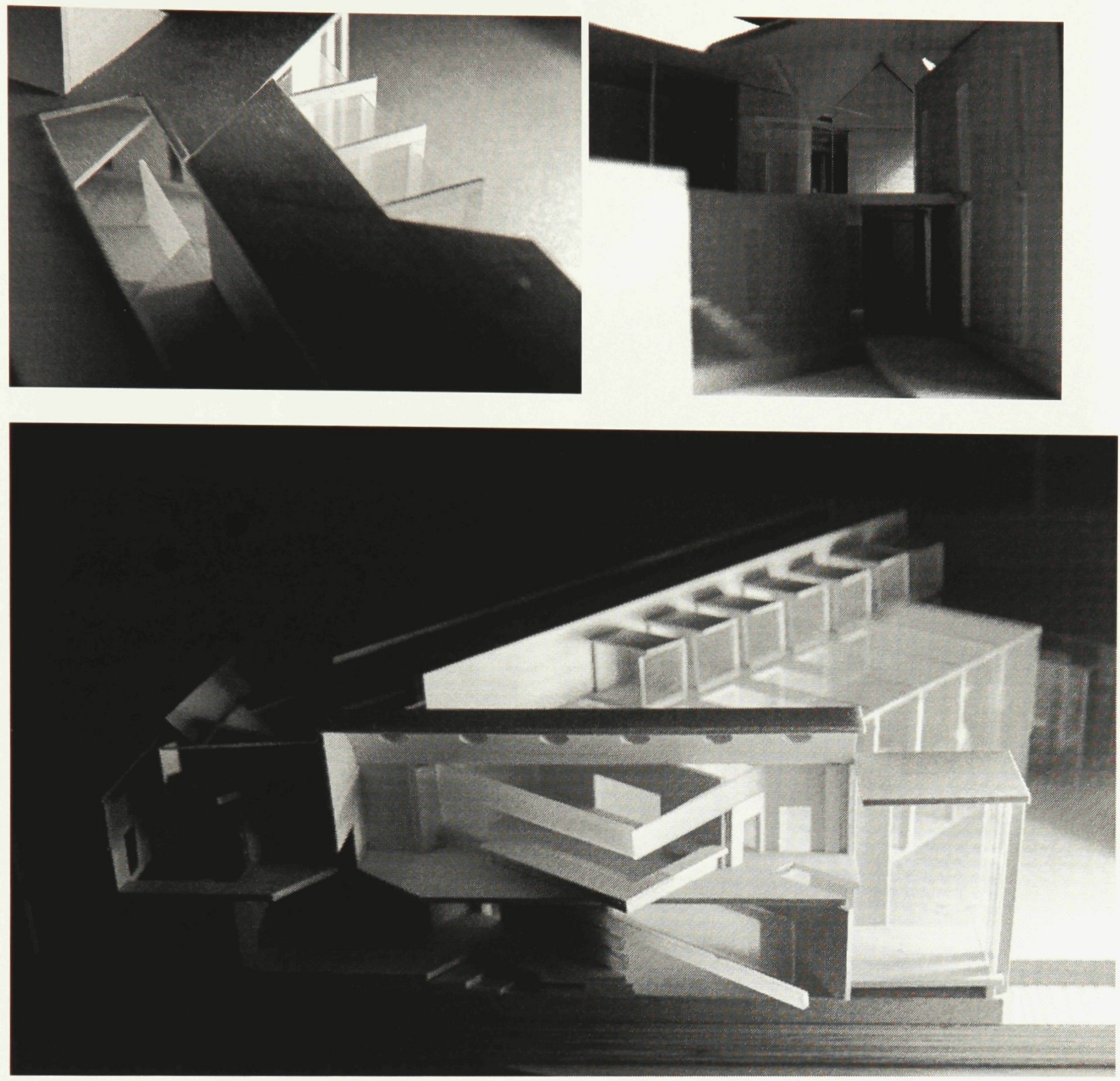

Plate 15: Model detail - Dock Master's entrance, model section with hotel rooms and event space - S side 


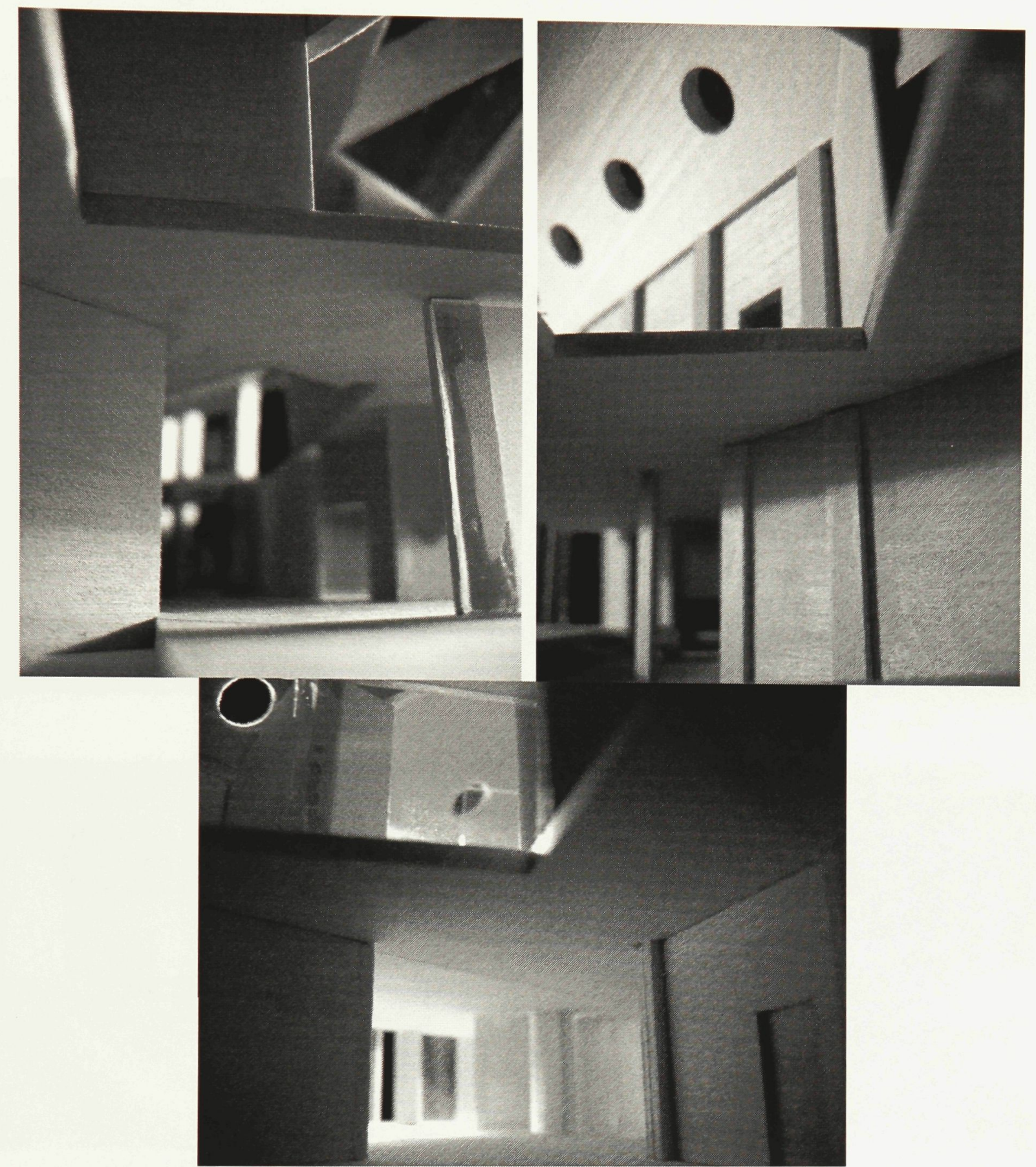

Plate 16: Model detail at core of reorientation - towards ferry entrance, towards city, towards Dock Masters entrance 

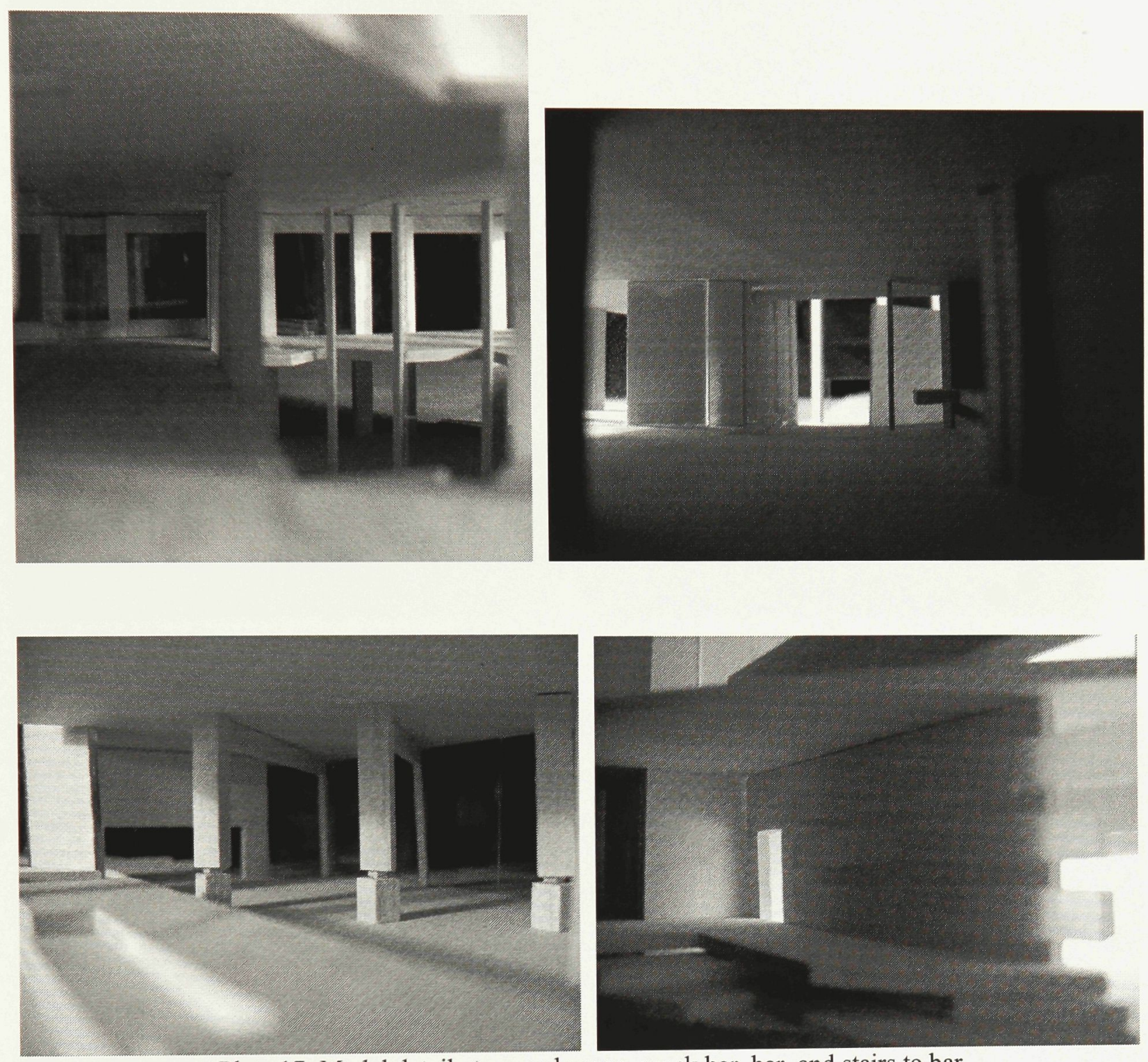

Plate 17: Model detail at upper lounge, snack bar, bar, and stairs to bar 

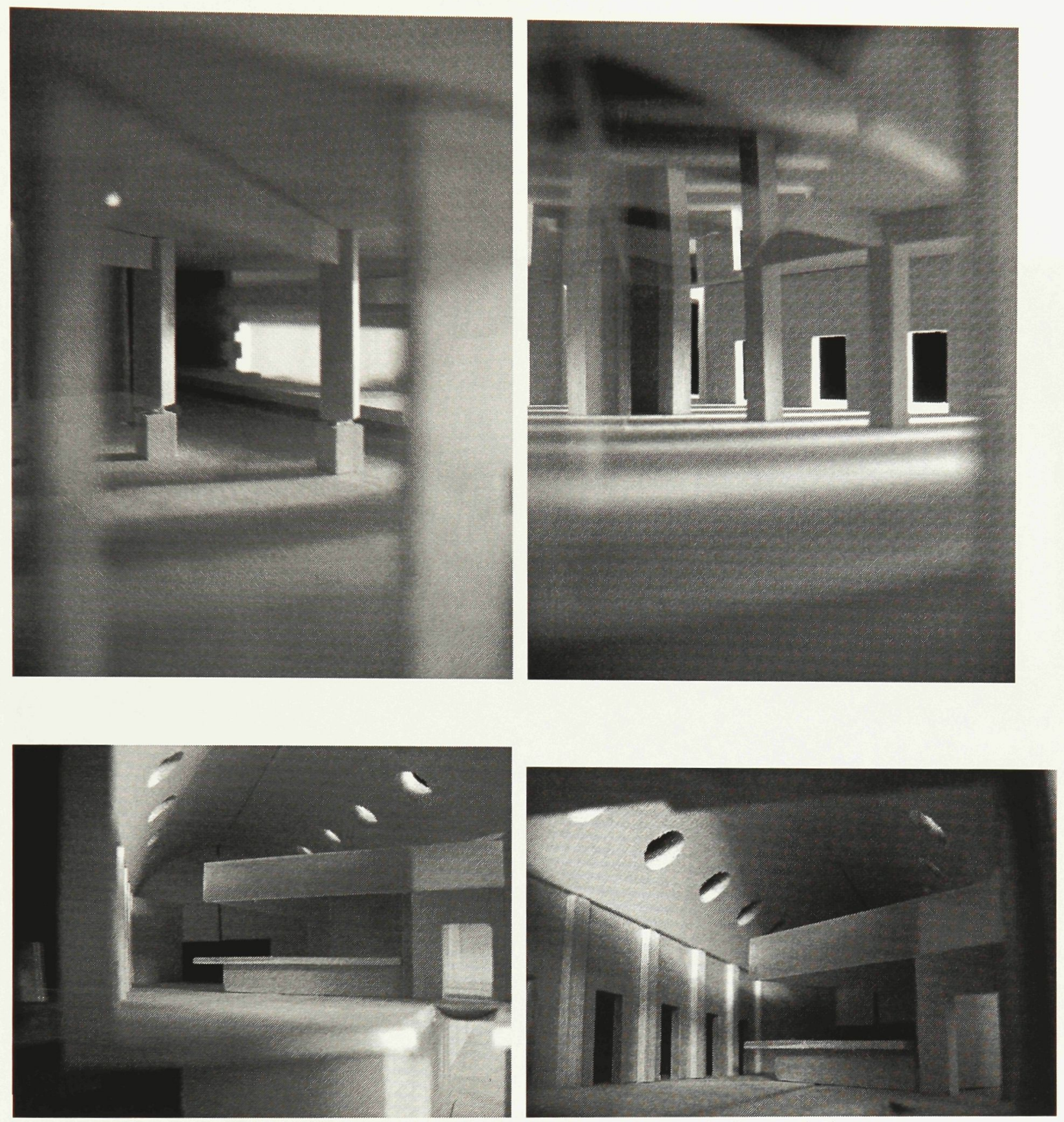

Plate 18: Model detail at bar, upper restaurant, ballroom (x2) 


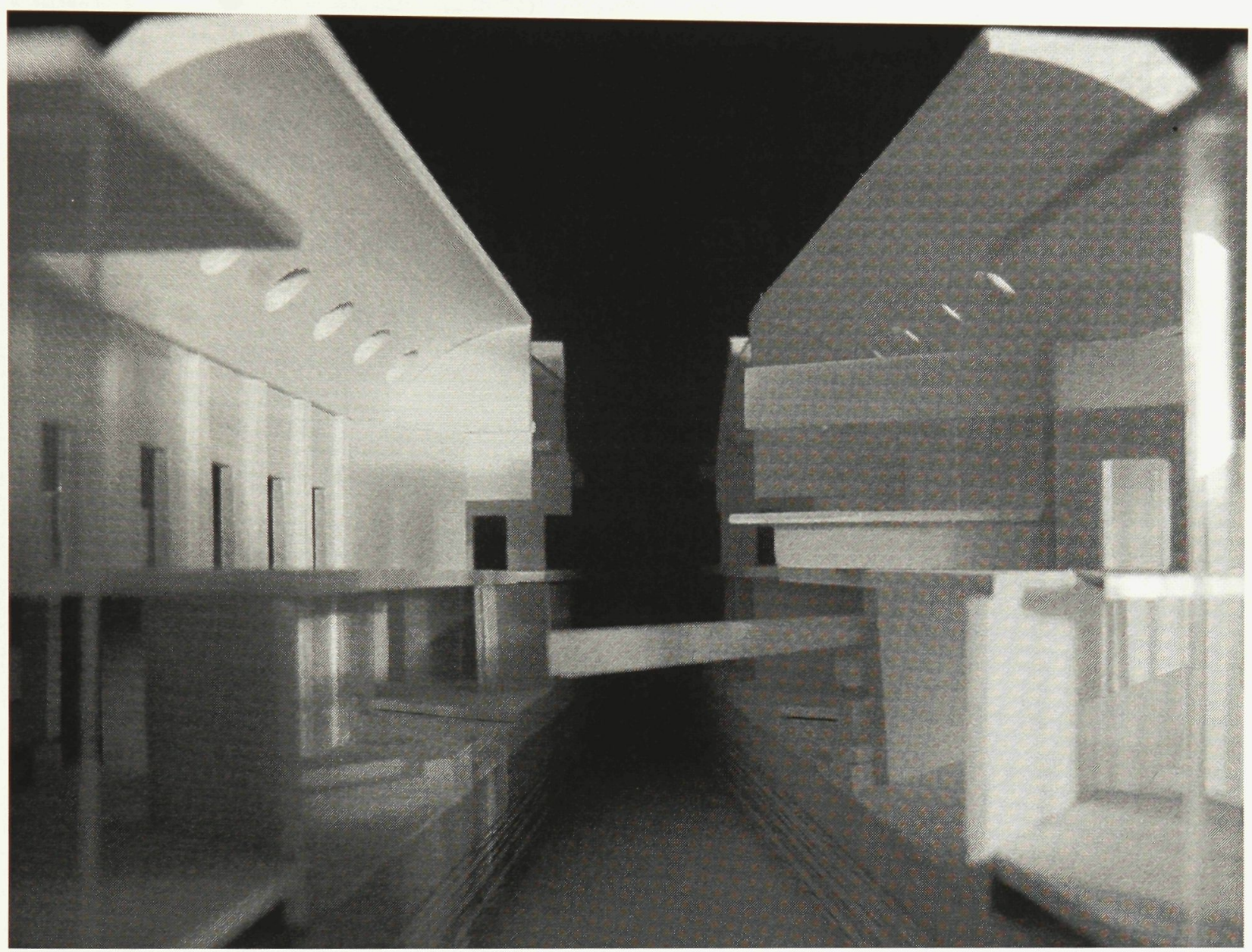

Plate 19: Section of model through core of RCYC - Looking E 


\section{Appendix 1: List of Images}

\section{$\underline{\text { Architecture In Place }}$}

Figure 1 Le Plain Voisin - Le Corbussier. Delirious New York - 256.

Figure 2 Guggenheim Museum proposal, NY - Frank Gehry. http://www.thecityreview.com/gehry.html (05/02/06)

Figure 3 Guggenheim Museum - Frank Gehry. Photo by Author. 2005

Figure 4 Castelvecchio Museum - Carlos Scarpa. http://www.studiocleo.com/gallerie/scarpa/castelvecchio3.jpg (03/08/05)

Figure 5 Reitfield House - Gerrit Rietfiled. Sheryl Boyle: 2004

Figure 6 Façade of the Reichstag - Norman Foster. Rebuilding the Reichstag - 61.

Figure 7 Interrior of the Reichstag - Norman Foster. Rebuilding the Reichstag -83.

\section{Memory Framing the Contemporary Event}

Figure 8 Tate Modern - Herzog and DeMeuron http://www.sarakadee.com/feature/2000/10/images/tate modern.jpg $(03 / 05 / 06)$

Figure 9 Tate Modern, Turbine Hall - Herzog and DeMeuron http://www.tate.org.uk/modern/building/construction.htm - (03/05/06)

\section{A Site Under Transformation}

Figure 10 Toronto 1854. No Mean City- Arthur 112. Edith Whitfield. Index ref: MTL T10276

Figure 11 RCYC scow 1852. A Club with Purpose - RCYC Historical Video. A Shipman Group Production - Frame capture

Figure 12 RCYC Clubhouse 1897 - James Smith. RCYC Private Archives - Uncatalogued $(10 / 30 / 05)$

Figure 13 Toronto 1879. No Mean City 164-165. Published by Willing and Williamson - index ref: MCG, Notman Collection

Figure 14 Arial photograph of Toronto c. 1925. National Air Photo Archives. Index ref: A3249 070

Figure 15 RCYC City Station - Dick and Wickson. Lost Toronto - 41. Index ref: Credit: Metropolitan Library Board

Figure 16 RCYC Island Clubhouse - Darling and Curry. RCYC Private Archives Un-catalogued (10/30/05)

Figure 17 RCYC Island Clubhouse 2 - Darling and Curry. RCYC Private Archives Un-catalogued (10/30/05)

Figure 18 RCYC Island Clubhouse - Sproatt and Rolph. RCYC Private Archives Postcard - Un-catalogued (10/30/05)

Figure 19 Toronto waterfront. A Toronto Album - Glimpses of the City That Was 74-75. 
Figure 20

Figure 21

Figure 22

Figure 23

Figure 24

Figure 25

Figure 26

Figure 27

Toronto waterfront. A Toronto Album - Glimpses of the City That Was 74-75.

RCYC gardens. RCYC Private Archives - Un-catalogued (10/30/05)

RCYC gardens. Annals of the Royal Canadian Yacht Club - 112. W. James SR., RCYCA 1979-088-PH

RCYC Island Clubhouse façade. RCYC Private Archives - Un-catalogued $(10 / 30 / 05)$

RCYC Island Clubhouse (launch dock and verandas). RCYC Private Archives - Un-catalogued (10/30/05)

The RCYC and the city. The Royal Canadian Yacht Club: 1852-1952 inside cover.

Arial photograph of Toronto c. 1925. National Air Photo Archives. Index ref: A3249 070

Ballroom - RCYC clubhouse. Photo by Author. (2005)

\section{Between the Architecture and the City}

Figure 28 Seagram Plaza - Mies van der Rohe.

http://www.thecityreview.com/park375.html - (04/24/06)

Figure 29 Toronto Skyline. Photo by Author. Digital collage from photographs (2005)

Figure 30 The façade of $X Y Z$ - Wallace Harrison. Photo by Author. (2003)

Figure 31 City as framed by veranda. Photo by Author. (2005)

\section{Liberating Traditional Spaces}

Figure 32 Surrealist space - Roberto Matta Echaurren 1938 (Illistration). Object to be Destroyed - 8. "Mathematique Sensible-Architecture du Temps," Minotaure. Courtesy Artists Rights Society (ARS) 1999.

Figure 33 Food - Gordon Matta-Clark (1971).. Object to be Destroyed - 57.

Figure 34 Bronx Floor - Gordon Matta-Clark.

http://images.google.com/imgres?imgurl=http://www.artincontext.org/ima ges/IMI/0100/IMI0114D.jpg\&imgrefurl=http://www.artincontext.org/LIS TINGS/IMAGES/FULL/1/2BOVYPM1.htm\&h $=352 \& w=352 \& \mathrm{sz}=47 \& \mathrm{tb}$ nid=N7S68qPrqO6EQM:\&tbnh=116\&tbnw=116\&hl=en\&start=1\&prev=/i mages $\% 3 \mathrm{Fq} \% 3$ Dbronx $\% 2 \mathrm{Bfloor} \% 2 \mathrm{Bmatta}-$ clark $\% 26$ svnum $\% 3 \mathrm{D} 10 \% 26 \mathrm{hl} \% 3 \mathrm{Den} \% 26 \mathrm{lr} \% 3 \mathrm{D} \% 26$ client $\% 3$ Dsafari $\% 26$ rls\%3Den\%26sa\%3DN - March 30, 2006. Holly Solomon Gallery, New York.

Figure 35 Bingo - Gordon Matta-Clark (1974). The Space Between - 104. Courtesy of the Gordon Matta-Clark Estate and David Zwirner Gallery.

Figure 36 Circus (interior details) - Gordon Matta-Clark (1978). Object to be Destroyed - 159. Museum of Contemporary Art, Chicago, IL. 
Figure 37 Bronx Floors - Gordon Matta-Clark (1972-1973). Object to be Destroyed -78 .

Figure 38 Bronx Floors: Threashole - Gordon Matta-Clark (1972-1973). Object to be Destroyed -79 .

Figure 39 Circus - Gordon Matta-Clark (1978). Object to be Destroyed - 155. Museum of Contemporary Art, Chicago, IL.

Figure 40 Circus - Gordon Matta-Clark (1978). Object to be Destroyed - 48-49. Museum of Contemporary Art, Chicago, IL.

Figure 41 Circus: interior details - Gordon Matta-Clark (1978). Object to be Destroyed - 150-151. Museum of contemporary Art, Chicago, IL.

\section{Reorienting Edwardian Architecture}

Figure 42 Existing plan $-1^{\text {st }}$ floor. Drawings by Quadrangle Architects Limited, Toronto. Digitally manipulated by Author.

Figure 43 RCYC Island Clubhouse (NW corner) - Photo by Author / Subtractive model crafted and photographed by Author

Figure 44 Final model (NW corner) - crafted and photographed by Author

Figure 45 Existing plan $-2^{\text {nd }}$ floor. Drawings by Quadrangle Architects Limited, Toronto. Digitally manipulated by Author.

Figure 46 RCYC North Island - Arial photo. RCYC Private Archives (postcard) Un-catalogued (10/30/05)

Figure 47 Ferry at RCYC arrival pier - RCYC Private Archives - Un-catalogued $(10 / 30 / 05)$

Figure 48 RCYC's protecting landscape. Photo by Author: 2006.

Figure 49 RCYC's ballroom. Photo by Author: 2006.

Figure 50 RCYC's veranda - space between central spaces and city. Photo by Author: 2006.

Figure 51 Existing formal dining room below ballroom facing city. Photo by Author: 2006.

Figure 52 Cut in ballroom floor - Photo of model. Photo and model by Author: 2006.

Figure 53 Schematic plan of kitchen spaces - Hand drawing digitally layered. All Drawing and digital rendering by Author: 2006.

Figure 54 End of the Ballroom - Photo of model - Photo and model by Author: 2006.

Figure 55 Schematic plan of axis and entrances - hand drawing digitally layered. All work by author. All drawing and digital rendering by Author: 2006.

Figure 56 Early schematic sketch of circulation. Drawing by Author: 2006

Figure 57 Design Proposal - model image. Photo and model by Author: 2006. 


\section{$\underline{\text { Design Plates }}$}

Plate 1 Physical collage - printed images on paper. By Author.

Plate 2 Study drawing - Graphite on Mylar, physical collage on backside. By Author.

Plate 3 Study drawing - Graphite on paper. By Author.

Plate 4 Physical collage - cut-outs on paper. By Author.

Plate 5

RCYC aerial image. RCYC Private Archives - Un-catalogued (10/30/05)

Plate 62 Presentation panels. Digital renderings of hand drawings and photographs. By Author.

Plate 7 Detail of presentation panel - ground floor. By Author.

Plate 8 Detail of presentation panel $-2^{\text {nd }}$ floor. By Author.

Plate 9 Detail of presentation panel $-3^{\text {rd }}$ floor. By Author.

Plate 10 Image of model. Both by Author.

Plate 11 Image of model. Both by Author.

Plate 12 Image of model. Both by Author.

Plate 13 Image of model. Both by Author.

Plate 14 Image of model. Both by Author.

Plate 15 Image of model. Both by Author.

Plate 16 Image of model. Both by Author.

Plate 17 Image of model. Both by Author.

Plate 18 Image of model. Both by Author.

Plate 19 Image of model. Both by Author. 


\section{Appendix 2: Bibliography}

Arthur, Eric. Toronto - No Mean City. Toronto: University of Toronto Press, 1986. $\left(3^{\text {rd }}\right.$ edition Rev by Stephan A. Otto)

Attlee, James., Le Feuvre, Lisa. Gordon Matta-Clark: The Space Between. Glasgow: Nazraeli Press, 2003.

Etd. Audi, Robert. The Cambridge Dictionary of Philosophy - Second Edition. New York: Cambridge University Press, 1999.

Beszedits, Stephen. Eminant Toronto Architects of the Past - Their Lives and Works. Toronto: B\&L Information Services, 1983.

Canada, Royal Commission on the Future of the Toronto Waterfront, Persistence and Change: Waterfront Issues and the Board of Toronto Harbor Commissioners. Publication No. 6 (Ottawa: Minister of Supply and Services Canada, 1989.

Chipperfield, David. Recent Work. USA: Watson-Guptill Pubns, 1997.

Crowe, Norman. Nature and the Idea of a Man-Made World. Cambridge: MIT Press, 1997.

Dal Co, Francesco. and Gluseppe Mazzariol. Carlo Scarpa: the complete works. Milano: Editrice Electa, 1984.

Deluse, Gilles. Kant's Critical Philosophy. Minneapolis: University of Minnesota Press, 1996.

Dendy, William. Lost Toronto. Toronto: McClelland \& Stewart Inc., 1978.

Dendy, William. Toronto Observed. Toronto: Oxford University Press, 1986.

Filey, Michael. A Toronto Album - Glimpses of the City That Was. Toronto: University of Toronto Press, 1970. 
Foster, Norman-. Rebuilding the Reichstag. Woodstock: Overlook Press, 1999.

Foucault, Michel. "Of Other Spaces: Utopias and Heterotopias" Rethinking Architecture. London: Routledge, 1997.

Fulford, Robert. Accidental City. Toronto: MacFarlane Walter \& Ross, 1995.

Gayford, Martin. "A New Space for a New Art" Tate Modern: The First Five Years. London: Tate, 2005.

Greenhill, Ralph. The Face of Toronto. Toronto: Oxford University Press. 1960 (intro by: Gowans, Alan)

Koolhaas, Rem. Delirious New York. New York: Monacelli Press, Inc., 1994.

Lee, Pamela M.. Object to be Distroyed: The Work of Gordon Matta-Clark. Cambridge: MIT Press, 2000.

Lilley, Wayne. Queen City Yacht Club. Toronto: Overleaf Design Ltd., 1989 Lin, Maya. Boundaries. New York: Simon \& Schuster, 2000.

Lin, Maya. Maya Lin : [American Academy in Rome, 10 Dicembre 1998-21 Febbraio 1999 / saggi di Michael Brenson ... et al. ; traduzioni, Cynthia De Nardi Ipsen,

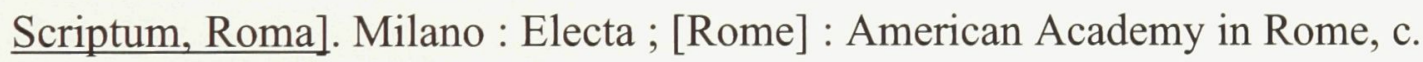
1998.

McEwan, Indra Kagis. Socrates' Ancestor - An Essay on Architectural Beginnings. London: MIT Press, 1994.

Moore, Arthur Cotton. The powers of preservation : new life for urban historic places. New York : McGraw-Hill, 1998.

Moore, Rowan. Building Tate Modern : Herzog \& De Meuron transforming. Eds: Giles Gilbert Scott, Rowan Moore, Raymund Ryan. London : Tate Gallery, 2000. 
Mostaedi, Arian. Building Conversion \& Renovation. Barcelona: Filabo, S.A., 2003.

Etd. Mott, Henery A.. The Yachts and Yachtsman of America- volume 1. New York: International Yacht Publishing Co., 1894.

Norberg-Schulz, Christian. "Order and Change in Architecture" Constancy and Change in Architecture. Huston: Texas A\&M University Press, College Station, 1991. 4360.

Ondaatje, Michael. In the Skin of a Lion. Toronto: McClelland and Stewart, 1987.Ovens, Frank., et al., Annals of the Royal Canadian Yacht Club. Toronto, Roux and Mann, 1937.

Pawson, John. Minimum. London: Phaidon Press Ltd., 1998.

Powell, Ken. Architecture reborn : converting old buildings for new uses New York : Rizzoli, 1999.

Etd. Quantrill, Malcolm; Webb, Bruce. " Constancy and Change in Architecture. Huston: Texas A\&M University Press, College Station, 1991.

Rodgers, Richard. Architecture: A Modern View. London: Thames and Hudson, 1990.

Rossi, Aldo. The Architecture of the City. Cambridge: MIT Press, 1984.

Scarpa, Carlo. Carlo Scarpa: The Complete Works. New York: Rizzoli, 1984.

Sorkin, Michael. Lecture. National Gallery of Canada, Ottawa. 02/13/06 


\section{Appendix 3: Interviews - Meetings}

"Town Hall" meeting. RCYC, Toronto, 02/21/06

Held by the elected RCYC architectural board for all members (over 400 attended) to obtain feed back from member regarding their wishes for the coming changes to the RCYC island clubhouse

Beattie, Jim. Personnel Interview. Toronto, 09/16/05.

Past Vice Commodore of the RCYC, current Head of Fleet, internationally competitive racer

Beattie, Sue. Personnel Interview. Toronto, 09/19/05., 11/1/05.

Currently writing a PhD at the University of Toronto in Art History, Avid Racer, and cruiser

English, Arthur. Personnel Interview. Toronto, 09/19/05.

Present Commodore of the RCYC, member of the Renovations Committee, internationally competitive racer, and cruiser

MacIntosh, Mark. Personnel Interview. Toronto, 11/01/05

Buildings and Grounds manager for the Royal Canadian Yacht Club, involved with the renovation project

Provan, Jen. Personnel Interview. Toronto, 09/18/05.

Member of the Canadian Olympic Team, competitor in the 2004 Athens Summer Games 